\title{
Coal Fueled Diesel System For Stationary Power Applications-Technology Development
}

\section{Topical Report}

August 1995

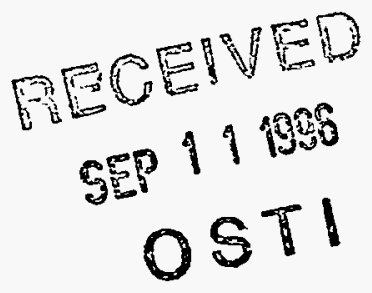

Work Performed Under Contract No.: DE-AC21-88MC25124

For

U.S. Department of Energy

Office of Fossil Energy

Morgantown Energy Technology Center

Morgantown, West Virginia

By

Arthur D. Little, Inc.

Combustion and Fuel Technology

20 Acorn Park

Cambridge, MA 02140-2390 


\section{Disclaimer}

This report was prepared as an account of work sponsored by an agency of the United States Government. Neither the United States Government nor any agency thereof, nor any of their employees, makes any warranty, express or implied, or assumes any legal liability or responsibility for the accuracy, completeness, or usefulness of any information, apparatus, product, or process disclosed, or represents that its use would not infringe privately owned rights. Reference herein to any specific commercial product, process, or service by trade name, trademark, manufacturer, or otherwise does not necessarily constitute or imply its endorsement, recommendation, or favoring by the United States Government or any agency thereof. The views and opinions of authors expressed herein do not necessarily state or reflect those of the United States Government or any agency thereof. 


\section{DISCLAIMER}

Portions of this document may be illegible in electronic image products. Images are produced from the best available original document. 


\title{
Coal Fueled Diesel System For Stationary Power Applications- Technology Development
}

\section{Topical Report \\ August 1995}

Work Performed Under Contract No.: DE-AC21-88MC25124

\author{
For \\ U.S. Department of Energy \\ Office of Fossil Energy \\ Morgantown Energy Technology Center \\ P.O. Box 880 \\ Morgantown, West Virginia 26507-0880
}

By

Arthur D. Little, Inc.

Combustion and Fuel Technology

20 Acorn Park

Cambridge, MA 02140-2390 


\section{EXECUTIVE SUMMARY}

\section{INTRODUCTION}

The Fossil Energy Division of the U.S. Department of Energy, through the Morgantown Energy Technology Center (METC) initiated a concentrated effort to develop coal burning diesel and gas turbine engines. The diesel engine work in the METC sponsored program was performed at Arthur D. Little (Cooper-Bessemer as subcontractor), Bartlesville Energy Technology Center (now NIPER), Caterpillar, Detroit Diesel Corporation, General Motor Corporation (Electromotive Division), General Electric, Southwest Research Institute, and various universities and other research and development organizations. This DOE-METC coal engine RD\&D initiative which spanned the 1982-1993 timeframe is the topic of this review document.

In terms of total investment and technical progress, it appears that the METC Program has made more progress and successfully incorporated more diverse technologies than all of the previous efforts over the period 1890-1980 to develop coal burning reciprocating engines. At the outset of this METC program, it was clear that major technical hurdles had never been satisfactorily overcome in the previous programs, using various standard engine technologies. It was apparent that new engine component designs and new materials were needed in order to design systems that had acceptable reliability and durability. New coal fuel forms with lower ash and thus more compatible with the engine were also needed. Moreover, to meet modern environmental standards, it would be necessary to add emission control technology to make a coal engine competitive and attractive. As described in this report, the solutions developed under the 1982-93 DOE program generally added some complexity and some additional cost to the conventional diesel engine system. However, the METC program has resulted in the development of coal-fueled engine systems that are expected to be competitive with other fossil fuels once the price of the other fuels continues to escalate.

It now appears that in the 2005-2030 timeframe, that the prices of petroleum and natural gas may ultimately increase to the point where the cost of direct coal utilization in engines will be competitive. There are no required technical breakthroughs, and the coal-diesel technology now appears ready for market introduction, although this must be confirmed by field demonstrations of "base-loaded" engines. Coal-fueled engine technology will be competitive in the market at that time. The accomplishments of the METC coal fueled diesel engine program must therefore be preserved for use at that time. The objective of this report is to provide a well defined starting point for future projects in the coal fueled diesel engine area.

\section{Approach}

First, the starting point for the METC program is identified in terms of the major technical hurdles that had to be addressed. Then, the structure of the METC program to address these hurdles is briefly described and the key participants identified for future reference. The remaining sections, and the major portion of the report is devoted to discussion of the work 
that was done in each problem area. Emphasis is placed on the status of the work as of 1993 and identification of the best starting point for continuation of the work in the future. The last section of the report is a summary of the key design features that must be incorporated in a successful engine, based on the current available technology. A reference list is included as well as a complete bibliography of references that are related to the development of a coal burning diesel engine.

\section{Summary}

The use of coal-water slurry in medium-speed engines has been demonstrated to be technically feasible. This conclusion is based upon the use of well formulated coal-water slurries (CWS) in the range of 45-50 weight percent coal loading, using bituminous coals ground to 5-12 micron mean size particles, with a top size limit of 30-85 microns, and sulfur and ash contents in the range of 1-2 percent each by mass. The ranges in coal specification reflect the GE and ADL/Cooper engine test experience. Higher ash contents may be usable in certain larger (and slower RPM) engines, but the technology for coal cleaning has advanced to the point where 1-2 percent ash clean coal is reasonable to produce. Approximately 1500 hours of engine operation with CWS have been achieved in the aggregate in the GE and the Arthur D. Little/Cooper programs alone.

The current state of the technology is such that special engine and component design modifications for coal water fuels (CWS) can be very well defined for engines that operate in the speed range below $1000 \mathrm{rpm}$. The design details of modifications for CWS needed for higher speed engines are not as well defined, because the operating experience in these engines is less extensive.

The CWS fuel specification is somewhat dependent on the engine speed, in that the operating experience indicates that the slower $400 \mathrm{rpm}$ engines are somewhat less sensitive to coal fuel characteristics than the $1000 \mathrm{rpm}$ engine. The following specification therefore represents an attempt to satisfy the requirements of the 400-1000 rpm engines, realizing that the specified coal fuel will be marginally better than required for operation of the slower engines.

\begin{tabular}{||l|c|}
\hline \multicolumn{2}{|c|}{ CWS Specification ${ }^{(125)}$} \\
\hline Coal & Bituminous \\
\hline Mean Coal Size & $5-12$ Microns \\
\hline Top Particle Size & $15-85$ Microns \\
\hline Ash Content (dry coal basis) & $1-2$ Percent by Mass \\
\hline Sulfur (dry coal basis) & $1-2$ Percent by Mass \\
\hline Viscosity & $<300$ Centipoise @ 1000 ${ }^{-1}$ sec \\
\hline Additive & Dispersant \\
\hline
\end{tabular}




\section{Fuel System}

Details of the CWS fuel system design are described as a major portion of this report. The following are the salient points that are common to all CWS fuel system designs and should be considered as the starting point for future work in this area:

(a) Piping - Smooth pipe, no dead volumes, no rapid changes in flow area

(b) Tank - Continuously recirculating, horizontal-cylindrical tank equipped with a floating suction, and discharge through a manifold with exit holes designed to produce flow with circulation.

(c) Injection Pump - Conventional diesel injection pump sized to inject the required amount of slurry to achieve full load and coupled to the engine, supplying diesel fuel pressure pulses to a shuttle piston assembly.

(d) Shuttle Piston Assembly - Conventional injection pump barrel and plunger assembly design parameters of surface finish and clearances, titanium nitride coated, sized to displace 150 percent of the required full load slurry flow, and with an L/D of approximately 1 .

(e) Nozzle Holes - Sapphire or diamond compact inserts.

(f) Needle Valve - Tungsten carbide plasma coated steel.

(g) Needle Valve Seat - Tungsten carbide seat insert

\section{Combustion Chamber}

The results of the METC Program indicate that conventional open chamber, direct injection, low swirl combustion chambers are acceptable for operation on CWS. Combustion efficiencies of 99 percent were routinely demonstrated in these designs if the intake air temperature and pressure are made as high as practical within the mechanical limitations of the engine components. The bowl shape can be either a shallow "Mexican Hat" design, as used in the GE and SwRI/Detroit Diesel projects, or a shallow bowl as used in the Cooper engine.

\section{Air Temperature}

It is clear that turbocharging is required to achieve acceptable breathing characteristics, especially with the higher manifold air temperatures required for operation on CWS. The manifold air temperature should be at least $135^{\circ} \mathrm{C}$ and the pressure should be in the range of $300 \mathrm{kPa}$. 


\section{Pilot Fuel}

While autoignition was demonstrated as feasible in the GE, the Cooper, Adiabatics, and the Detroit Diesel engines, positive ignition timing control is essential for reliable and efficient operation of these a CWS engine. Pilot injection of small quantities (1-5\% of heating value) of diesel fuel appears to be the best method of ignition control. It offers the opportunity for cold starting and operation at the part load conditions, especially idle, where the demonstrated experience on CWS indicates that the engine temperatures drop below the levels required for reliable operation on CWS.

\section{Rings and Liners}

The rings and liners should be tungsten carbide coated and the lubricant should contain high concentrations of dispersant additive to prevent excessive wear of these components. It appears that filtration of the lube oil using the best available filter technology (pleated paper filter with 5 micron pore size) is sufficient to control wear rates in the rest of the engine. 


\section{ACKNOWLEDGEMENTS}

The author and editor would like to thank all of the engineers and scientists that have participated in the Coal Fuel Diesel Engine Program. The technical success of the program is based on their efforts and on the excellent technical, management, and financial support provided by the Morgantown Energy Technology Center, particularly Larry Carpenter, Mike McMillian, Nelson Rekos, Leland Paulson, and the late Dr. Holmes (Sandy) Webb. The author would also like to thank Professor Jerry Caton for his tireless efforts in organizing the many technical sessions covering the work performed in the program and for his work in providing, in it's entirety, the section of this report summarizing the modelling work. 


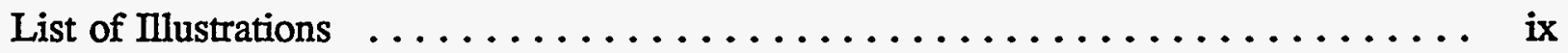

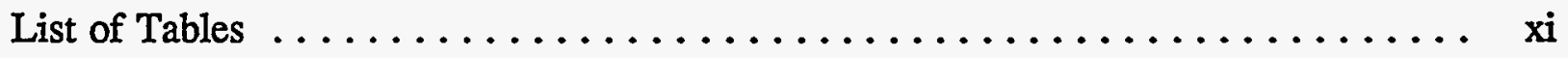

INTRODUCTION $\ldots \ldots \ldots \ldots \ldots \ldots \ldots \ldots \ldots \ldots \ldots \ldots \ldots$

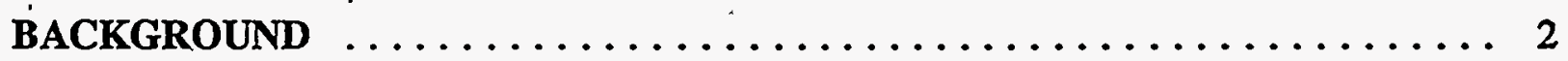

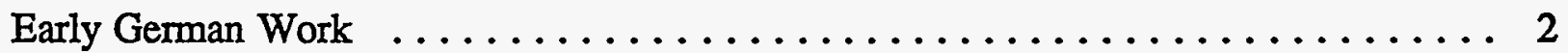

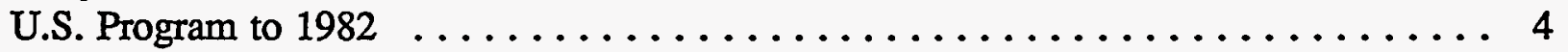

Morgantown Energy Technology Center Program $\ldots \ldots \ldots \ldots \ldots \ldots \ldots \ldots$

FUEL SYSTEM DEVELOPMENT $\quad \ldots \ldots \ldots \ldots \ldots \ldots \ldots \ldots \ldots$

Fuel Storage and Handling $\ldots \ldots \ldots \ldots \ldots \ldots \ldots \ldots \ldots \ldots \ldots \ldots \ldots \ldots \ldots \ldots$

Injection System Design $\ldots \ldots \ldots \ldots \ldots \ldots \ldots \ldots \ldots \ldots \ldots \ldots \ldots \ldots \ldots \ldots \ldots \ldots$

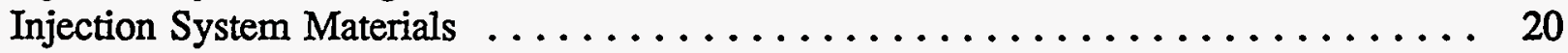

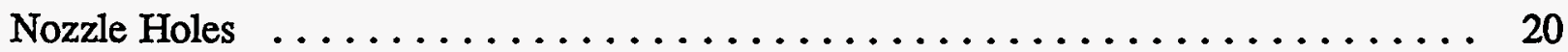

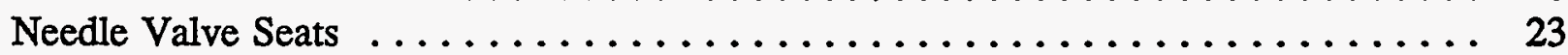

COMBUSTION SYSTEM DEVELOPMENT $\ldots \ldots \ldots \ldots \ldots \ldots \ldots \ldots$

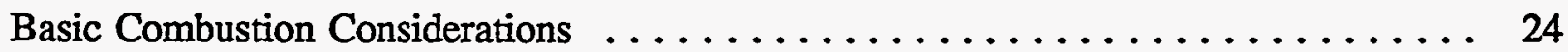

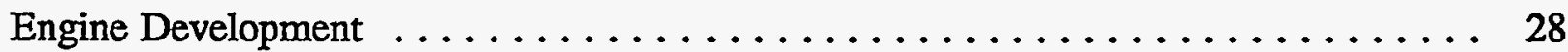

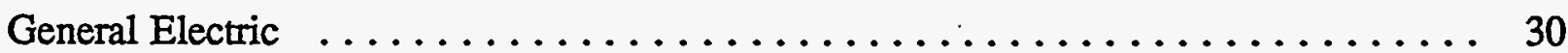

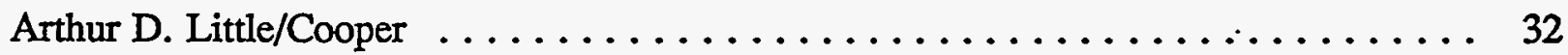

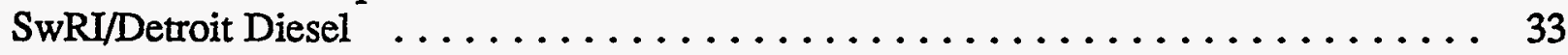

COAL-WATER SLURRY PROPERTIES $\ldots \ldots \ldots \ldots \ldots \ldots \ldots \ldots \ldots$

INJECTION CHARACTERISTICS $\ldots \ldots \ldots \ldots \ldots \ldots \ldots \ldots \ldots \ldots$

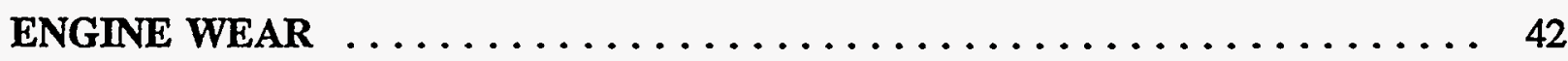

ENGINE MODELING $\ldots \ldots \ldots \ldots \ldots \ldots \ldots \ldots \ldots \ldots \ldots \ldots \ldots$

vii 
Table of Contents (Continued)

$\underline{\text { Page }}$

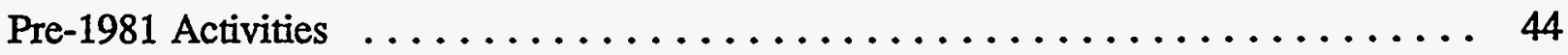

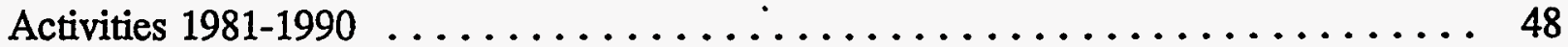

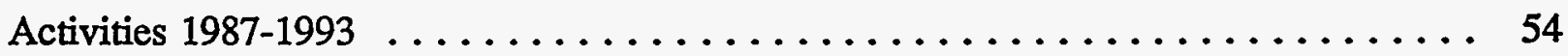

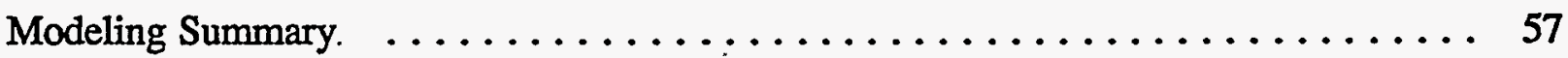

CWS ENGINE STATUS $-1994 \ldots \ldots \ldots \ldots \ldots \ldots \ldots \ldots \ldots$

Fuel Specification for Coal Slurry $\ldots \ldots \ldots \ldots \ldots \ldots \ldots \ldots \ldots \ldots \ldots$

Fuel System Design for Coal Slurry $\ldots \ldots \ldots \ldots \ldots \ldots \ldots \ldots \ldots \ldots \ldots, 60$

Engine Design for Coal Slurry Fuel $\ldots \ldots \ldots \ldots \ldots \ldots \ldots \ldots \ldots \ldots \ldots, 60$

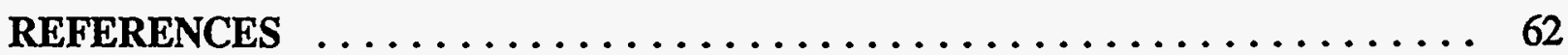

APPENDIX A: COAL-FUELED DIESEL REVIEW BIBLIOGRAPHY $\ldots \ldots$ A-1 


\section{List of Illustrations}

Page

1. Coal Water Slurry Storage Tank System ... . . . . . . . . . . . . 11

2. SwRI Two-Fluid Unit Injector $\ldots \ldots \ldots \ldots \ldots \ldots \ldots \ldots \ldots \ldots \ldots \ldots \ldots$

3. General Electric Fuel System Schematic ... . . . . . . . . . . . . . 14

4. Schematic of the General Electric Accumulator

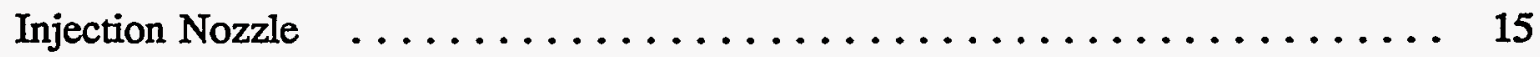

5. SwRI Fuel Injector (Cross-Section) $\ldots \ldots \ldots \ldots \ldots \ldots \ldots \ldots \ldots$

6. SwRI Coal Water Slurry Injection System Development Test Stand . . . . . . . 18

7. Slurry Fuel Supply Check Valve $\ldots \ldots \ldots \ldots \ldots \ldots$

8. Injection Nozzle Hole Wear Pattern $\ldots \ldots \ldots \ldots \ldots \ldots \ldots \ldots \ldots \ldots$

9. Coal and Carbon Burnout Time and Engine Speed

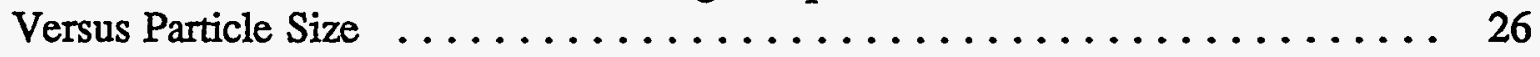

10. General Electric Coal Water Slurry Burn Rate Data . . . . . . . . . . . . . 28

11. Engine Combustion Chamber Schematics for Operation on

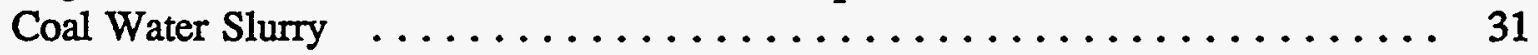

12. Combustion Pressure Traces for the 149 Engine Operation on Coal Water Slurry $\ldots \ldots \ldots \ldots \ldots \ldots \ldots \ldots$

13. Heat Release Rates Computed from the Pressure Data

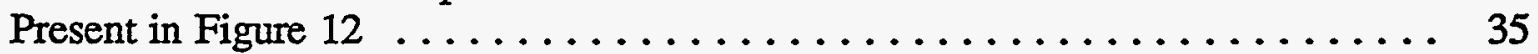

14. Viscosity Versus Shear Rate for CWS's with Different Mean and Top Particle Sizes

15. Nozzle Hole Geometries used in Reference $73 \quad \ldots \ldots \ldots \ldots \ldots$

16. Cone Angles Versus Injection Pressure for Different CWS's . . . . . . . . . 41 
17. Average SMD of CWS Sprays Versus Injection Pressure $\ldots \ldots \ldots \ldots \ldots . \ldots 42$

18. Arthur D. Little Ring and Liner Wear Data ${ }^{(37)} \ldots \ldots \ldots \ldots \ldots \ldots$

19. Ring and Liner Wear Rate Data for Conventional and Hard Materials ${ }^{(84)} \ldots . .44$

20. Liner Wear Rates for Various Materials ${ }^{(31)} \ldots \ldots \ldots \ldots \ldots \ldots \ldots$

21. Ring Wear Rates for Various Materials ${ }^{(31)} \ldots \ldots \ldots \ldots \ldots \ldots \ldots$

22. Schematic of Engine Modelling Approach to CWS Combustion $\ldots \ldots \ldots 48$

23. Schematic of the Solid Particle Combustion Model $\ldots \ldots \ldots \ldots \ldots$. . . 49

24. Effect of Particle Size on Thermal Efficiency, Injection Timing, and Unburned Fuel Mass Fraction for the Class B Engine $\ldots \ldots \ldots \ldots \ldots \ldots \ldots \ldots \ldots \ldots \ldots$

25. Indicated Thermal Efficiency Computed as a Function of the Gas Temperature

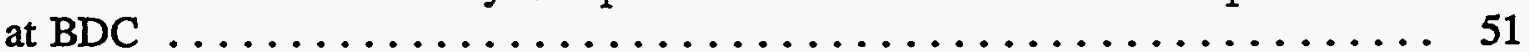

26. Indicated Thermal Efficiency Computer as a Function of the Gas Temperature at BDC for Different Fuels $\ldots \ldots \ldots \ldots \ldots \ldots \ldots \ldots \ldots \ldots \ldots \ldots \ldots \ldots \ldots \ldots \ldots$

27. Calculated Indicated Thermal Efficiency Versus Particle Size for

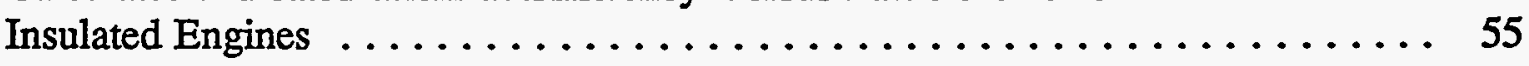

28. Computed Indicated and Brake Thermal Efficiency Versus CWS Drop Size . . . 57 


\section{List of Tables}

Page

1. German Formulation of Hardened Materials $\ldots \ldots \ldots \ldots \ldots \ldots \ldots$

2. DOE METC Coal-Fueled Diesel Engine Program Part One (1982-1986) $\ldots \ldots$. 7 DOE METC Coal-Fueled Diesel Engine Program Part Two (1987-1993) . . . . . . 8

3. Material Evaluated for Use in Injection Nozzle Holes $\ldots \ldots \ldots \ldots \ldots \ldots 22$

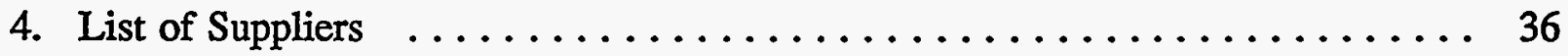

5. CWS Properties Tested $\ldots \ldots \ldots \ldots \ldots \ldots \ldots \ldots \ldots \ldots \ldots \ldots \ldots \ldots \ldots \ldots \ldots$

6. Yanmar Engine Results $\ldots \ldots \ldots \ldots \ldots \ldots \ldots \ldots \ldots \ldots \ldots \ldots$

7. CWS Fuel Specification $\ldots \ldots \ldots \ldots \ldots \ldots \ldots \ldots \ldots \ldots \ldots \ldots \ldots \ldots \ldots \ldots \ldots$ 


\section{INTRODUCTION}

The use of coal as a fuel for diesel engines dates back to the early days of the development of the engine. Dr. Diesel envisioned his concept as a multi-fuel engine, with coal a prime candidate due to the fact that it was Germany's primary domestic energy resource. It is interesting that the focus on coal burning diesel engines appears to peak about every twenty years as shortages of other energy resources increase the economic attractiveness of using coal.

This periodic interest in coal started in Germany with the work of Diesel ${ }^{(1)}$ in the timeframe 1898-1906. Pawlikowski carried on the work from 1916 to 1928. Two German companies commercialized the technology prior to and during World War II. The next flurry of activity occurred in the United States in the period from 1957-69, with work done at Southwest Research Institute ${ }^{(2)}$, Virginia Polytechnical University ${ }^{(3)}$, and Howard University ${ }^{(4)}$. The current period of activity started in 1978 with work sponsored by the Conservation and Renewable Energy Branch of the U.S. Department of Energy. This work was done at Southwest Research Institute and by ThermoElectron at Sulzer Engine in Switzerland. In 1982, the Fossil Energy Branch of the U.S. Department of Energy, through the Morgantown Energy Technology Center (METC) initiated a concentrated effort to develop coal burning diesel and gas turbine engines. The diesel engine work in the METC sponsored program was performed at Arthur D. Little (Cooper-Bessemer as subcontractor), Bartlesville Energy Technology Center (now NIPER), Caterpillar, Detroit Diesel Corporation, General Motor Corporation (Electromotive Division), General Electric, Southwest Research Institute, and various universities and other research and development organizations. This DOE-METC coal engine RD\&D initiative which spanned the 1982-1993 timeframe is the topic of this review document.

In terms of total investment and technical progress, it appears that the METC Program has made more progress and successfully incorporated more diverse technologies than all of the previous efforts over the period 1890-1980 to develop coal burning reciprocating engines. At the outset of this METC program, it was clear that major technical hurdles had never been satisfactorily overcome in the previous programs, using various standard engine technologies. It was apparent that new engine component designs and new materials were needed in order to design systems that had acceptable reliability and durability. New coal fuel forms with lower ash and thus more compatible with the engine were also needed. Moreover, to meet modern environmental standards, it would be necessary to add emission control technology to make a coal engine competitive and attractive. As described in this report, the solutions developed under the 1982-93 DOE program generally added some complexity and some additional cost to the conventional diesel engine system. However, the METC program has resulted in the development of coal-fueled engine systems that are expected to be competitive with other fossil fuels once the price of the other fuels continues to escalate.

It now appears that in the 2005-2030 timeframe, when the supplies of petroleum and natural gas recoverable at low cost begin to be limited and the prices begin to increase in response to the normal supply-demand pressures, the accomplishments of the METC Program will be of very valuable in providing lower cost coal alternatives to oil and gas. It is therefore very important that the accomplishments of this program be clearly documented, summarized, and reduced to definition of the best available technology. The initial efforts in the current 
objective of this report is, therefore, to provide a well defined starting point for future projects in the coal fueled diesel engine area.

The report is broken down into several sections. The next section contains a very brief summary of the historical work done before 1979. Soehngen ${ }^{(1)}$ and Caton and Rosegay ${ }^{(5)}$ provided excellent summaries of this work that will serve as the historical references. The starting point for the METC program will be identified in terms of the major technical hurdles that had to be addressed in each component area (fuel preparation and handling, fuel injection, ignition and combustion, wear prevention, and emissions control). The structure of the METC program will be briefly described and the key participants identified for future reference. The remaining sections, and the major portion of the report will be devoted to discussion of the work that was done in each component development area. Emphasis is placed on the status of the work in 1993 and identification of the best starting point for continuation of the work in the future. The last section of the report is a summary of the key design features that must be incorporated in a successful engine, based on the current available technology. A reference list is included as well as a complete bibliography of references that are related to the development of a coal burning diesel engine.

\section{BACKGROUND}

\section{Early German Work}

An excellent summary of the available historical information on coal burning diesel engines was prepared by E.E. Soehngen ${ }^{(1)}$ for the Office of Fossil Energy of the Energy Research and Development Administration (ERDA), more recently the U.S. Department of Energy. This report was summarized, along with several other publications, by Caton and Rosegay ${ }^{(5)}$ and presented as a technical paper for the Society of Automotive Engineers.

The history of solid fuel burning engines dates back to the work of the French scholar Montgolfier ${ }^{(4)}$ in 1780 . Dr. Rudolf Diesel worked periodically on the concept for approximately 10 years (1898-1908). Soehngen ${ }^{(1)}$ indicated that Diesel worked on the coal diesel only because he had mentioned the use of coal in his basic engine patent. His tests were apparently limited to fumigation of coal dust into the intake air. He observed high wear and the accumulation of deposits on the piston and cylinder wall. He ceased working on the concept after an accident (possibly a coal dust explosion) occurred during operation on coal dust.

Pawlikowski, a co-worker of Dr. Diesel, apparently continued the work using dry powder coal until approximately 1928 . As described by Soehngen ${ }^{(1)}$, there are apparently 30 patents and 50 reports describing this work. The patents describe various concepts for introduction of the coal powder in the engine and for the design of rings and seals to mitigated the wear problems associated with the use of coal. The reports have apparently been lost and were not available when Soehngen performed his review of the German work. While it may be of historical value to have access to the reports and patents, it is likely that the material is of little technical value because of the low firing pressures, low efficiencies, and material and manufacturing limitations typical in that time frame. 
Development of the basic Pawlikowski engine apparently continued in at least four different industrial organizations in Germany, prior to and during World War II. Soehngen ${ }^{(1)}$ indicates that while these efforts may have had some qualified successful results, metered fuel injection and engine wear continued to be major problems that were not permanently overcome. It is likely that the results of these experiments would provide little new information if details were available because the key issues remained to be engine wear, fuel metering and injection, and fuel handling.

There were several major developments of this early work that have only partly been exploited in the more recent coal fueled engine program. One key observation from the older work is the fact that there were several patents developed for piston-cylinder concepts designed to prevent contact of the coal dust on the oil wetted cylinder. This was a greater problem for the early engine designs because most coal dust mixture preparation schemes did not confine the coal to a wetted spray. These experiments verify what is intuitively clear, and that is that coal particles that interact with the relatively cool lubricant film on the cylinder wall will most probably not ignite and burn, and will definitely increase the cylinder liner and piston ring wear rates. Coal particles must, therefore, be prevented from interacting with the lubricant film in the engine (as much as possible). For example, fumigation of coal during the intake process, or injection of coal fuel directly on the cylinder liner would accelerate wear rates.

Another important observation from this early work is a reference to the development of hardened materials for use in the manufacture of the piston rings and cylinder liners. It appears the German company Schichau Werke developed a material and process for hardening cast iron liners and rings. The alloy composition is listed in Table 1, but no information was available regarding the hardening process. It was clear that this process mitigated the wear problem in the pre-war German engines, based on the fact that the process was sold to the other coal engine manufacturers and that there were no more references to wear problems in the remainder of the German work. Hardened rings and liners (or hard film coatings) are therefore an essential element of a commercial coal fueled diesel engine.

Table 1. German Formulation of Hardened Materials ${ }^{(1)}$

\begin{tabular}{|l||c|c|}
\hline \multicolumn{2}{|c|}{ Liner } & Ring \\
\hline Carbon & $3-4 \%$ & $2-4 \%$ \\
\hline Manganese & $2-7 \%$ & - \\
\hline Silicon & $0.5-1 \%$ & $1-2 \%$ \\
\hline Nickel & $0.1-1 \%$ & $0.5-1.5 \%$ \\
\hline Chromium & -- & $0.3-0.7 \%$ \\
\hline
\end{tabular}

Coal dust fuel metering and coal dust introduction into the engines were continuing problem areas in these early engines. Low-pressure intake of coal dust through an extra valve and the use of pre-chambers were widely.attempted. It appears that the most successful systems involved some form of air atomization. Erosion of internal passages, plugging and sticking of coal-contacted moving components, and erosion and abrasion of seals and seating surfaces were problems that were encountered in all of the early work. Several patents were 
issued in this area, but no clear mechanical solution was obvious. It appears that the Germans did some fundamental work to determine the basic mechanisms of the wear problems, but they lacked the materials and the manufacturing technology required to solve these problems.

The Germans also did some fundamental combustion experiments that indicated that coal ignition and combustion rates provide the fundamental limit of the speed of operation of a coal fueled diesel. However, the experiments, as described in Reference 1, were performed in a laminar flow system. The experiments showed that diesel fuel drops also burned at a finite rate, which limits engine speed. It is almost certain, as will be discussed in some detail in the sections describing the very recent work, that the turbulence levels in an operating diesel engine are sufficiently high that the combustion rate (coal burn out rate) in the actual engines is faster than the laminar flow experiments would suggest. Coal particle size and coal type were shown to affect the combustion rate. The early data agrees with the more recent work that indicates that coal particle size and volatility are extremely important (as will be described in later sections).

\section{U.S. Program to 1982}

Work in the United States in the period from 1945 to 1978 was very limited and consisted mainly of attempts to operate convention diesel engines on slurries of coal in diesel fuel oil. The most notable of these efforts were those of Marshall and Shelton ${ }^{(3)}$ and Marshall and Walters ${ }^{(6)}$. Additional work on coal-oil mixtures was performed at the University of North Carolina, Southwest Research Institute, and Howard University. The results of all of these efforts are of limited use because the fuels were generally not characterized in terms of actual particle size and flow characteristics. Because of the recent advances in preparing coal water slurries, economic studies indicate that coal oil mixtures are much less economically viable. However, the results of the coal-oil experiments did extend the findings of the German work with dry powders. The results can be summarized as follows:

1. Fuel injection of coal-oil mixtures was a problem in conventional pump-line-nozzle systems using the standard materials and the standard clearances. Sticking of components and plugging could generally be reduced by increasing clearances, but long term durability and fuel metering continued to degrade with time.

2. Cylinder liner and ring wear was reported to be a problem in most coal-oil mixture engine experiments in which wear characteristics were examined.

3. Combustion rate and combustion efficiency were adversely affected by the presence of the coal. However, the reduction in combustion performance may have been due to the effects of the coal on the flow characteristics of the fuel and the resulting degraded atomization in the engine.

Two programs, sponsored by the Office of Conservation and Renewable Energy of the U.S. Department of Energy, were started in 1978 to study in detail the effects of various alternative coal fuels on operation of diesel engines. One program, performed by Thermo Electron, was focused on application in very large stationary engines. The other program, performed at Southwest Research Institute (SwRI), was focused on use of coal fuels in smaller diesel 
engines used in transportation. The efforts in both projects involved the use of a variety of fuels including slurries of solids in diesel fuel.

The Thermo Electron work ${ }^{(7)}$ was performed in a relatively large $(900 \mathrm{~mm}$ bore) $100-\mathrm{rpm}$ engine manufactured by Sulzer Brothers Ltd., of Switzerland. The fuels in the initial experiments included coal-liquids and coal-oil slurries. The experiments were extended in 1982 to include the use of coal in water slurries. Four well-characterized coal slurries with loadings of approximately 50 weight percent were studied. This represented the first detailed characterizations of these types of fuels and indicated the complex nature of the mixtures, including the non-Newtonian behavior of some of the slurries. The engine design included two complete injection systems, one for pilot injection of diesel fuel and one for the slurry. The pilot system provided absolute control of the ignition timing. A special accumulator injection system, developed on this project, apparently solved the fuel metering and injection problems encountered on all of the prior slurry experiments.

The combustion and thermal efficiencies were generally somewhat lower with the slurries, with the Otisca slurry demonstrating the same, or slightly higher thermal efficiency as compared to the baseline. Particulate emissions appeared to be higher than the baseline, but all other emissions were lower. Ring and liner wear rates were a factor of 5 greater than the corresponding rates on diesel fuel.

A limitation of the usefulness of this work was the fact that Sulzer Brothers Ltd patented the injection system design and this somewhat restricted its use in the other U.S. funded projects.

The work at Southwest Research Institute ${ }^{(8,9)}$ was performed in a much higher speed single-cylinder research engine manufactured by Laboratory Equipment Company. The initial experiment consisted of screening tests of a very wide range of alternative liquids and solids, generally mixed in various concentrations in diesel fuel to provide sufficient ignition quality for auto-ignition in the test engine. The results of these experiments were presented in the form of comparisons with diesel fuel. The slurries, formulated in the baseline diesel fuel, included various biomass solids as well as coals, cokes, and carbon black. The injection system was standard pump-line-nozzle technology with increased clearances to prevent sticking and plugging.

The results of the experiments demonstrated the complexity of the rheological properties of the slurries and interactions of these properties with the injection and atomization of the slurries in the engine. A second project was initiated ${ }^{(10,11)}$ to examine in detail the interaction of the properties of the solids, the slurry properties, the injection and atomization characteristics, and the combustion performance in the research engine. The solids used in these experiments were various commercial carbon blacks and cokes that could be purchased in a range of particle sizes and containing various quantities of volatiles. It was clear from this work that the maximum solids loading in the diesel fuel were limited to 30 weight percent or less due to the shear thickening nature of these mixtures. It was also clear that solid burnout was directly related to the quality of the injection process. 


\section{Morgantown Energy Technology Center Program (1982-93)}

The Morgantown Energy Technology Center (METC) initiated a coal-fueled heat engine program in 1982 involving the use of coal, direct fired in both gas turbine and diesel engine systems. The initial emphasis of the program was on use of coal-water slurries in gas turbine engines, primarily because it was perceived that the continuous combustion systems in these engines would be much easier to adapt to the use of coal than the intermittent combustion in diesel engines. The ultimate successes of the diesel program and the very difficult problems associated with erosion, corrosion, and deposition in the turbine engines focused added interest on the diesels, and after 1988 the two programs became more competitive in funding levels and in their approach to commercial development.

The gas turbine program provided significant contributions to the diesel program in the way of fuel developments and emission-control technology options. These contributions will be discussed in the appropriate sections of this report. The emphasis of this report is, however, on the diesel program. It is important for future development of the coal-fueled diesel to have a clear picture of the resources that were devoted to this effort in the period from 1982 to 1993. Table 2 is a summary of the approximate total DOE funding levels for the coal fueled diesel program, the major participants in each year of the program, and a summary of the activities in each project.

The initial efforts in 1982 and 1983 consisted of laboratory experiments to explore the feasibility of the use of coal-water slurry (CWS) and coal powders in diesel engines. The results were promising, and a major procurement announcement was released by DOE-METC in 1984. Three major feasibility studies were awarded in early 1985 to three leading mediumspeed engine manufacturers (Cooper-Bessemer, GE, and GM Electromotive): The goal of these feasibility studies was to identify the critical technical barriers impeding the development of the engine systems, and to assess the relative difficulty of overcoming these barriers. The focus of the Cooper-Bessemer project (Arthur D. Little as prime contractor) was the development of a stationary co-generation engine system based on the $400 \mathrm{rpm}$ LS engine Model. General Electric and General Motors both focused on the development of railroad locomotive systems based on engines designed for approximately $1000 \mathrm{rpm}$. All three studies included economic assessments which identified the conditions under which coal diesel systems could be competitive in the respective applications. Over the course of the project, new technologies were developed and the economic assessments were reevaluated in terms of the new information. The results of the GE and the Arthur D. Little feasibility studies both indicated that relatively inexpensive clean coal slurries were feasible to produce. General Motors, on the other hand, concluded that the Electro-Motive engines would require the more expensive ultra-clean coals.

As shown in Table 2, a major procurement was issued in 1988 to support proof-of-concept demonstration of full-scale coal-fired diesel systems with complete emission controls for both the GE and the Cooper/Arthur D. Little technology. Work was halted on the General Motors project because GM Electro-Motive continued the development efforts using only ultra-clean coals, which was an approach that DOE economic studies had indicated was not economically viable. 
Table 2. DOE METC Coal-Fueled Diesel Engine Program Part One (1982-1986)

\begin{tabular}{|c|c|c|}
\hline Year & Participants & Activity \\
\hline 1982 & $\begin{array}{l}\text { SWRI } \\
\text { NIPER }\end{array}$ & $\begin{array}{l}\text { (1) Effects of Temperature on CWS Combustion } \\
\text { (2) Preliminary Test of CWS in a Diesel Engine }\end{array}$ \\
\hline 1983 & $\begin{array}{l}\text { SWRI } \\
\text { NIPER }\end{array}$ & $\begin{array}{l}\text { (1) Continued } \\
\text { (2) Continued }\end{array}$ \\
\hline 1984 & $\begin{array}{l}\text { SwRI } \\
\text { NIPER } \\
\text { Adiabatics }\end{array}$ & $\begin{array}{l}\text { (1) Continued } \\
\text { (2) Continued } \\
\text { (3) Coal Powder Combustion in a Diesel Engine (DOE } \# 23006 \text { ) }\end{array}$ \\
\hline 1985 & $\begin{array}{c}\text { SwRI } \\
\text { Adiabatics } \\
\text { GM/SwRI } \\
\text { GE } \\
\text { ADLCooper/MIT }\end{array}$ & $\begin{array}{l}\text { (1) Continued } \\
\text { (3) Continued (DOE \#23006) } \\
\text { (4) Coal-Fueled Diesel Feasibility Study (DOE \#22123) } \\
\text { (5) Coal-Fueled Diesel Feasibility Study (DOE \#22181) } \\
\text { (6) Coal-Fueled Diesel Feasibility Study (DOE \#22182) }\end{array}$ \\
\hline 1986 & $\begin{array}{l}\text { SwRI } \\
\text { Adiabatics } \\
\text { GM/SwRI } \\
\text { GE } \\
\text { ADL/Cooper/MIT }\end{array}$ & $\begin{array}{l}\text { (1) Continued } \\
\text { (3) Continued (DOE \#23006) } \\
\text { (4) Continued (DOE \#22123) } \\
\text { (5) Continued (DOE \#22181) } \\
\text { (6) Continued (DOE \#22182) }\end{array}$ \\
\hline
\end{tabular}


Table 2. DOE METC Coal-Fueled Diesel Engine Program

Part Two (1987-1993)

\begin{tabular}{|c|c|c|c|}
\hline Year & Participants & Activity & DOE Funds \\
\hline \multirow[t]{4}{*}{1987} & Adiabatics & (3) Coal Powder Diesel (DOE \#23006) & NA \\
\hline & GM/SWRI & (4) Coal-Fueled Diesel Feasibility (DOE \#22123) & $\$ 2,494,000$ \\
\hline & GE & (5) Coal-Fueled Diesel Feasibility (DOE \#22181) & $\$ 2,366,000$ \\
\hline & ADUCooper $M I T$ & (6) Coal Diesel Feasibility Study (DOE \#22182) & $\$ 799,000$ \\
\hline \multirow[t]{7}{*}{1988} & Adiabatics & (3) Continued (DOE \#23006) & $\$ 68,000$ \\
\hline & GMSWRI & (4) Continued (DOE \#22123) & $\$ 304,000$ \\
\hline & GE & (5) Continued (DOE \#22181) & \\
\hline & ADLCooperMIT & (6) Continued (DOE \#22182) & $\$ 241,000$ \\
\hline & GE & (7) System Development Demonstration (DOE \#23174) & $\$ 3,405,009$ \\
\hline & ADUCooper/CQ/AMBAC & (8) System Development and Demonstration (DOE \#25124) & \\
\hline & Caterpillar & (9) Gasifier Engine (DOE \#25141) & $\$ 714,000$ \\
\hline \multirow[t]{5}{*}{1989} & GE & (7) Continued (DOE \#23174) & $\$ 5,000,000$ \\
\hline & ADLCooper/CO/AMBAC & (8) Continued (DOE \#25124) & $\$ 1,998,000$ \\
\hline & SwRI & (10) Basic Wear Study & NA \\
\hline & Adiabatics & (11) Now Injoction (DOE \#25132) & $\$ 95,000$ \\
\hline & Caterpillar & (9) Continued (DOE \#25141) & $\$ 1,492,000$ \\
\hline \multirow[t]{6}{*}{1990} & GE & (7) Continued (DOE \#23174) & $\$ 4, \pi 7,000$ \\
\hline & ADLCooper/CQ/AMBAC & (8) Continued (DOE \#25124) & $\$ 3,243,000$ \\
\hline & SwRI & (10) Continued & NA \\
\hline & Adiabatics & (11) Continued (DOE \#26305) & $\$ 194,000$ \\
\hline & Caterpillar & (9) Continued (DOE \#25141) & $\$ 1,200,000$ \\
\hline & DDC/SwRI & (12) High Speed Coal Diesel (DOE \#27222) & $\$ 320,000$ \\
\hline \multirow[t]{6}{*}{1991} & GE & (7) Continued (DOE \#23174) & $\$ 2,298,000$ \\
\hline & ADUCooper/CQ/AMBAC & (8) Continued (DOE \#25124) & $\$ 4,398,000$ \\
\hline & SwRI & (10) Continued & NA \\
\hline & Adiabatics & (11) Continued (DOE \#26305) & $\$ 118,000$ \\
\hline & Caterpillar & (9) Continued (DOE \#25141) & $\$ 953,000$ \\
\hline & DDC/SwRI & (12) High-Speed Coal Diesel (DOE \#27622) & $\$ 503,000$ \\
\hline \multirow[t]{6}{*}{1992} & GE & (7) Continued (DOE \#23174) & $\$ 1,690,000$ \\
\hline & ADUCooper/CQ/AMBAC & (8) Continued (DOE \#25124) & $\$ 3,497,000$ \\
\hline & SWRI & (10) Continued & - \\
\hline & Adiabatics & (11) Continued (DOE \#26305) & - \\
\hline & Caterpillar & (9) Conlinued (DOE \#25141) & $\$ 514,000$ \\
\hline & DDC/SwRI & (12) Continued (DOE \#27222) & $\$ 410,000$ \\
\hline \multirow[t]{4}{*}{1993} & GE & (7) Continued (DOE \#23174) & - \\
\hline & ADL/Cooper/CQ/AMBAC & (8) Continued (DOE \#25124) & $\$ 578,000$ \\
\hline & Caterpillar & (9) Continued (DOE \#25141) & - \\
\hline & $\mathrm{DDC} / \mathrm{SwRI}$ & (12) Continued (DOE \#27222) & - \\
\hline
\end{tabular}


The Cooper/Arthur D. Little Project was focused on the continued development and demonstration of technologies examined in the feasibility study. The goal was to demonstrate these technologies on a multi-cylinder engine complete with emission controls at the Cooper research facility in Mount Vernon, Ohio. This goal was achieved in 1993.

The GE Project also included continued development of the technologies introduced in the feasibility studies. The goal of this project was to demonstrate these technologies in a multicylinder GE engine operating a locomotive on the test track at the GE facility in Erie, Pennsylvania. This goal was achieved in 1992.

Selection of the medium-speed engines as the focus of the program was based on some modeling work done by Caton and Rosegay ${ }^{(12)}$, which indicated that the maximum engine speed for burn-out of coal particles in the 10 micron size range was $1000 \mathrm{rpm}$. While these model results were in agreement with modeling work done later ${ }^{(13,14)}$, some preliminary experiments reported by Kakwani ${ }^{(15)}$ indicated that much higher engine speeds appeared to be possible. These results were corroborated in a project with Detroit Diesel Corporation and SwRI ${ }^{(16,125)}$, conducted in 1990-93, and performed in a $1900 \mathrm{rpm}$ Detroit Diesel $8 \mathrm{~V}-149$ engine used in mine haul truck applications.

A project was initiated in 1988 at Caterpillar ${ }^{(17,126,127)}$ to examine the use of a novel high pressure gasifier system in conjunction with a large Caterpillar engine. The scope of the project involved demonstration of operation of the engine on a gas mixture simulating the gasifier output. The project also involved demonstration of the gasifier concept that included the use of pre-loaded canisters of coal that undergoes gasification at elevated pressure.

None of the METC projects were continued after they ended in 1993, due in part to successful demonstrations and in part to shifting METC priorities (e.g., toward natural gas advanced technology). The emphasis of U.S. Government funding for alternative fuels R\&D in the 1993-2000 timeframe shifted to natural gas technology. The prices of gas appeared to be low, domestic supplies appeared to be adequate for some time, and the low carbon content appeared attractive from the standpoint of control of the greenhouse gas, $\mathrm{CO}_{2}$.

As indicated previously, the economics of clean coal engines will become favorable in the future, as the supplies of the other energy resources are depleted or become more costly to recover. The objective of this report is to provide a clear starting point for future work in coalfueled engines. The following sections contain detailed descriptions of the work that was done in this program and specifications of the fuel and engine components.

\section{FUEL SYSTEM DEVELOPMENT}

Injection system development historically had been the primary obstacle to development of coal-fired diesel engines, primarily because coal dust was the fuel form rather than coal slurry. While dry powder coal was of primary interest in the early development work, it was not emphasized in the METC Program. Not only are there fuel handling and safety issues associated with the use of these finely divided powders, but micronized coal slurry technology had been significantly advanced. The emphasis of the METC Program was centered on the development of systems that could handle coal water slurries with mass loadings of 
approximately 50 percent coal. It was quickly realized that conventional high pressure jerkpump injection systems could be used with coal-water slurry fuels with suitable nozzle modifications. The development of the successful injection systems was actually tied very closely with the development of the fuels. The particle loading, the particle size distribution, the coal type, and the additive package all affected the flow characteristics of the resulting slurry and, in turn, the operation and performance of the injection system. The emphasis of this section will be on describing the efforts that went into development of the mechanical components of the successful fuel systems. The resulting mechanical system specification assumes that the fuel will meet the fuel specifications discussed in a later section.

\section{Fuel Storage and Handling}

Coal-water slurries will always be unstable if the viscosity of the base liquid is kept low, and the particle loading is below the volume-filled condition, a situation where the particle loading is high enough that the entire fluid volume is essentially filled with contacting particles. In other words, if the slurry has the characteristic of a fluid of reasonable viscosity, the density difference between the coal particle and the water will always cause settling.

Coal-fueled systems must therefore incorporate special features in the fuel storage and handling systems that accommodate the separation problem. Piping systems should include smooth internal flow passages, with no rapid volume changes, or changes in flow direction. The goal in the design of the piping system is to eliminate components that allow the formation of recirculation zones and volumes-where the flow velocities become very low, and settling can occur. The piping system should also include allowances for flushing of the system with water or other clear fluid prior to shut-down.

Progressive cavity pumps have been used to accomplish recirculation in fuel tanks and for transport of the slurry from the tank to the engine. ${ }^{(18-20)}$ Another option is air-driven intensifier pumps. Recent work at SwRI ${ }^{(21)}$ indicates that air driven intensifier pumps, typically used in high pressure paint spray systems, can be configured with components designed to handle abrasive materials. A pump in this configuration has operated reliably and at much higher discharge pressures than can be achieved using a progressive cavity pump.

Storage of CWS in tanks presents a problem in that the coal will eventually separate if the fuel is not continuously circulated throughout the tank. It is imperative, however, that the agitation be accomplished using the lowest possible shear rates to prevent "working" of the slurry and the increase in viscosity that can accompany the particle size reductions that occur in "worked" slurries.

The basic concept for a storage tank system, shown schematically in Figure 1, is one of removing fuel from the top of the tank and re-introducing it at the bottom through a manifold designed to create two large counter-rotating eddies that flow outward along the entire length of the bottom of the tank and down at the center. A floating intake always insured that the pump removed slurry of the lowest concentration at the top of the tank. It was felt that this was important for cyclic operation of the system, and for those situations where the circulation system was shut-off for an extended period of time. In the worst case of total settling, the 
pump removes the water layer on the top of the tank and re-introduces it at the bottom, where its kinetic energy is used to re-mix the slurry.

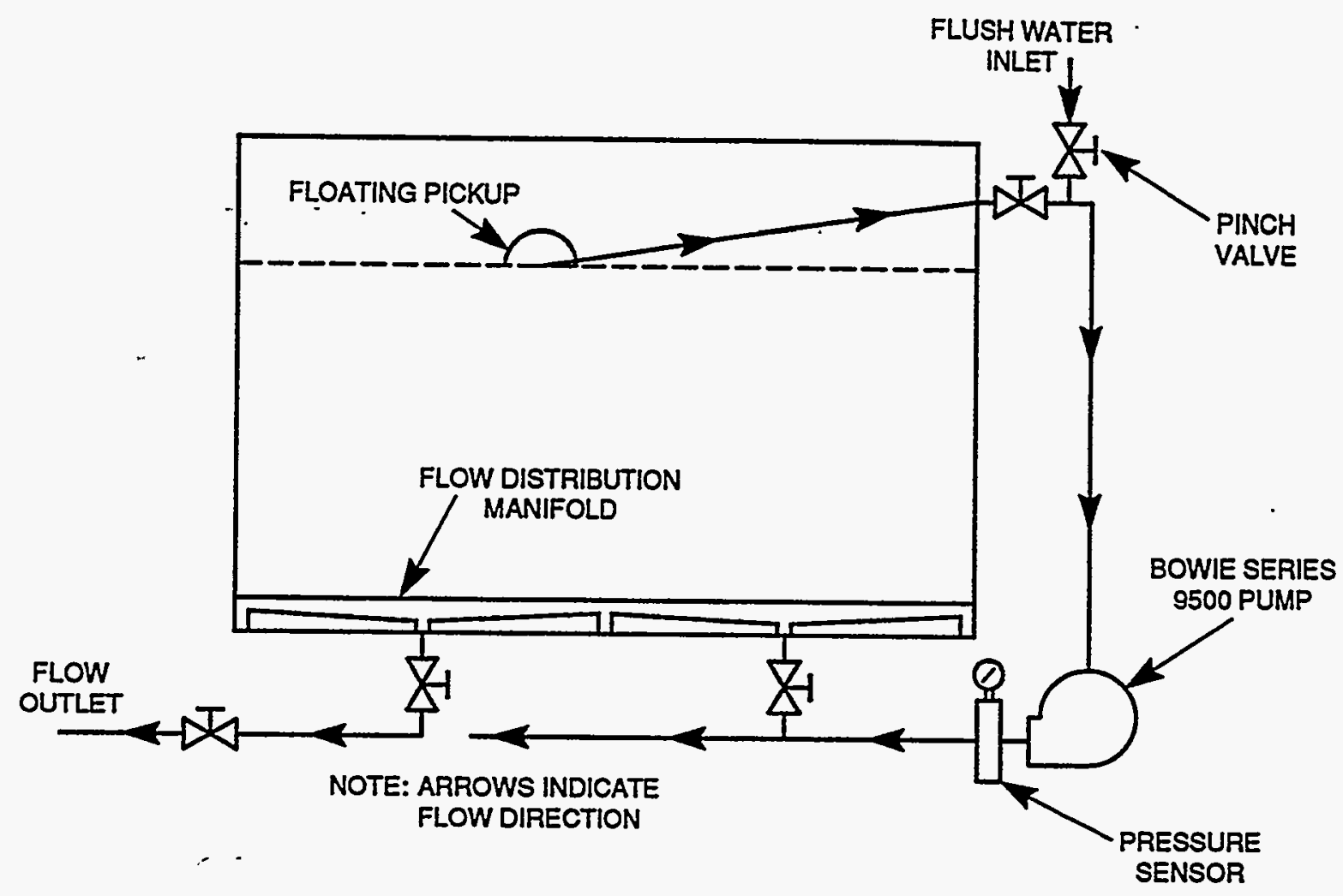

Figure 1. Coal-Water Slurry Storage Tank System

Computational fluid dynamics was used to design the manifold located at the bottom of the tank and to select the appropriate flow velocities, and in turn to design the piping system and select the pump. In non-dimensional form, the optimum design condition is one in which $\mathrm{R}_{\mathrm{e}} \times \mathrm{H}=5.7$, where the Reynolds Number $\left(\mathrm{R}_{\mathrm{e}}\right)$ is based on the tank diameter and the flow velocity at the exit of the manifold, and $\mathrm{H}$ is the ratio of the manifold discharge orifice diameter to the tank diameter. A tank system designed to these specifications was used to store a slurry of 51 weight percent coal for a two year period at SwRI. The system was operated on a 15 minutes on/off cycle over that period. The only failure was with the first gear pump. Subsequent experience with a rotating vane pump and progressive cavity pumps indicate that these are better choices. Intensifier pump designs may also be a good choice depending on the pressure requirements of the fuel system. The Cooper/ADL project had similar successful coal slurry storage for two years in a 6000 gallon tank with periodic recirculation.

\section{Injection System Design}

Diesel fuel injection systems have three functions: (1) to meter the quantity of fuel needed to maintain the engine speed and load, (2) to inject the fuel at high velocity into the combustion chamber, and (3) to time the start of injection. Older designs include an injection pump that is coupled directly to an output shaft on the engine. The pump simultaneously 
provides the fuel metering and high pressure pumping functions. The high pressure pulse of fuel is supplied through a length of tubing to an injection nozzle that incorporates a needle valve that opens in response to the fuel injection pulse. Fuel passes through the seating area of the needle valve, typically forming a spray by radially flowing through several small diameter holes and into the engine. The goals in designing the pumping element and the nozzle hole configurations are to provide sufficient turn-down to operate the engine from idle through full load, and to provide sufficient flow velocity in the fuel jets so that they penetrate across the combustion chamber, in order to utilize all the air. Impingement on the combustion chamber walls occurs in some design with satisfactory results.

Current designs for highway truck diesel applications are called unit injectors, and they incorporate the pumping and metering functions inside the injection nozzle. New unit injectors also incorporate an electrically actuated solenoid valve that is used to accurately control the beginning and ending of injection over the entire speed-load range of the engine.

The manufacturing technology for injection systems have evolved to the point where tolerances in the range of 2.5 to 25 microns are common in the barrel and plunger assemblies and the needle valves of these systems. These clearances are smaller than the mean particle size of most slurries, but the size distributions are typically Gaussian and contain a sufficient number of very small particles that can enter the clearance and cause wear and sticking of the elements. In addition, finite element analysis of the barrel assembly, performed at SwRI as a part of the work described in Reference 22, indicated that the barrel expands sufficiently during injection to admit particles that are significantly larger than the static clearances. These theoretical considerations were verified in several experiments as part of the feasibility projects, where standard injection systems were used for testing slurries. Typical times to failure for these tests ranged from instantly, to a few minutes. It was observed, however, that relatively long periods of operation could be achieved if the tolerances were actually increased and the slurry was allowed to leak through the sealing areas. ${ }^{(18)}$ It should be noted that failures, in the form of increased leakage and decreased fuel delivery, always occurred with these systems, even when sticking was not a problem.

Several different slurry injection system designs were evaluated in the various projects of the feasibility study. The work at SwRI included examination of two different pump-linenozzle systems with increased clearances ${ }^{(23,24)}$, a unit injector with increased clearance ${ }^{(24)}$, a Cummins Pressure-Time system ${ }^{(25)}$, a unit injector equipped with a diaphragm to separate diesel fuel and slurry inside the injector (see Figure 2) ${ }^{(24),}$ and a pump-line nozzle system equipped with a free piston located between the nozzle and the injection pump, and separating the slurry from diesel fuel that is circulated through the injection pump ${ }^{(21)}$. The initial efforts at $\mathrm{GE}^{(26)}$ also involved the use of a diaphragm system, as well as an accumulator system that used the diaphragm system as the pressurization system for the accumulator ${ }^{(27)}$. The basic layout of the GE diaphragm system is shown in Figure 3, and a cross-section of the accumulator nozzle is shown Figure 4. The Arthur D.Little-Cooper-AMBAC team worked on the development of a pump-line-nozzle system that incorporated a free piston (called by AMBAC a shuttle piston) to separate the two fuels rather that a diagram ${ }^{(28)}$, as well as a common rail system ${ }^{(29)}$ that was not pursued once the shuttle piston system proved reliable. A shuttle piston system was also developed at SwRI for use in the High-Speed engine tests on the DDC 8V-149 engine. ${ }^{(21)}$ 


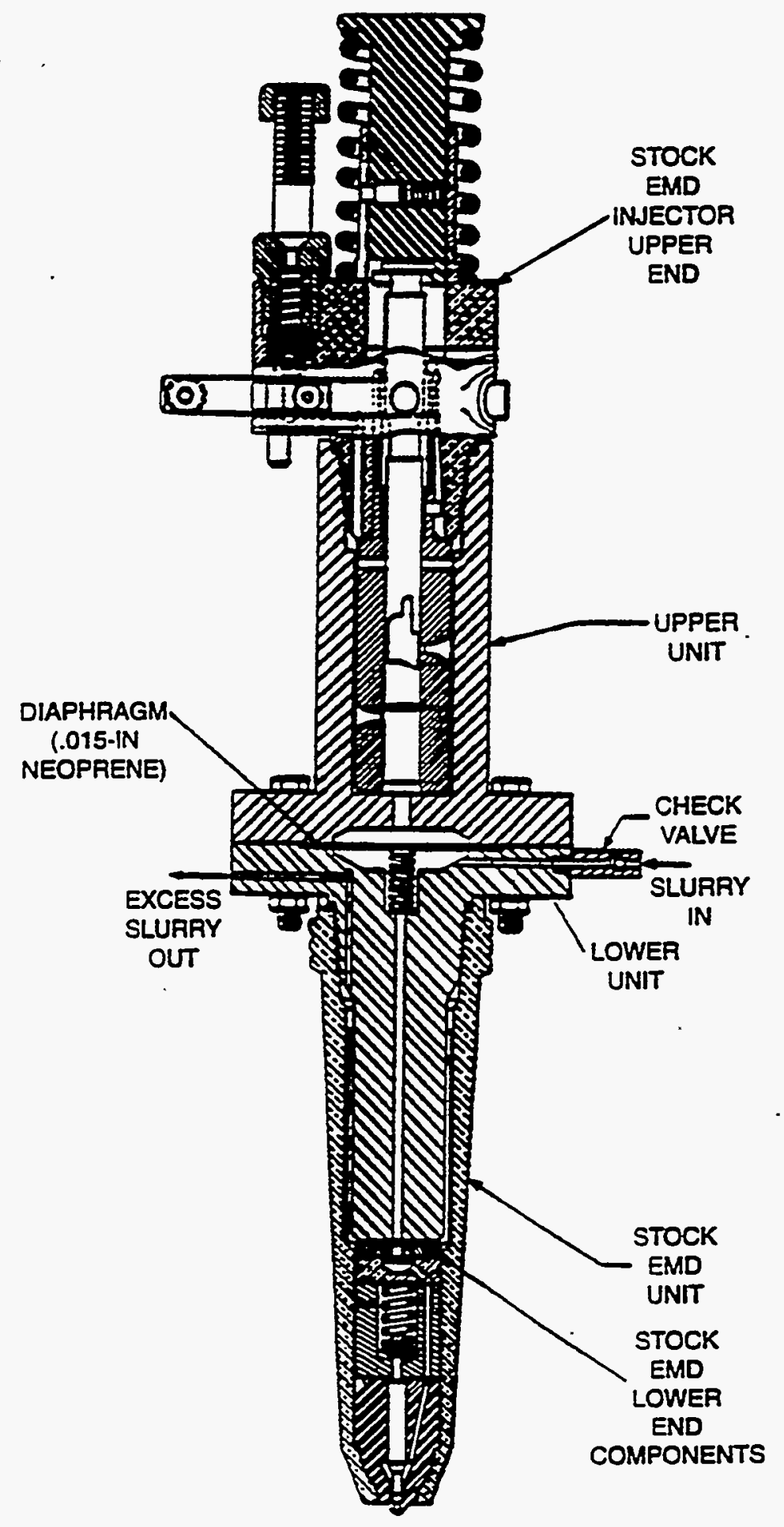

Figure 2. SwRI Two-Fluid Unit Injector 


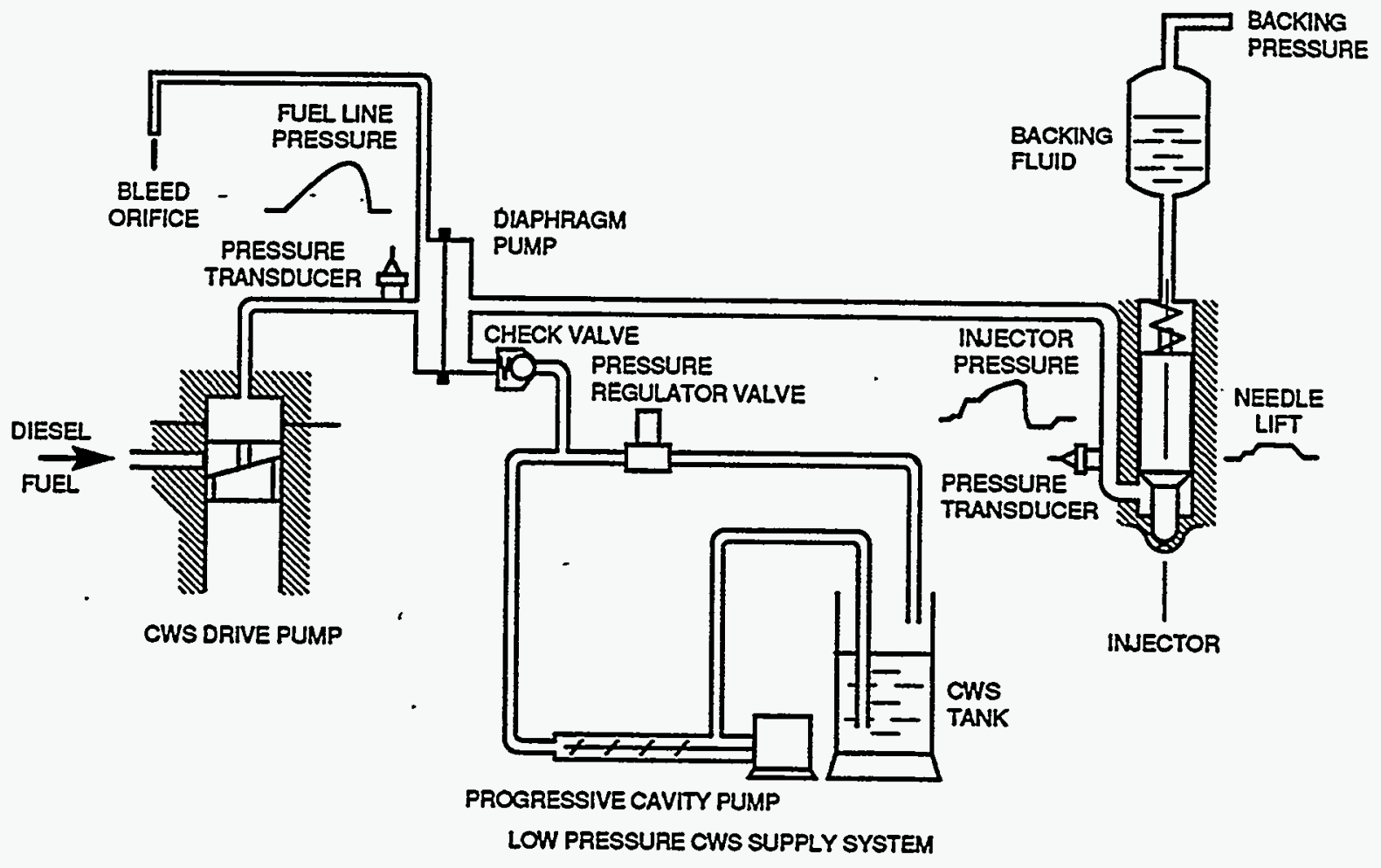

Figure 3. General Electric Fuel System Schematic

It became clear from test results that it is essential that the slurry be separated physically from the barrel and plunger assemblies of the injection system. Both the diaphram concept and the shuttle-piston concept accomplish this objective. Other solutions such as increased clearances in conventional injection systems, and conventional surface preparation did not prove to be acceptable.

The shuttle-piston approach proved to be the "winner" because the design constraints on the diaphragm systems tested in both by both GE and SwRI proved to be unacceptable. Fatigue failure was a problem with diaphram systems, almost independent of the material selection, if the diaphragm was made small enough to produce acceptable injection pressure characteristics. Increasing the size of the diaphragm to reduce the magnitude of the deflections resulted in a large increase in the volume of the high pressure section of the system. The GE $\mathrm{Team}^{(30)}$ abandoned the diaphragm approach in favor of the shuttle piston concept.

The shuttle piston approach developed by the Cooper/Arthur D. Little Team (with AMBAC) has evolved as the most reliable CWS injection system concept. Basically, the injection system looks like a conventional pump-line-nozzle system, except that a free piston, or shuttle piston assemble is installed in the injection line between the pump and the nozzle. The section between the injection pump and the shuttle piston is filled with diesel fuel that acts on one side of the shuttle during the injection event. Motion of the shuttle translates the pressure pulse to the slurry that fills the other side of the system. The pressurized slurry then opens the needle valve in the injection nozzle and slurry is injected into the engine. A drawing showing some detail of the SwRI combined shuttle-piston-nozzle assembly is presented in 


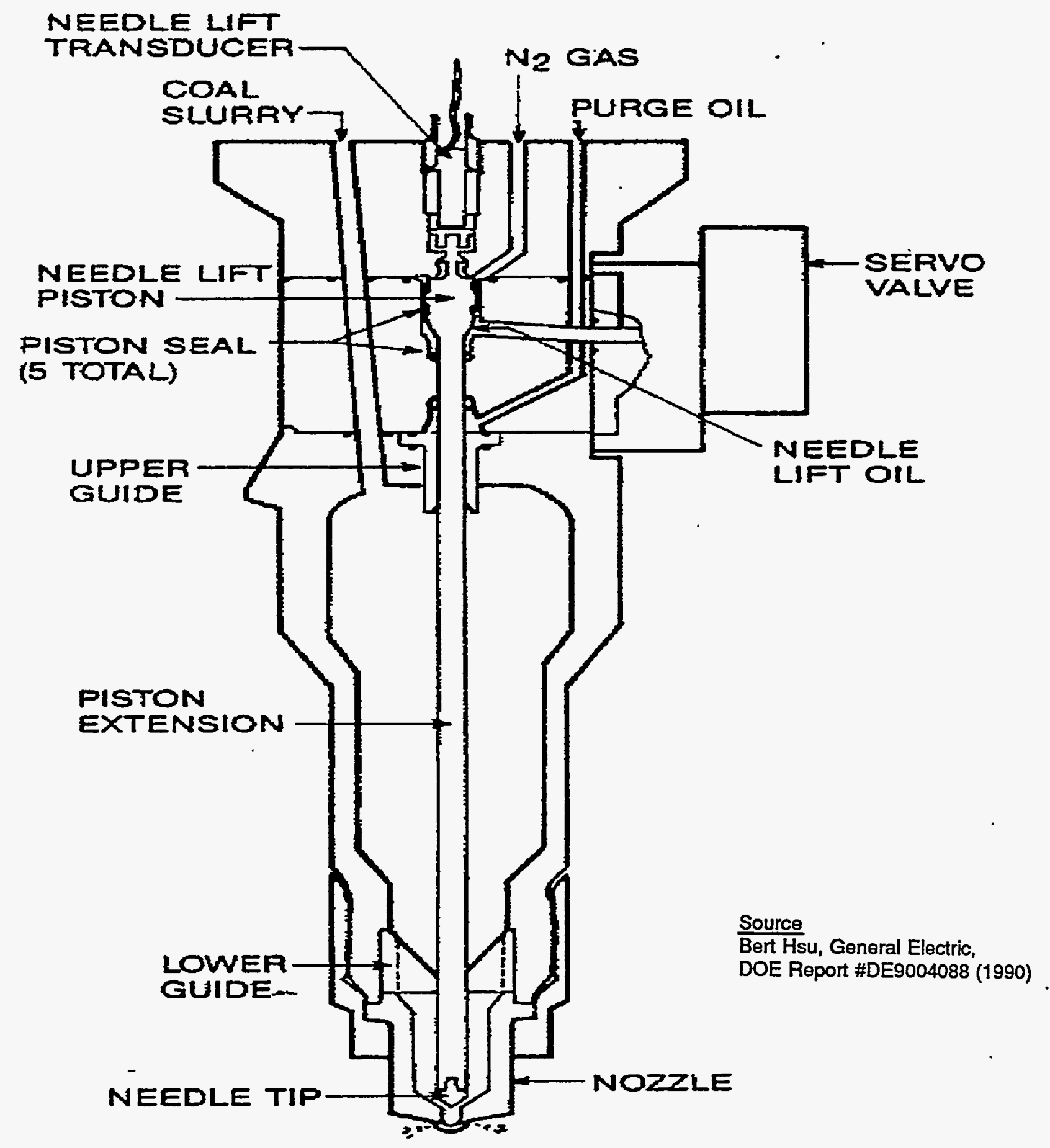

Figure 4. Schematic of the General Electric Accumulator Injection Nozzle 
Figure 5. Development of this technology and that used in the Arthur D. Little Project was done with significant guidance from Mr. Jack Kimberley of AMBAC. The designs developed in the other projects share the main features shown in the drawing.

The design details of the shuttle piston assembly are very similar to those use in standard injection system barrel and plunder designs, in terms of the clearances (on the order of 2.5 to 25 microns clearance on the diameter) and the surface finish. The displacement volume of the shuttle must be approximately 50 percent larger than the fuel delivery required for full load. This excess capacity insures that the shuttle will not "bottom out" and will accommodate those situations where the shuttle does not return completely. Durability of the shuttle piston assembly is greatly improved if the shuttle is coated with titanium nitride and the barrel is made of nitralloy. The GE Team developed a shuttle piston design in which the piston was made from tungsten carbide. Durability of this system was also acceptable. ${ }^{(31,128,129)}$

Selection of the shuttle diameter and stroke is governed by the response time required for return of the shuttle and the compressibility of the trapped fuel. The longer the stroke - the longer the return time. The larger the diameter - the larger the trapped volume by the square of the diameter. It appears that a good rule of thumb is that the diameter should equal the diameter of plunger in the injection pump, and the length of the stroke should be as close to the diameter as allowed by the 50 percent excess volume requirement.

Seal oil ports, shown in Figure 5, supply seal oil to the center of the shuttle piston stroke and to the center of the guide area of the needle valve. The seal oil is usually supplied using intensifier pumps operating with discharge pressures greater than the peak injection pressures. The seal oil acts to lubricate the moving parts and prevent the passage of coal particles into the tight clearances. The experience at SwRI ${ }^{(21)}$ and in the Arthur.D.Little work ${ }^{(32)}$ indicated that the seal oil must be supplied to both locations. Optimum operation of the shuttle piston is accomplished if the piston is undercut in the region where the seal oil is introduced. Experience at SwRI indicated that the method did not work as well if the flow clearance is made in the barrel assembly.

The shuttle piston designs developed at Cooper/Arthur D. Little, SwRI, and GE all emphasized the use of nearly conventional injection nozzles. The GE Team did some preliminary development work on an accumulator design that was intended to be used in their project on full scale locomotive demonstration of the system. ${ }^{(26)}$ Single-cylinder engine experiments using the $\mathrm{GE}$ accumulator injection nozzle were very promising because the design offered the opportunity for variation and control of the injection timing. ${ }^{(30)}$ A schematic of the system, reproduced from Reference 30, is presented in Figure 4. The accumulator housing in the injection nozzle was pressurized with slurry to injection pressure using a shuttle piston injection system. Injection timing was controlled by an electrically actuated solenoid valve that allowed high pressure hydraulic fluid to open the needle valve. Work was halted on development of this design as the METC Program was coming to a close.

A schematic of the bench test fixture used in the SwRI shuttle piston work is presented in Figure 6. The important features of this drawing are the piping diagrams for the injection system. The most important details are the diesel fuel supply-line connection through a check valve to the injection line and the slurry fuel supply line to the shuttle piston assembly. It was 


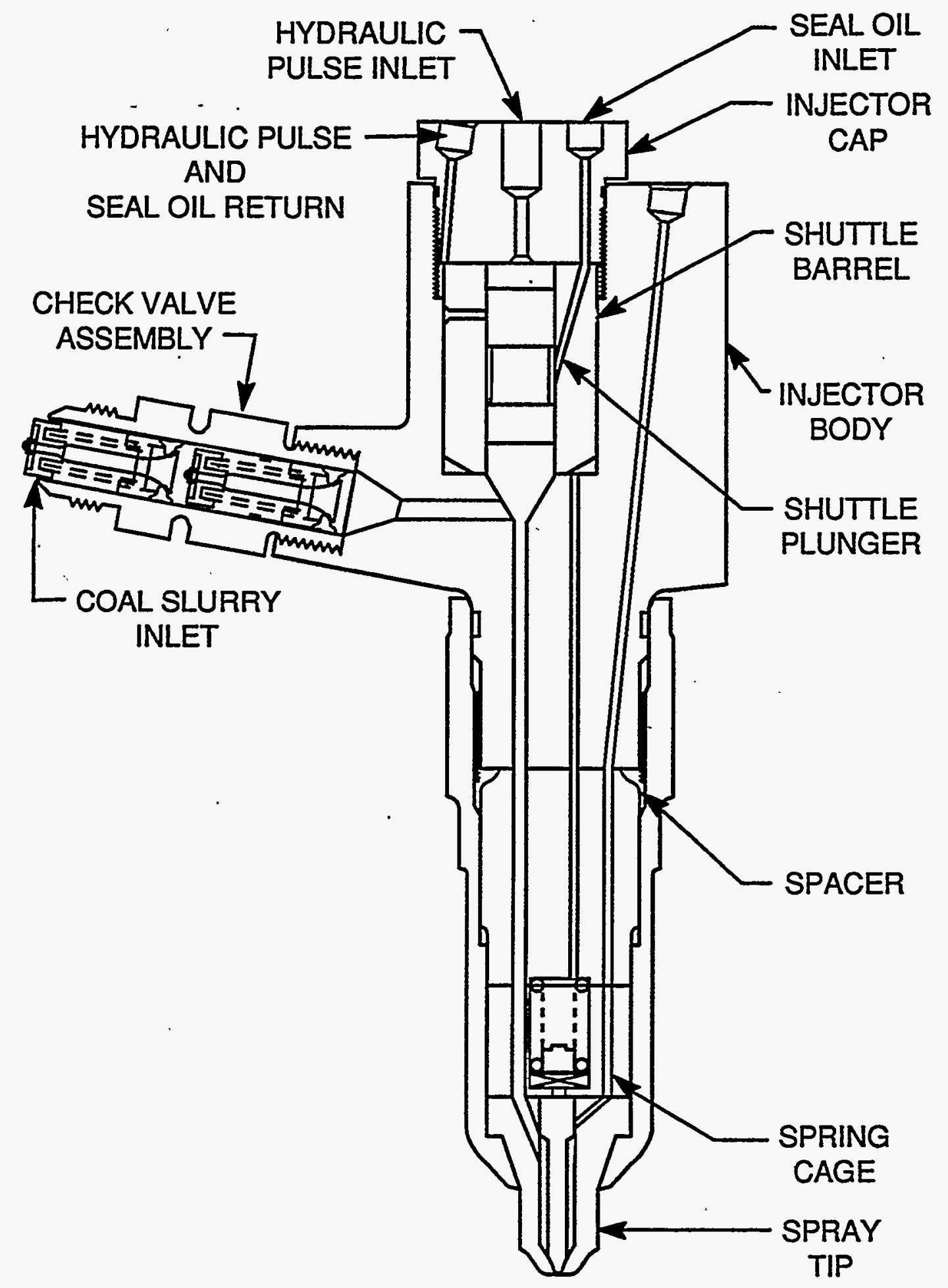

Figure 5. SwRI Fuel Injector (Cross-Section) 


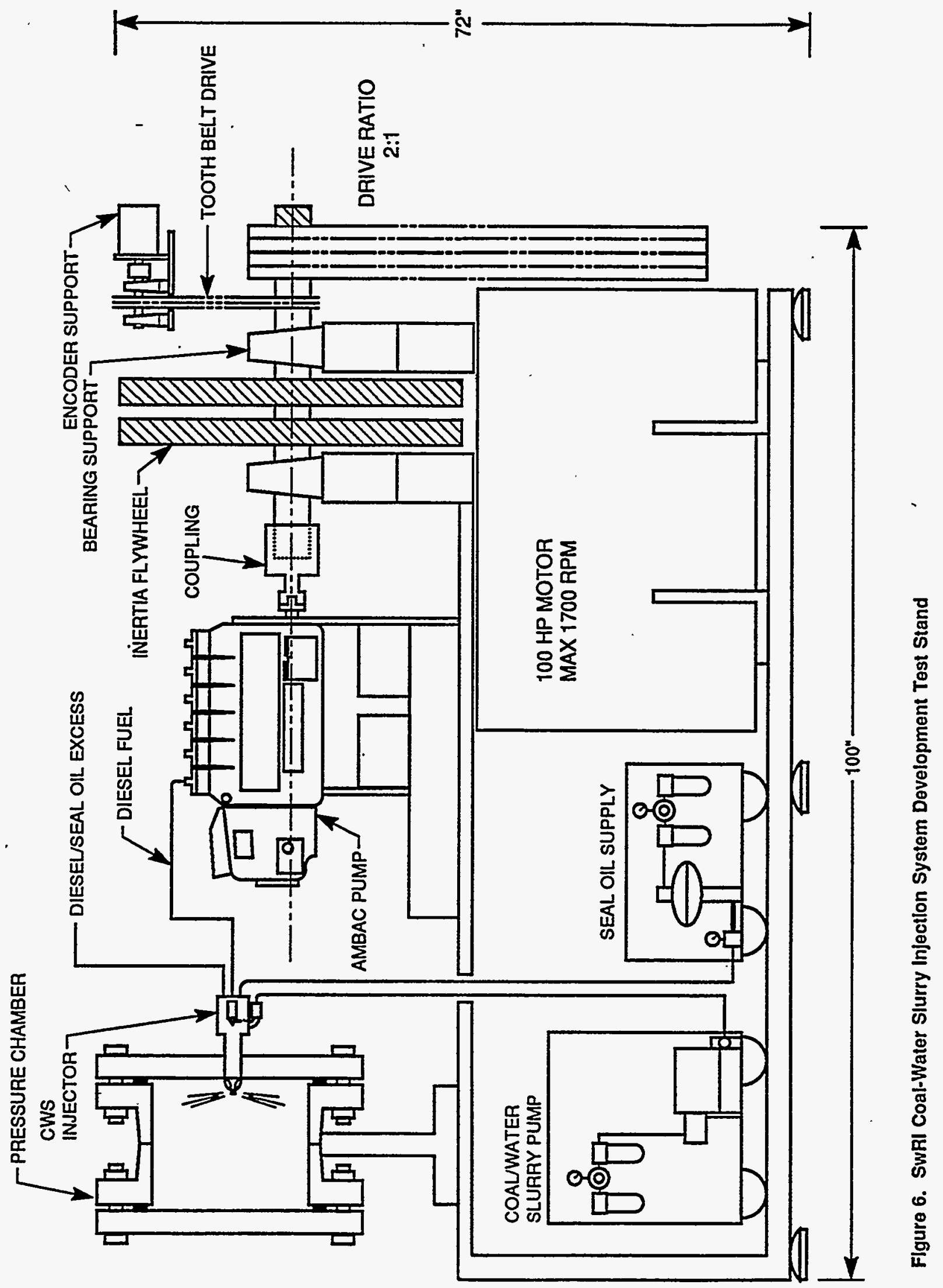


found that the diesel fuel supply pressure to the injection pump head and the injection line had to be maintained at approximately $700 \mathrm{kPa}$ in order to maintain the pressure above the saturation pressure of the fuel in the injection line during the retraction of the shuttle piston.

The diesel fuel between the injection pump and the shuttle piston is captured in this section of fuel line and undergoes repeated compression during operation of the system. Two problems were observed in the work at SwRI. The first problem was that it is somewhat difficult to remove trapped air that affects the performance of the system. The second, and the more important problem was the occurrence of cavitation during the return stroke of the injection pump. This problem is compounded by the fact that the fluid gets very hot due to the repeated compressions and the fact that the shuttle piston must retract at the same rate of volume change as the injection pump plunger in order to maintain constant pressure. This problem was not reported by the Arthur D. Little Team or the GE team, but they were operating their systems at maximum speeds of 200 and 500 injections per minute, respectively. The SwRI experiments were on an $1900 \mathrm{rpm}$ two-stroke engine that required fuel injection every cycle, almost an order of magnitude difference in speed of operation over the lower speed four-stroke engine used in the Cooper/Arthur D. Little project.

The slurry is supplied through a special double check valve assembly to the shuttle piston. Several iterations of the check valve design were performed as a part of the Cooper/Arthur D. Little project and the details are important for reliable operation of the fixture. The configuration of the check valves as of mid-1993 is as shown in Figure 7, with spring loaded poppet valves having very loose fits on the poppet stems and tapered seat faces with an angle of 52 degrees. The poppet valve seating face and the valve seats were both made of tungsten carbide to prevent wear.

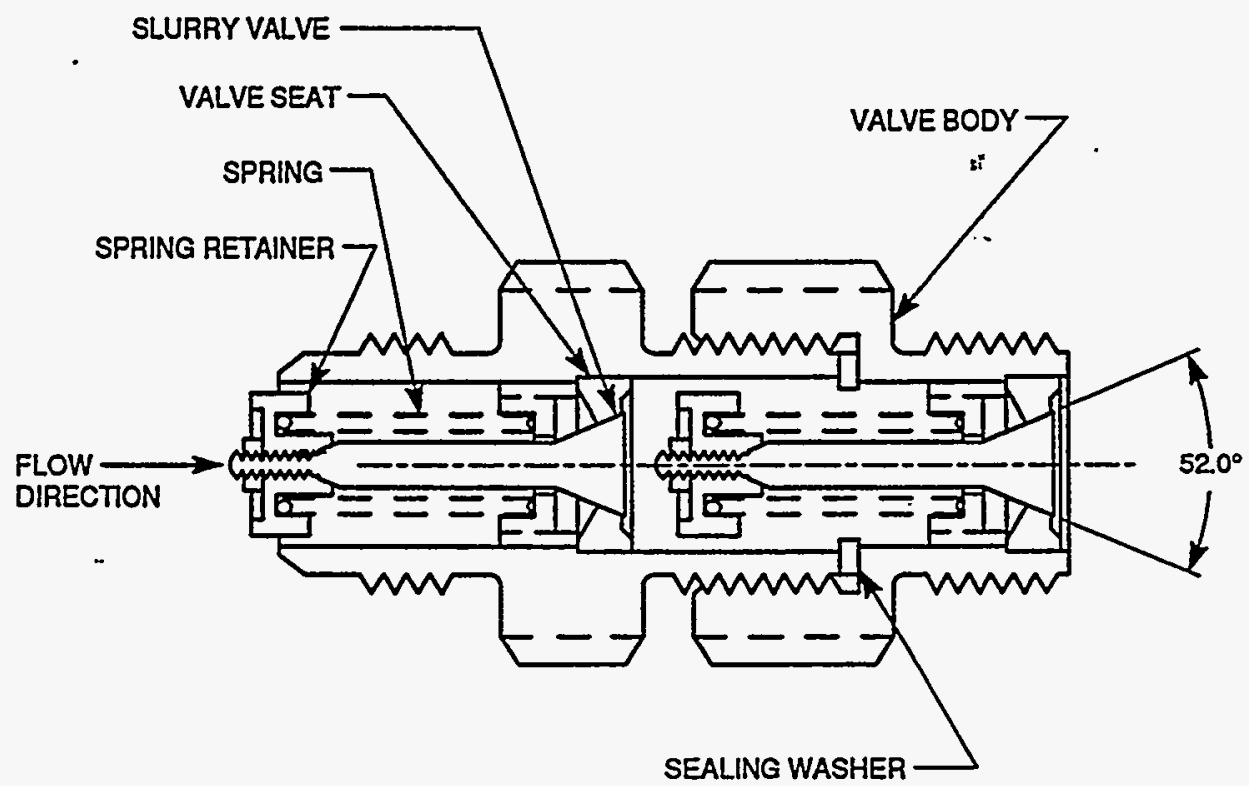

Figure 7. Slurry Fuel Supply Check Valve 
The slurry supply pressure to the shuttle piston assembly must be high enough to overcome the diesel fuel supply pressure and the friction forces on the piston so that the shuttle piston will retract at the same rate as the injection pump plunger. Cavitation occurs on the diesel fuel side if the shuttle does not retract properly and maintain pressure on the diesel fuel side. Slurry supply pressure in the DDC/SwRI work was maintained at $2.1 \mathrm{MPa}$ in combination with the $700 \mathrm{kPa}$ diesel fuel supply pressure. The key issue in reliable operation of the system is the balance between the baseline diesel fuel pressure and the baseline slurry pressure. The actual values may vary depending of the specific design of the shuttle assembly and the speed of operation of the system.

\section{Injection System Materials}

As indicated above, wear prevention in the shuttle piston assembly is greatly improved by the appropriate selection of materials and coatings. Two other significant areas for wear in the injection system are the nozzle holes and the needle valve seat.

\section{Nozzle Holes}

Dunlay et al. ${ }^{(33)}$ reported significant nozzle hole wear in the Sulzer engine with conventional steel nozzles after a few hours operation on a 34 percent coal in oil slurry. Nydick $^{(34)}$ reported nozzle hole enlargement using sintered tungsten carbide inserts in the same Sulzer engine. Based on results obtained from four different slurries, Nydick concluded that the wear was more dependent on particle size than ash content. Ryan et al. ${ }^{(25)}$ reported a doubling of the nozzle hole diameter after 25 hours operation on a 50 percent CWS during bench tests using a conventional Cummins P-T nozzle made from carbonized steel. Hsu ${ }^{(35)}$ reported 10 percent decreases in the injection pressure after minutes of operation on CWS using conventional carbonized steel injection nozzle tips. Schwalb et al. ${ }^{(21)}$ reported wear rates of from 0.5 to 1.6 percent increase in the nozzle hole flow area per minute of run time, using conventional steel alloys. Rao et al. ${ }^{(28)}$ reported increases in the nozzle hole exit diameter of up to 50 percent after less than one hour of operations on low ash (less than 2 percent) coal, and substantially more wear with a 3.8 percent ash coal, a conclusion that is in direct conflict with Nydick's ${ }^{(34)}$ conclusion regarding the importance of ash content.

Hard steel alloys, coatings of very hard materials, and monolithic ceramic and hardened materials have been tested in both bench experiments and in actual CWS engine tests. Some caution must be exercised in drawing absolute conclusions from the results of bench experiments. Both the Cooper/Arthur D. Little ${ }^{(36)}$ and the $\mathrm{GE}^{(31)}$ Teams reported significant nozzle hole wear in conventional materials during engine tests with CWS. Both Teams reported a wear pattern in which the entrance to the hole showed abrasive rounding, the exit showed enlargement that greatly exceeded the entrance enlargement, and wear pattern in the hole with a "trumpeting" appearance (see Figure 8, reproduced from Reference 3). 


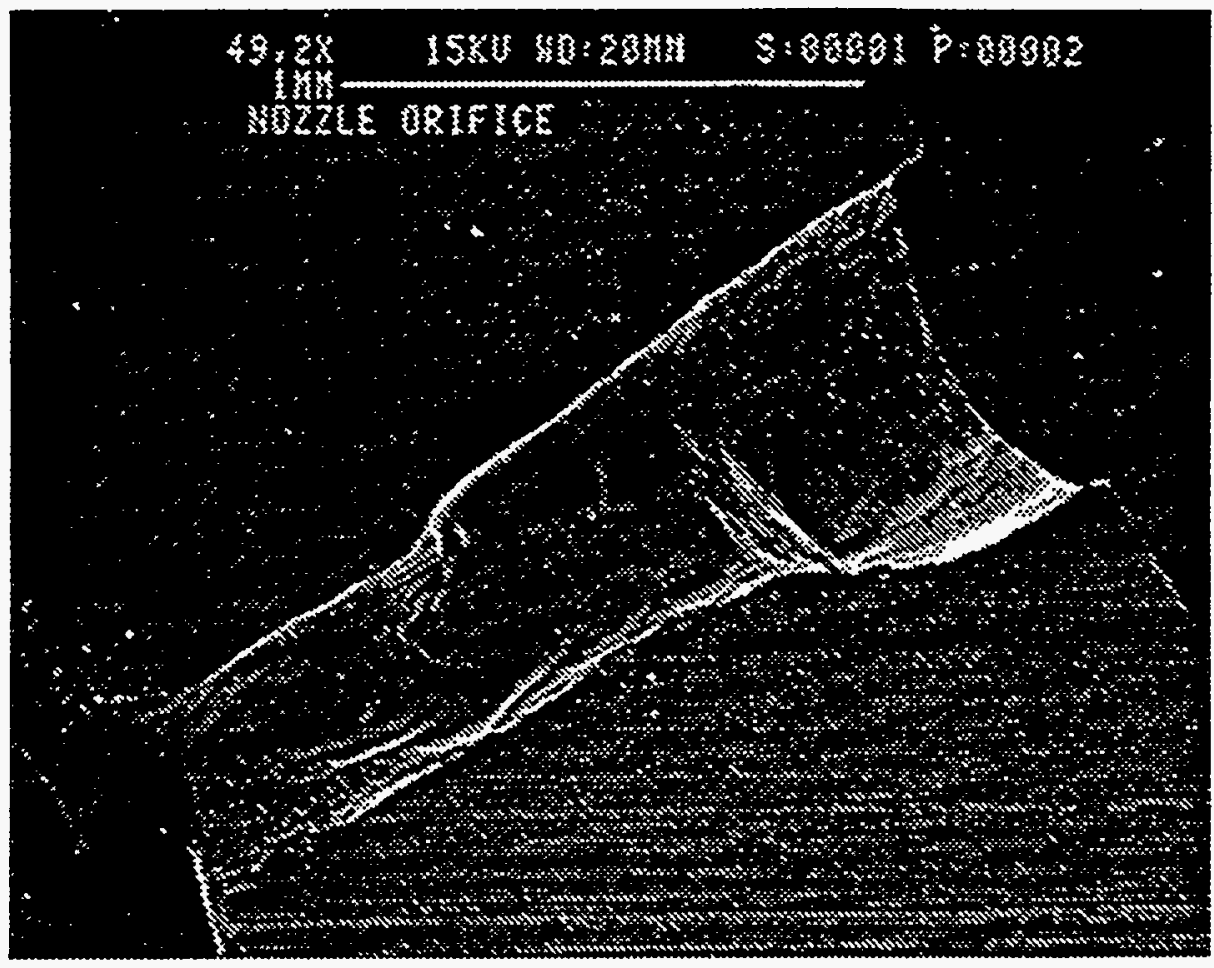

Figure 8. Injection Nozzle Hole Wear Pattern

Efforts to reproduce these wear patterns in continuous flow bench experiments were unsuccessful at Arthur D. Little and $\mathrm{SwRI}^{(38)}$ and at $\mathrm{GE}^{(31)}$. The bench experiments were all performed using continuous flow through an orifice assembly in which the materials and the configuration of the hole could be easily changed. The two differences between these experiments and the actual engine were continuous versus transient operation, and the temperature. It was suggested that the trumpeted wear was due to cavitation of the CWS, starting at the exit to the nozzle. It was hypothesized that the coal particles in the slurry provided high density solids that enhanced the wear during collapse of the cavitation bubbles. Temperatures in the test fixtures presumably were too low to support cavitation.

The hard materials that were tested in all of the studies as a means to reduce the wear ate are listed in Table 3. The ranking of the materials are also listed as reported by the different project teams. The GE rankings presented in the table are based on the results of bench experiments. ${ }^{(131)}$ Another example of the problem of using bench experiments is the fact that engine experiments at GE using the Kennametal K313 tungsten carbide indicated high wear rates. The Cooper/Arthur D. Little data were all obtained during actual engine tests.

Despite the variation in results in Table 3 , it is possible to select some of the more promising hard materials. It is generally agreed that the best material choices are selected formulations of tungsten carbide/cobolt, cubic boron nitride, diamond compact, and sapphire.

It appears that the performance of the tungsten carbides depends heavily on the formulation, with the finer grain carbides demonstrating lower wear rates. The Cooper/Arthur D. Little Team $^{(36)}$ reported very low wears rates using a monolithic assemblies fabricated from the Kennametal K714 formulation. The assembly consisted of a piece, called a button, that contained the nozzle holes and that was held in place at the tip of the nozzle by compression, 
Table 3. Material Evaluated for Use in Injection Nozzle Holes

\begin{tabular}{||l|c|c|c||}
\hline \multirow{2}{*}{\multicolumn{1}{|c|}{ Materials }} & \multicolumn{2}{c|}{ Relative Wear Rates } \\
\cline { 2 - 4 } & $\begin{array}{c}\text { Cooper/ } \\
\text { Arthur D. Little }\end{array}$ & General Electric & DDC/SwRI \\
\hline Steel Alloys & High & High & High \\
\hline Titanium Nitride Coating & High & -- & - \\
\hline Stellite 6B & - & High & - \\
\hline Titanium Alloy/Titanium Diboride Coating & High & Low & - \\
\hline $\begin{array}{l}\text { Carboloy 883 } \\
\text { (Tungsten Carbide/6\% Cobolt Binder }\end{array}$ & -- & Moderate & - \\
\hline $\begin{array}{l}\text { Tungsten Carbide 6\% Cobolt Binder } \\
\text { (Kennamental K313) }\end{array}$ & -- & Low & - \\
\hline $\begin{array}{l}\text { Tungsten Carbide/Cobalt Binder } \\
\text { (Kennamental K714) }\end{array}$ & - & -- & - \\
\hline Cubic Boron Nitride & -- & Low & - \\
\hline Silicon Carbide (Hexalloy SA) & -- & Moderate & - \\
\hline Diamond Compact & Low & Low & - \\
\hline Sapphire & Low & Low & -- \\
\hline
\end{tabular}

using a screw on retaining nut. Based on observed wear rates after 150-200 hours of testing, it was projected that these components would survive from 500-2000 hours of engine operation on CWS. The GE team concluded that the tungsten carbide family of materials does not have sufficient erosion resistance for use in the nozzle holes. ${ }^{(39)}$ The GE team did, however, propose a similar approach to installing very hard materials in the location of the nozzle tip holes, with the "button" actually fabricated as a small insert that is installed inside the tip in the region of the holes.

Experience with the cubic boron nitride have been excellent, but the results with the diamond compact material and the sapphire have been as good. ${ }^{(40)}$ The diamond compact and the sapphire offer a significant cost advantage over the ceramics in the fact that they are both used commercially in the configuration needed for use in the nozzle holes. The diamond compact is a composite that is commonly used in wire making dies. Commercial dies are available with holes of dimensions typical of diesel injection nozzle holes. Sapphires are available commercially as jewel bearings for mechanical chronometers and fine motors. They are also available with holes of the appropriate dimensions. Both the sapphires and the diamond compact dies are available in cylindrical geometries with the hole running through the axis.

Both the Cooper/Arthur D. Little and the GE teams have developed designs in which these small cylindrical pieces are installed as inserts in the injection nozzle tip in the locations of each of the nozzle holes. The diamond compact inserts, a product of GE Specialty Materials, are brazed in a stainless steel nozzle tip using very precise control of the brazing temperature to prevent graphitization of the diamond. ${ }^{(39)}$ The sapphires are swaged into a small metal support that is in turn electron beam welded into the nozzle tip. ${ }^{(36)}$ 


\section{Needle Valve Seats}

Operation of conventional nozzles on CWS results in wear in two areas of the needle valve $^{(36,39)}$, even with seal oil supplied to the guide section of the needle. The leading edge of the guide section of the valve becomes rounded after approximately 150 hours of operation. The other area of wear is on both elements of the valve seat. The conclusion from both projects is that the seat should be a tungsten carbide insert used in combination with a tungsten carbide plasma coated needle valve. Not enough operating time was accumulated to determine if the barrel (above the seat) also needs protection.

\section{COMBUSTION SYSTEM DEVELOPMENT}

Combustion of CWS involves several very complex processes that are occurring in the combustion chamber once every engine cycle. The event begins with injection of the nonNewtonian, two-phase fuel at pressures that can exceed 100MPa, into an environment of hightemperature, high-pressure air and combustion products. The fuel jets, traveling with initial exit velocities up to $300 \mathrm{~m} / \mathrm{s}$, entrain air and slow to $20-50 \mathrm{~m} / \mathrm{sec}$, and then traverse approximate 7.5 to $20 \mathrm{~cm}$ prior to impacting in the combustion chamber. Conventional wisdom suggests that the jets entrain and mix with air during the 1-10 milliseconds that is available before they impact on cold combustion chamber (piston) walls. Ignition of CWS is generally thought to involve a three-phase process in which (1) the water evaporates, (2) devolatization of the coal occurs, and (3) ignition of vapor mixture occurs. Theory also suggests that combustion of the volatiles then occurs at the edge of the fuel spray, followed by char combustion via carbon oxidation to $\mathrm{CO}$ on the surface and continued oxidation to $\mathrm{CO}_{2}$ in regions surrounding the char particles. The location of initial ignition of the spray is obviously farther from the nozzle tip than when there is already a standing flame into which the remaining spray is injected.

Estimates of the characteristic time of the overall mechanism of coal combustion in engines suggests that CWS can be used only in medium-speed engines (e.g., 30 micron coal particles can burnout within $40-50$ crank angles at $1000 \mathrm{rpm}$. The results of both Kakwani et al. ${ }^{(15)}$ and Schwalb et al. ${ }^{(21)}$, however, show that engine speeds up to $1900 \mathrm{rpm}$ can be achieved with acceptable coal combustion efficiencies, provided that most of the coal particles are approximately 20 microns or less. One difference between the theoretical and laboratory measured combustion rates and those observed in engines is the higher turbulence levels that are present in engines (which might contribute to higher coal burn rates).

As will be discussed, the fuels are non-Newtonian and can shear-thicken during injection, and possibly exhibit poor atomization characteristics. As the apparent viscosity increases, the air entrainment rate can decrease with an accompanying increase in the jet tip velocity, and increasing the probability of jet-wall interactions. Impingement of the unreacted air/slurry plume on the solid piston surface enhances the mixing process through deflected plume mixing and entrainment. Deposition of the coal on the relatively cool $\left(500-800^{\circ} \mathrm{F}\right)$ combustion chamber walls may occur temporarily, but Cooper observed no accumulated layer on the piston after over 200 hours of operation. Coal type, source, processing, and particle size distribution all contribute to the rheological properties of the CWS. In addition, these properties control the ignition and combustion characteristics of the CWS both directly, through the volatile 
content and composition, and indirectly, through the atomization characteristics.

Direct impingement of CWS sprays on lubricant wetted surfaces (cylinder walls) is to be avoided because it would lead to deposition of the unreacted coal on the surfaces, degraded combustion efficiency, and greatly increased cylinder liner and ring wear. Based on test results, it appears that the CWS can impinge on the piston crown with satisfactory atomization and ignition characteristics. It is believed, however, that certain configurations of engine designs and long duration CWS spray events used in the METC Program may have resulted in some fuel impingement on the cylinder liner. Certain engine designs incorporated very shallow combustion chambers that may have allowed some fuel splash and direct impingement on the liners, depending on the injection timing and the injection rate. The piston "uncovers" the liner after several tens of degrees crank angle after TDC. In addition, suspended residual traces of ash and unburned coal are available in the combustion chamber and no doubt contributed to the ring and liner wear, even if the combustion efficiency was nearly 100 percent. This wear effect is believed to be greater when the coal/ash particles are smaller than the diametrical clearance (piston liner).

The combustion system development work is discussed in terms of the basic coal combustion considerations important to operation of CWS in an engine and the actual engine development work. Each of these items are discussed in the following sections.

\section{Basic Combustion Considerations}

In addition to the injection studies, the ignition characteristics of dry coal and coal slurries have also been examined. Clingenpeel, et al. ${ }^{(41)}$ in experiments with slurries of $45 \mathrm{wt} \%$ coal and nonpetroleum carriers, found that an engine run without a pilot injector and a glow plug would suffer a torque loss of approximately 20 percent as compared to an engine run using combustion assist mechanisms. It was also noted by Robben, et al. ${ }^{(42)}$ that, without combustion assist devices, significantly higher compression temperatures (1100 to $1200 \mathrm{~K})$ would be required. Kamo, et al. ${ }^{(43)}$ conducted tests in which he fed coal powder with a maximum particle size of 20 microns directly into the intake air manifold of a single-cylinder Caterpillar engine. The engine was modified to an adiabatic design by coating the combustion chamber with a ceramic coating and removing the water cooling system. These changes brought about a 40 percent reduction in heat rejection by the engine. They found that powdered coal could be run in the engine without the aid of a diesel fuel pilot. Exhaust unburned coal was not measured, however.

Other researchers of coal ignition have concentrated on studying the ignition delay time. Murdoch, et al. ${ }^{(44)}$ studied the ignition delay of coal/water slurries and found it to be a function of water content, initial temperature, coal type, and particle size. They noted that the ignition delay decreases with preheating of the slurry and with decreases in particle size, and that ignition delay increases with the water content of the slurry. This increase is caused by the extra time required to vaporize the water in the drop and expose the coal particle. Siebers and Dyer ${ }^{(45)}$ conducted tests in a constant-volume combustion bomb in which they compared the ignition delay of a $46 \mathrm{wt} . \% \mathrm{coal} / \mathrm{water}$ slurry to diesel fuel (DF-2). They determined that the ignition delay for the slurry was temperature and pressure dependent and increased by a factor of 5 over that of DF-2 fuel. 
The combustion of coal is another area that has undergone a great deal of study. Research has focused on basic combustion topics, such as particle reaction rate, and more applied topics, such as defining required temperatures and pressures for coal slurry combustion in engine-type environments. Sakai and Saito ${ }^{(46)}$ concluded that the combustion of coal slurry fuels is a twostage process consisting of gas-phase combustion followed by solid combustion. The first stage, or physical stage, is for the vaporization of the carrier. The second stage, or chemical stage, is the substantially longer period that is required for the coal agglomerate to react. Szekely and Faeth ${ }^{(47)}$ found that the reaction of the agglomerate required 90 to 95 percent of the lifetime of the particle, even where agglomerate reaction rates were at a maximum. They added that the introduction of a catalyst increased agglomerate reaction rates, except at diffusion-controlled conditions. Wells, et al. ${ }^{(48)}$ studied the chemical stage at various temperatures by looking at the char reactivity. They determined that at low and medium temperatures ( 550 to $750 \mathrm{~K}$ and 1070 to $1270 \mathrm{~K}$, respectively) char reactivity was dominated by parent coal type. However, they noted that char reactivity was dominated by the pore diffusional resistance of the agglomerate at high temperatures (1300 to 1700K). Liu, et al. ${ }^{(49)}$ conducted experiments in which they studied high-intensity pulverized coal flames with water injection. They found that the water injection did not affect the coal reactivity, although it did lower the flame temperature. However, they also demonstrated that "the controlling reaction mechanism through the whole temperature range is physical (diffusion), not chemical (kinetic)," this being in direct contrast to coal combustion behavior in normal intensity flames. Both Law, et al. ${ }^{(50)}$ and McHale, et al. ${ }^{(51)}$ in studies of coal/oil mixtures for furnaces and boilers (typical droplet sizes 100-200 microns) found that internal circulation, or swirl of the secondary air is an important factor in combustion. They reported that a high degree of swirl resulted in a significant improvement in carbon burnout. If true for the much smaller drop size in diesels (20 microns), this would lead to the hypothesis that increased turbulence within the cylinder would similarly improve coal particle burnout in a diesel engine. However, droplets in the 20 micron size range quickly equilibrate to local flow velocities even in turbulent flow.

The time required for a particle of coal of a given radius to burn completely is known as the coal-burning time. The faster the coal burns, the higher the allowable engine speed. Some of the first studies of coal-burning times were conducted by Nusselt and Wentzel ${ }^{(1)}$. They performed tests on pulverized coal in pressurized combustion vessels to simulate engine conditions. They concluded that coal particles in the 80-100 micron size range were slow burning and that the maximum engine speed for which coal dust would be practical as a fuel was $400 \mathrm{RPM}$. As a result of their findings, most of the early coal-dust-fueled engines were designed for low-speed and low-power operation. It was not until later, when performing similar tests on diesel oil, that it was realized their combustion vessel produced burning times much longer than those in an actual engine due to the combustion vessel's lack of turbulent conditions that exist in the cylinder of an engine.

Essenhigh ${ }^{(52)}$ studied the burning times for ideal spherical particles in dust flames. He based his study on two different means of reaction control: diffusion and chemical reaction. He noted that when both mechanisms were present in particle burning, the effects of the two were additive. He also realized that turbulence could reduce burning times, but felt the decrease would be 50 percent at most, depending on particle size. Essenhigh and Yorke ${ }^{(53)}$ conducted tests on the effects of coal particle shape and swelling on burning times. They determined that shape had no significant influence on burning times, because irregularly shaped 
particles burn down to a spherical shape by the time they are half burned. They also found that coal particles swell according to coal rank in two stages to a final diameter that is 1.5 times larger than the original diameter. When this swelling was taken into account, the values they measured for burning times corresponded to those calculated using the Nusselt square law. Both Essenhigh ${ }^{(52)}$ and Kanury ${ }^{(54)}$ presented combustion time data for coal and carbon particles of various sizes. These data are summarized in Figure $9^{(43)}$. Typical ideal combustion duration for engines is 30 degrees of engine crankshaft rotation at rated power (more than 30 degrees and efficiency suffers). Based on this criteria, engine speed is plotted along the right axis. The results in Figure 9 indicate that the size of the dry particles must be in the range of from 5 to 50 microns for engine speeds from $400-2000 \mathrm{rpm}$.

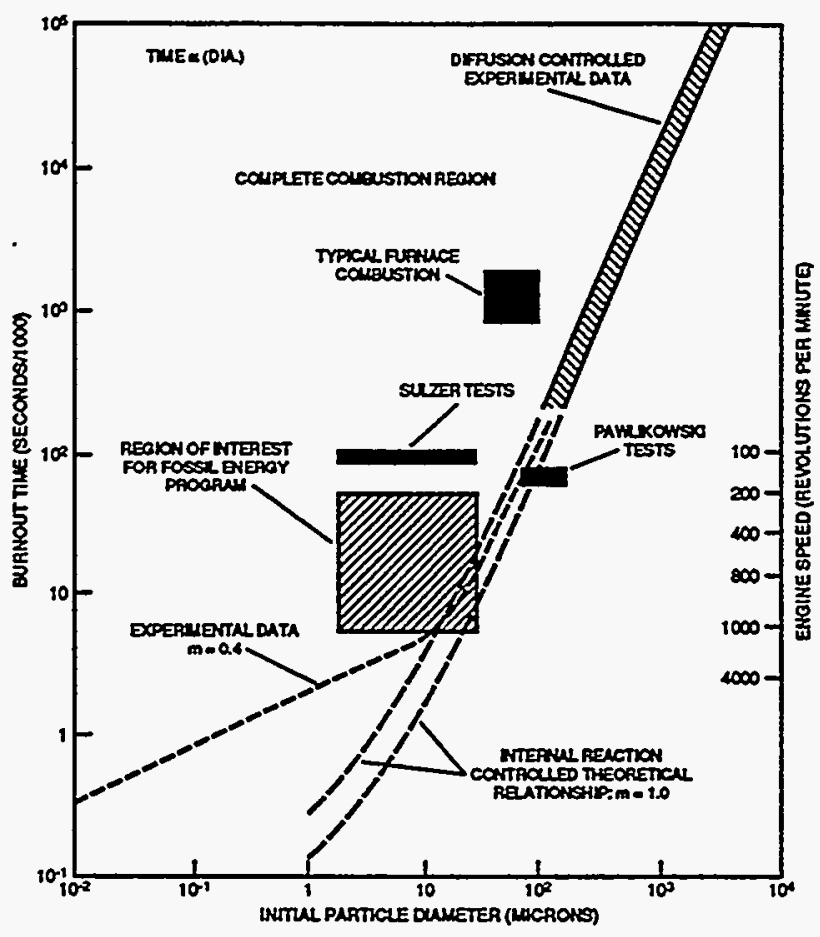

Figure 9. Coal and Carbon Burnout time and Engine Speed Versus Particle Size

Rawlins, et al. ${ }^{(55)}$ also studied coal particle burnout rates. They performed their tests in a vertical laboratory-scale combustor on coal/water mixtures of 70 and $73 \mathrm{wt. \%}$ coal. The mass-mean coal particle diameter of the slurry was about 20 microns, although due to swelling and agglomeration, some of the particles reached 200 microns in a diameter. They found that with secondary swirl the coal burnout was around 98 percent for average particle residence times less than $100 \mathrm{~ms}$ (equivalent to $30 \mathrm{deg}$ crank angle at $100 \mathrm{RPM}$ ). Holve ${ }^{(56)}$ used a numerical model to determine that agglomeration increases burning time by a factor of four to eight. His model also predicted that particles less than 30 microns should react completely in less than 35 milliseconds (equivalent to $30 \mathrm{deg} \mathrm{CA}$ at $300 \mathrm{RPM}$ ), while those less than 10 microns would take less than $8 \mathrm{~ms}$ to burn out (equivalent to $30 \mathrm{deg}$ CA at $1000 \mathrm{RPM}$ ). These values are similar to those obtained by Essenhigh. ${ }^{(52)}$ Petela ${ }^{(57)}$ used a mathematical model to analyze the combustion of a coal/oil droplet. He noted that the combustion of the oil part of a coal/oil droplet takes less time due to the larger surface area of the oil. He went on to predict that if small enough coal particles were used in the coal/oil mixture, and if agglomeration could be prevented, then "the overall combustion time of a coal/oil mixture 
droplet can be shorter than that of a pure oil droplet of the same size." Kamo, et al. ${ }^{(43)}$ also predicted that the burning time of micronized coal dust should be short enough to allow engine speeds up to 2000 RPM.

The size of the coal particles in the slurry may also have an effect on how well combustion takes place, depending on whether the slurry droplets (clusters of coal particles) disintegrate upon water evaporation. Caton ${ }^{(58)}$ used an engine cycle simulation based on a thermodynamic analysis with a particle combustion model to study the combustion characteristics of coal in a reciprocating, locomotive engine. He found that engine efficiency decreased with increasing engine speed. However, the decrease was less for smaller particles, and negligible with particle diameters less than 20 microns for engine speeds of 250 to 1000 RPM. This finding is approximately consistent with the GE engine test data if one assumes that the slurry disintegrates into coal powder. Fu, et al. ${ }^{(59)}$ performed tests in an oil-designed 100 -hp fire-tube boiler to determine the effects of coal particle size on combustion properties of coal/water fuels. They found that the use of micronized coal/water slurries did not provide a significant increase in carbon burnout or boiler efficiency compared to coal/water slurries made with larger coal particles. However, available combustion residence times for boilers are several hundred milliseconds, so one would not expect to see any effect of particle size.

Other studies have focused on what conditions are required for effective combustion in an engine-type environment. Siebers and Dyer ${ }^{(45)}$ conducted research comparing a coal/water slurry with DF-2 in a constant-volume combustion bomb. The slurry was made up of 45.8 wt.\% low-ash coal with a maximum particle size of 22 microns. They simulated diesel engine conditions in the bomb by igniting a premixed charge of hydrogen, oxygen, and nitrogen. They found that the rate of energy release during the coal combustion was slower for the slurry than for DF-2. They also determined that the minimum temperature in the bomb at which a significant portion of the slurry burned was $800 \mathrm{~K}$. Leonard and Fiske ${ }^{(26,60)}$ also performed experiments with coal/water slurries in a combustion bomb, using the ignition of a premixed charge to simulate the conditions in a diesel engine cylinder. However, they used higher injection pressure and gas density in order to best approximate combustion in a medium-speed diesel engine at full power. They found that after ignition the coal/water slurry burned faster than diesel at initial gas temperatures above $850 \mathrm{~K}$. At lower temperatures, the combustion quality rapidly deteriorated. These results are clearly shown in Figure 10 where the percent burned drops very quickly as the initial temperature approaches $850-900^{\circ} \mathrm{C}$. They theorized that below $850 \mathrm{~K}$, the cooling around the particle due to water evaporation inhibited complete combustion of the coal. They also felt that some of the unburned coal in their tests was due to the combustion bomb wall temperature being only $300 \mathrm{~K}$, as opposed to $500 \mathrm{~K}$ for the walls and piston in an engine. They felt this temperature difference would decrease the probability that the coal that impinged on the wall would burn. 


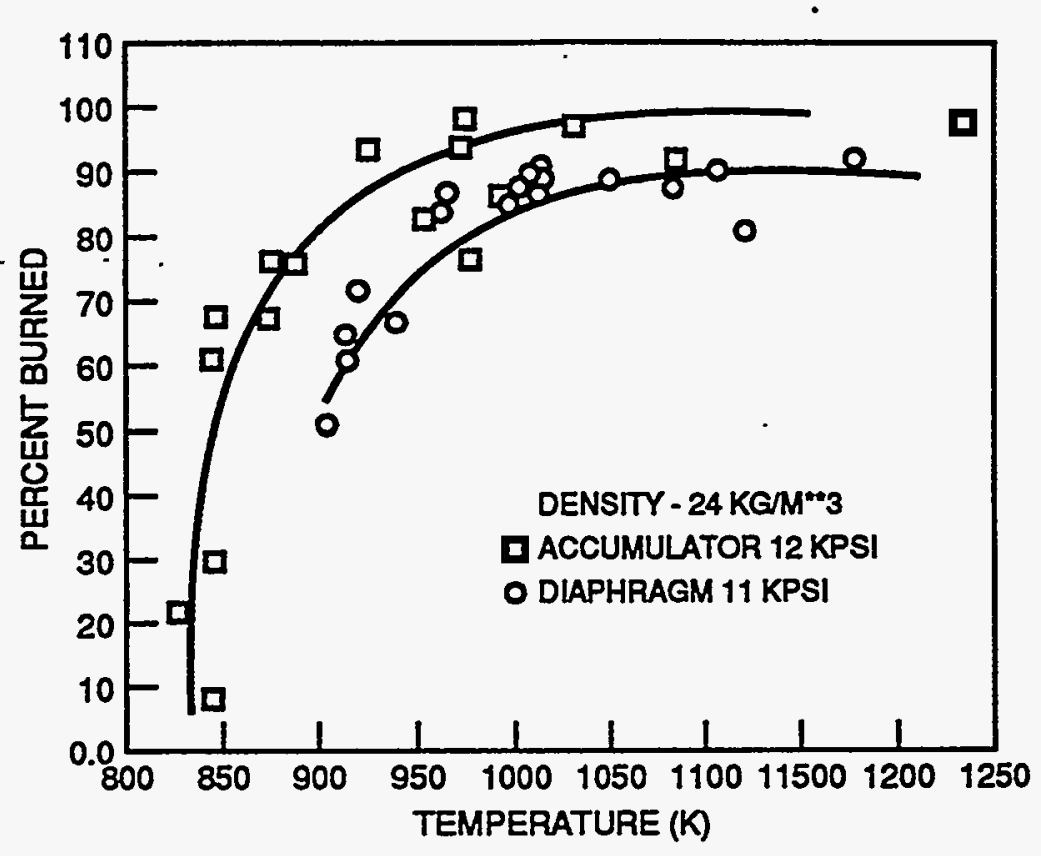

Figure 10. General Electric Coal-Water Slurry Burn Rate Data

The conclusions that can be drawn from these basic considerations of coal combustion are that the slurry properties must be tailored to meet the atomization and combustion requirements imposed by the time available and the thermodynamic conditions of the engine environment. The mean particle size of the coal in the slurry should probably be in the range of 10 microns mean size, with a loading on the order of 50 percent by weight, and $95 \%$ of particles less than 30 microns. Particles larger than these take too long to burn at 1000 RPM, and particles much smaller than these are too expensive to produce. The compression temperature must be as high as possible in order to achieve ignition and acceptable combustion rates. In fact, pilot injection of diesel fuel was suggested by the ignition temperature and combustion rate measurements in the basic experiments. The validity of these conclusions in the engine environment are discussed in the following section.

\section{Engine Development}

Coal-water slurries in the range of 50 percent by weight coal loading have been successfully tested in ten different engines during the METC Coal Diesel Development Program. Nelson ${ }^{(61)}$ performed experiments in a single-cylinder direct-injection engine equipped with a pilot injection system and a standard diesel fuel pump-line-nozzle system for injection of the CWS. Gurney ${ }^{(62)}$ also performed experiments in a single-cylinder research engine. Brehob and Sawyer ${ }^{(63)}$ observed slurry combustion in an optically accessible research engine. Likos and Ryan ${ }^{(23)}$ used both CWS and dry coal powder in a high-swirl, hightemperature pre-chamber engine, as did Kakwani ${ }^{(64,65)}$. The vast majority of the engine experience, however, has been reported by Hsu et al. ${ }^{(35,66-71)}$ and Rao et al., (28,72) each using two different 4-stroke medium-speed engines. Schwalb ${ }^{(21)}$ reported successful operation in a 2-stroke high-speed diesel engine operating in compression ignition mode. Basically, only three different types of engine designs were considered in the METC program. The vast 
majority of the engine development work was done in the four-stroke designs using very open combustion chambers and very low swirl ratios. The General Electric and the Cooper/Arthur D. Little engine development work were both based on this type of design. The SwRI/General Motors and the SwRI/Detroit Diesel work were both performed using two-stroke designs that incorporated the use of port scavenging and four exhaust valves. The combustion chamber designs in these two-stroke engines were both very similar to the four-stroke engines, in that they used the open, "Mexican Hat" designs, with very shallow bowls. Some limited work was also done using divided combustion chamber designs at Adiabatics Inc. ${ }^{(15)}$ and at SwRI $I^{(22,40)}$.

As indicated above, the likelihood of fuel impingement on the piston crown was very high in the open chamber designs used by GE and Cooper. In fact, Cooper found discoloration of spots on the piston crown at the center line of the fuel spray jets. However, fuel impingement was not associated with any problems, and in fact it may have been beneficial.

The goal of using a divided chamber design in the Adiabatics and SwRI work was to separate the injection and early combustion from the cold, lubricant wetted walls of the combustion chamber. These designs also offered the opportunity for utilization of thermally insulated surfaces to achieve higher temperatures and correspondingly higher ignition and combustion rates. Staged combustion for $\mathrm{NO}_{\mathrm{x}}$ control (via control of equivalence ratio) was also an objective. These designs were not pursued in the latter engine development activities primarily because they represented major changes in the head and piston designs of the category of engines being considered in the METC Program. These design changes would have required significant development work and would have also required very large investments to implement in a commercial engine. In addition, engine experience with CWS in the open chamber designs indicated that the combustion efficiencies were already very high, with ring and liner wear rates that could be controlled by appropriate selection of materials. Test results indicated that slurry fuel spray impingement on the piston crowns at GE and Cooper was not a problem.

The approach that was taken in all projects involved significant injection system development, followed by demonstration of operation on CWS in an engine, and then followed by system optimization in either single cylinder engines, or one cylinder of the actual development engine. The GE team and the Cooper/Arthür D. Little team both achieved several hundred hours of operation on CWS in medium speed diesel engines. The Detroit Diesel/SwRI Team achieved approximately 100 hours of operation in a high speed diesel engine. All of this work was performed using basically the same type of CWS fuel, consisting of a coal loading in the range of 50 percent by weight, with appropriate additives for control of sedimentation and viscosity.

The GE team based their system development on the GE Model 7FDL engine, which is a $1050 \mathrm{rpm}$ engine with a bore of $229 \mathrm{~mm}$ and a stroke of $267 \mathrm{~mm}$. Full scale engine development and testing were performed late in the program in a Dash-8 locomotive equipped with a 12 cylinder CWS engine. Cooper/Arthur D. Little performed the early (1985-91) system development work on a Cooper JS engine, which has a bore of $330 \mathrm{~mm}$, a stroke of $406 \mathrm{~mm}$, and an operating speed of $450 \mathrm{rpm}$. In 1992-93, system demonstration tests at Cooper were performed in a 6 cylinder LSC engine, which has a bore of $394 \mathrm{~mm}$, a stroke of $559 \mathrm{~mm}$, and 
a speed of $400 \mathrm{rpm}$. The high speed engine work at SwRI was performed in one cylinder of a Detroit Diesel 149 Series engine, which has a bore of $146 \mathrm{~mm}$, a stroke of $146 \mathrm{~mm}$, and a speed of $1900 \mathrm{rpm}$ at rated power. The configurations of the two 4-stroke engines were very similar, as can be seen in Figure 11, where cross-sectional schematics of both engines are compared. The 2-stroke, 149 Series engine used in the high-speed work was port scavenged, with four exhaust valves, a central injection nozzle location, and a shallow combustion chamber. Each of the three manufacturers' engine test series with coal slurry fuels is described below.

\section{General Electric}

The initial engine experiments at GE were performed using a diaphragm separated fuel injection system that produced injection pressures in the range of $40 \mathrm{MPa}$ at full load. Engine optimization included: variation in the intake air temperature from 85 to $110^{\circ} \mathrm{C}$; variation of intake pressure in the range from $112 \mathrm{kPa}$ to $329 \mathrm{kPA}$; and, simultaneous variation in the pilot and CWS injection timings. The early results indicated that combustion quality, based on coal burnout, was best at the highest possible intake pressure and temperature. They also found that the engine could be operated in compression ignition mode, but the performance was better if ignition was initiated using a pilot injection of diesel fuel, timed slightly in advance of the CWS injection. ${ }^{(66)}$ Coal burnout was reported to be in the range of 95 percent in these early experiments.

The combustion efficiency was increased to 99 percent and the conclusions regarding the injection timings were later modified after the compression ratio was increased to $13: 1^{(68)}$, and the CWS injection pressure was increased to $83 \mathrm{MPa}^{(69)}$ using an accumulator injection nozzle (Figure 4), and the number of holes in the injection nozzle tip reduced from 10 to 8 with the same total flow area ${ }^{(69)}$. It was concluded that it was best to inject the CWS as early as $35^{\circ}$ $\mathrm{BTDC}$ and to wait as long as possible to inject the pilot $\left(12^{\circ} \mathrm{BTDC}\right)$ in order to allow time for mixing and evaporation of the water from the slurry. As the load is decreased, however, they found that the trend reversed, and it was better to inject the pilot before the CWS in order to provide sufficient heat for evaporation of the water and ignition of the coal. $\mathrm{Hsu}^{(71)}$ verified by in-cylinder, high-speed photography that the high injection pressure resulted in impingement of the CWS on the hot piston crown, leading to improved atomization and more rapid combustion, if the pilot injection was delayed until $15^{\circ}$ BTDC.

It appeared that pilot quantities equivalent to 5-6 percent of the total energy input at full load is required across the load range in order to achieve stable operation. Optimization of pilot orientation and configuration resulted in the system shown schematically in Figure 11a. The pilot nozzle utilized a tip configuration in which the outer two holes had smaller diameter in order to maximize the interaction of the CWS jets with the pilot jets at the lowest possible pilot flow rate.

The emission characteristics with CWS were generally the same in all GE engines, where the $\mathrm{NO}_{\mathrm{x}}$ emissions were reduced due to the charge cooling effect of the water. The particulate and the sulfur emissions were higher due to the presence of ash and sulfur, respectively, in the fuel. An emission control system was developed by $\mathrm{GE}$ to reduce the $\mathrm{SO}_{2}$, the $\mathrm{NO}_{\mathrm{x}}$, and the particulate emissions. The GE system included injection of copper oxide sorbent for the $\mathrm{SO}_{\mathrm{x}}$ 


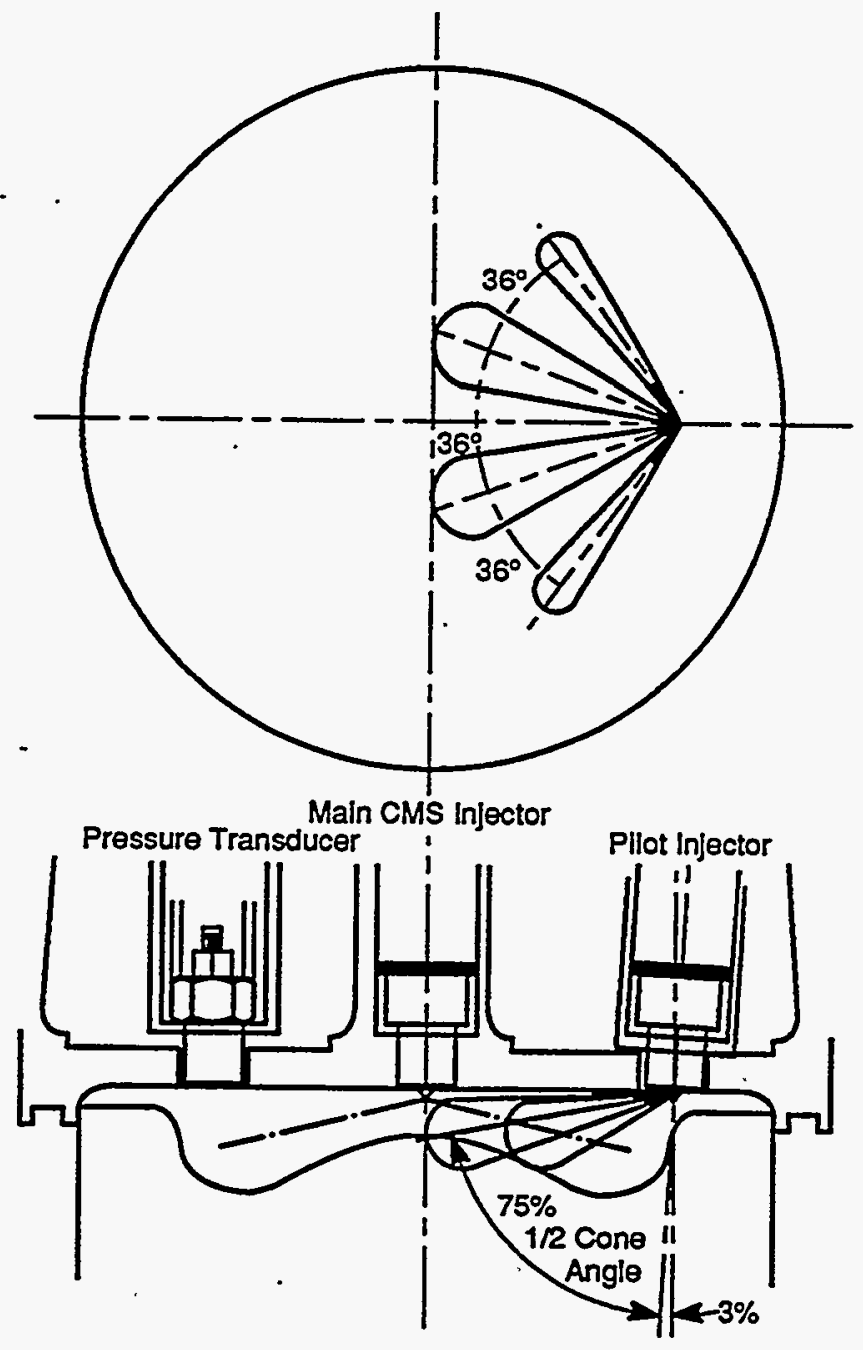

a. General Electric

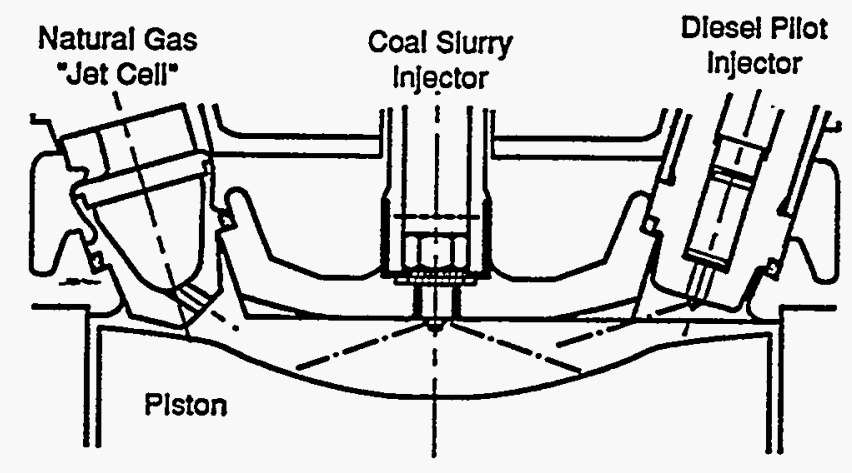

b. A. D. Little / Cooper

Figure 11. Engine Combustion Chamber Schematics for Operation on Coal-Water Slurry 
and ammonia for catalytic reduction of $\mathrm{NO}_{\mathbf{x}}$, downstream of the turbocharger. A barrier filter was installed at the end of the exhaust for removal of the particulate and the spent sorbent, for later regeneration. ${ }^{(70,131,132)}$

\section{Cooper/Arthur D. Little}

System optimization in the Cooper/Arthur D. Little program was performed in a single cylinder version of the Cooper Model JS engine. The initial experiments were performed using the shuttle piston injection system designed by AMBAC. ${ }^{(72)}$. Using this system, they were able to achieve injection pressures in excess of 80MPa, even in the early work. Like the GE engine, the Cooper engines are generally turbocharged and intercooled. The coal engine configuration evolved to a system where the intercooler was bypassed so that the intake air temperature was in the range of $145^{\circ} \mathrm{C} .^{(28)}$ They found that increasing the intake temperature beyond this level was effective in improving operation in compression ignition mode. They also concluded, however, that pilot injection gave more reliable operation, and that the $145^{\circ} \mathrm{C}$ intake air temperature was more than adequate when using a pilot to initiate combustion.

The optimum pilot characteristics in the Cooper $400 \mathrm{rpm}$ engine are very similar to the GE engine. It appears that the best pilot quantity is the equivalent of 2-6 percent of the total energy input at full load. In this slower engine, they found that the best pilot timing is to inject at the same time as the CWS, or at $18^{\circ} \mathrm{BTDC}$. Duration of injection was approximately 30-40 degrees crank angle.

Injection system optimization work centered on development of reliable components and optimum configurations for combustion. The effect of hole geometry was examined at $\mathrm{SwRI}^{(73)}$ in terms of the effects on atomization and mixing. Extensive engine experiments were also performed by Cooper/Arthur D. Little to determine the optimum configuration for durability of the nozzle and performance of the engine. These experiments included examination of the effects of the hole size, number, and orientation in the nozzle tip. The results showed that hole sizes from 0.4 to $0.65 \mathrm{~mm}$ were acceptable, and the number of holes could range from 12 to 20 for this size engine.

The Cooper experience in the JS engine was successfully transferred to the larger bore LSC engine, and demonstrated in a 6-cylinder configuration. The LSB coal engine was turbocharged without an intercooler so that the intake air temperature was in the range of $135^{\circ} \mathrm{C}$, with an injection pressure in the range of $100 \mathrm{MPa}$, and a CWS timing of $22^{\circ} \mathrm{BTDC}$. The pilot quantity was in the range of 2-4 percent of the full power energy input, and was injected two points $180^{\circ}$ apart. The timing was adjusted slightly in advance of the CWS injection.

The full scale LSC engine demonstration tests were performed using an extensive exhaust aftertreatment system that included ammonia injection and Selective Catalytic Reduction of $\mathrm{NO}_{\mathrm{x}}$, sodium based sorbent injection and collection for $\mathrm{SO}_{2}$ control, and the use of a bag house for sorbent recovery and particulate removal. 


\section{Detroit Diesel/SwRI}

Southwest Research Institute ${ }^{(25)}$ performed CWS experiments early in the METC program in both a 71 Series Detroit Diesel high-speed engine and a General Motors, Electro-Motive Division (EMD) 567 medium-speed engine. The Detroit Diesel engine is geometrically a onehalf scale version of the EMD engine. This early work, while limited in duration, pointed out the temperature advantage of using a 2-stroke engine for operation on CWS. In addition, Kakwani et al. ${ }^{(15)}$ were the first to point out that high speed engine can be operated on CWS if the in-cylinder temperatures are sufficiently high at the time of CWS injection. Detroit Diesel and SwRI, therefore, set out in 1990 to demonstrate that high-speed diesel engines could be successfully operated on CWS. ${ }^{(133)}$

An initial economic analysis indicated that the use of CWS in large mining equipment and in select marine applications offered some potential economic advantage over the use of diesel fuel. $^{(134)}$ The Detroit Diesel 149 Series engine, commonly used in these applications, was selected for use in the initial feasibility experiments. This engine is geometrically very similar to both the 71 Series and the EMD 567, except that it is generally equipped with electronic unit injectors and incorporates, in its standard diesel fuel configuration, a ceramic thermal barrier coating on the piston crown to allow the higher piston temperatures that accompany high output. The engine is port scavenged through four exhaust valves. Scavenging is accomplished using an engine driven blower and turbochargers. The air flow path is through the turbochargers, an intercooler, the blower, and then into the air box that surrounds the intake ports on each cylinder. The engine is equipped with a bypass valve that is used at some operating conditions to bypass the blower and charge the air box directly through the turbochargers. Control of the bypass rate affects the air box pressure, and in turn the scavenging ratio, the residual exhaust gas left in the cylinders, and the temperature of the air and residual gas charge in the cylinder at the start of the compression stroke. Controlling the bypass ratio is a very effective way of increasing the compression temperature, and is the primary design feature of this type of engine that has allowed Detroit Diesel to operate the engine in compression ignition mode on methanol.

The CWS development experiments were performed using one cylinder of an 8 cylinder engine. The head was modified to accept an in-cylinder pressure transducer, and the piston was changed to increase the compression ratio from the normal 15:1 to 19:1, in order to increase the compression temperature. This change was made based on modelling work ${ }^{(74)}$ that indicated that the higher compression ratio was needed in order to achieve the ignition delay times and combustion rates required for operation of the engine at $1900 \mathrm{rpm}$. A shuttle piston injection system was also developed for operation at these higher speeds. It is important to note the injection system on the $400 \mathrm{rpm}$ Cooper engine operates at 200 injection per minute, the injection system on the $1000 \mathrm{rpm}$ GE engine runs at 500 injections per minute, while the injection system on the DDC Model 149 engine had to operate at 1900 injections per minute, or almost 10 times as fast as the Cooper system, and 4 times as fast as the GE system. 
The modelling work ${ }^{(74)}$ indicated that the compression ratio had to be increased and a pilot injection of diesel fuel was required in order to achieve acceptable combustion rates and coal burnout. The results of the experiments indicated that reliable auto-ignition of the CWS could be achieved at the high load conditions if the intake temperature was made as high as possible. This was accomplished in the experimental engine by closing the blower bypass (route all of the air through the blower) and by stopping the flow of coolant to the intercooler. The problem was one of balancing these conditions across the speed-load range of the engine, when the in-cylinder temperatures tend to decrease as the load decreases. Injection timing was found to be critical for operation in compression ignition mode, where the peak cylinder pressure was excessive if the injection timing was advanced too far, and misfire occurred due to progressively lowering temperature as the injection timing was either retarded or advanced to far in the cycle. These results are demonstrated in Figures 12 and 13, where the cylinder pressure and heat release rate data are presented for different injection timing settings.

The best combustion results were obtained with an injection timing of $20^{\circ} \mathrm{BTDC}$ and the highest achievable air box pressure and temperature, or $125^{\circ} \mathrm{C}$ and $192 \mathrm{kPa}$, respectively. These conditions were limited by the constraints of the available hardware and were probably not optimum. Under these conditions, operation at part load was erratic due to reduced temperature, and the maximum load was limited by the fact that the peak pressures exceeded the design limits of the engine. It is probable that higher temperature and pressure would have improved the part load operation and reduced the ignition delay time and the high combustion rates at the higher loads. Coal burnout under these conditions reportedly still exceed 99 percent at the maximum load condition.

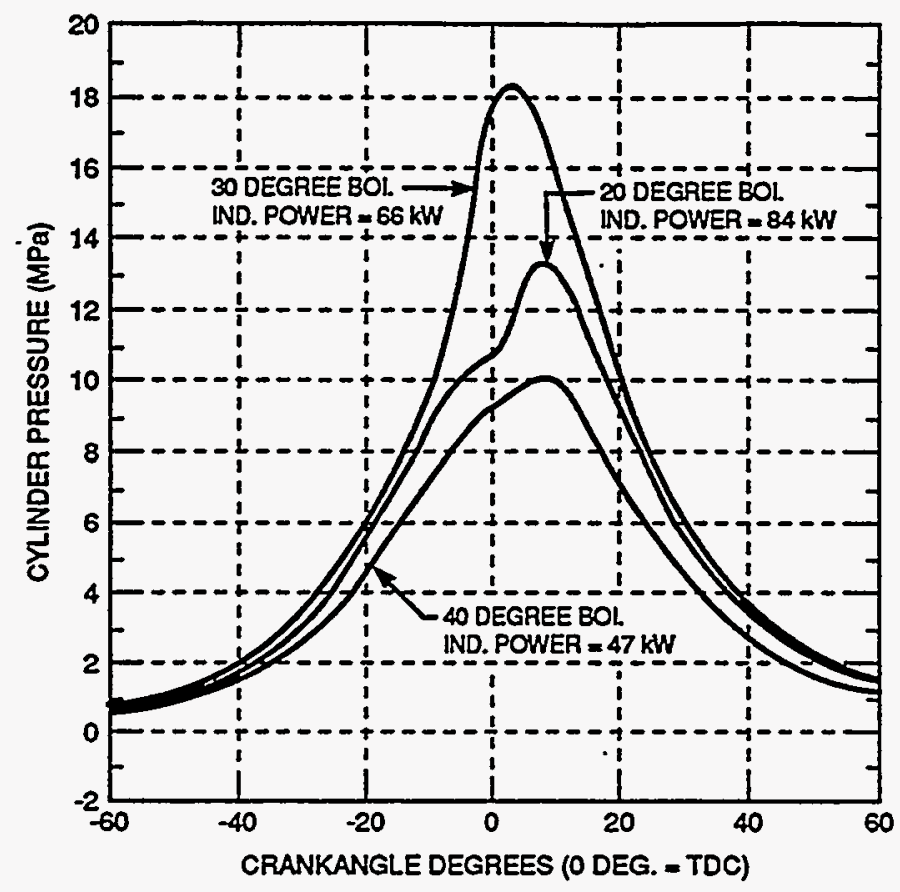

Figure 12. Combustion Pressure Traces for the 149 Engine Operation on Coat-Water Slurry 


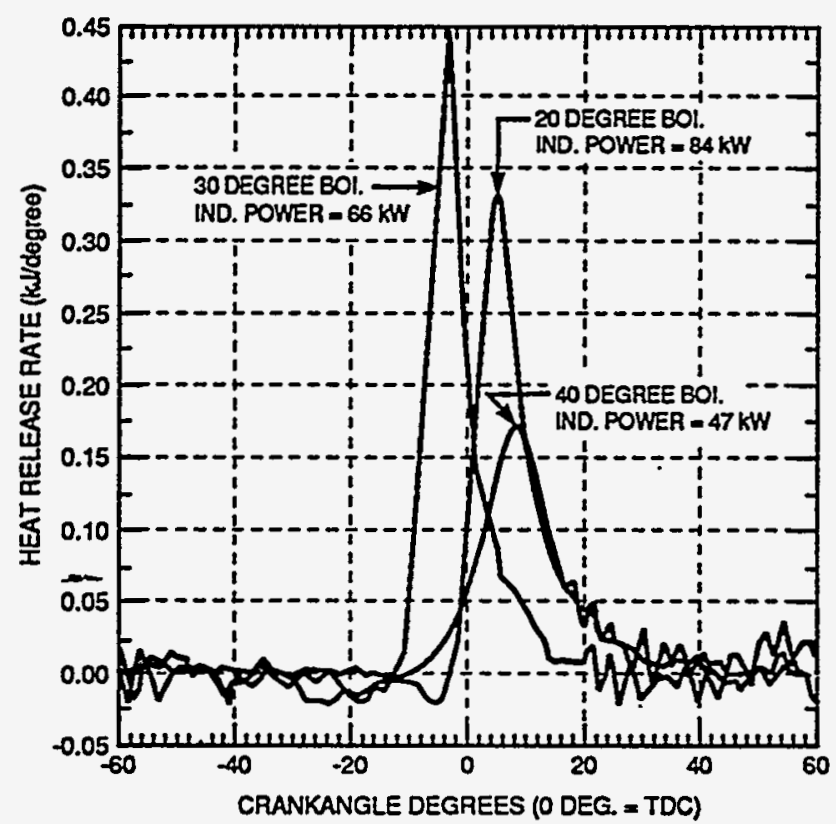

Figure 13. Heat Release Rates Computed from the Pressure Data Present in Figure 12

\section{COAL-WATER SLURRY PROPERTIES}

Coal-Water-Slurries (CWS) are two phase mixtures that generally exhibit complex flow and combustion characteristics. Important characteristics of these slurries include flow at no, or low, shear for settling properties of the solids, flow at high shears normally encountered in diesel injection systems, atomization and evaporation properties of slurry sprays, and ignition and combustion properties at conditions normally achievable in engines. These properties of the slurry are dependent on the coal rank and source, the particle size distribution of the solids . in the slurry, the mass loading of the coal, and the types and concentrations of additives that are used to improve stability, compatibility, and flow at high shear rate. This section is not meant to be an all inclusive review of slurry technology, but rather a brief summary of the findings of the METC Program related to the more important interactions of the slurry properties and performance in the engine hardware.

There were at least eleven suppliers of CWS in 1985 (see Table 4). Otisca Industries, AMAX, and United Coal were the main sources for the CWS used in the early METC sponsored projects. Many of these companies were not in the slurry business by 1988, and Energy International, University of North Dakota Energy \& Environmental Research Center, CQ Inc., and Otisca supplied most of the słurry for the work completed later in the program (1989-93).

CWS preparation involves several steps, including mining, shipping, crushing, cleaning, grinding, fine cleaning, and slurry preparation, additive blending, mixing, storage, and shipping. All of these processes add cost to the resulting CWS. The Cooper/Arthur D. Little team developed an economic model that they used to evaluate the different factors in the CWS processing stream that affects the cost. ${ }^{(75)}$ While the cost of the raw coal and transportation account for most of the cost of the CWS, coal cleaning and additive costs are significant. Cleaning technologies that were examined in the METC program included heavy media 
Table 4. List of Suppliers

\begin{tabular}{||l|l||}
\hline Advanced Fuels Technology & AMAX \\
Attn: Seymour Mark & Attn: Kurt Anast \\
618 Heron Drive & 5940 Mclntyre Street \\
P.O. Box 339 & Golden, CO 80403 \\
Bridgeport, NJ 08014 & (303) 279-7636 \\
(609) 467-411 & \\
\hline Atlantic Research Corporation & Coal Liquid, Inc. \\
Attn: Charles Chase & Attn: David C. Fuller \\
5390 Cherokee Avenue & Plainview Point \\
Alexandria, VA 22312 & Suite 100 \\
(703) 642-4089. & 10509 Timberwood Circle \\
& Louisville, KY 40223 \\
& (502) 425-881/Telex: 204313 \\
\hline Foster Wheeler Energy Corp. & Otisca Industries Limited \\
Attn: Gary T. Nedelka, P.E. & Attn: Clay D. Smith \\
110 South Orange Avenue & P.O. Box 127 \\
Livingston, NJ 07039 & Syracuse, NY 13208 \\
(201) 533-2838 & (315) 475-5543 \\
\hline OXCE Fuel Company & Resource Engineering Inc. \\
Attn: Robert J. McCormick & Attn: Norm Shapiro \\
1000 Prospect Hill Road & 80 Bacon Street \\
Windsor, CN O6095 & Waltham, MA 02154 \\
(203) 285-9025/Telex: 99297 & (617) 894-6720 \\
\hline Slurry Systems, Inc. & Systematics General Corporation \\
P.O. Box 772 & Attn: Robert B. Ryan \\
One President Street & 20030 Century Blvd. \\
Athens, OH 45701 & Suite 300 \\
(614) 594-5194 & Germantown, MD 20874 \\
& (301) 428-0905 \\
\hline United Coal Co. & \\
Attn: John H. Looney & \\
P.O. Box 1280 & \\
Glenway Ave. & \\
Bristol, VA 24203 & \\
(510) 580-2108 & \\
\hline & \\
\hline
\end{tabular}

separation, coarse flotation, fine flotation, oil agglomeration, and chemical cleaning. Several different approaches to each of these techniques are possible, but the teams generally examined only one example of the techniques that were available.

CWS property effects were examined as a part of the engine development activities at GE, Cooper/Arthur D. Little, Detroit Diesel/SwRI, and Adiabatics Inc. The initial goals were generally to improve the handling and combustion characteristics at a part of the engine optimization. $\mathrm{GE}^{(19)}$ examined three different sources of bituminous and two different sources of subbituminous coal. Blue Gem Seam of bituminous coal, chemically cleaned by Otisca to less than 1 percent ash and sulfur, was tested in two different sizes and with two different additive packages. Additives are generally used to control low and high shear viscosity, such as xanthan gun and surfactant, respectively, and dispersants to prevent agglomeration. 
The results of the GE studies indicated that while smaller coal particles produced faster burn rates, selection of the appropriate additive can be used to increase the burn rate of larger particles, at least for the Otisca cleaned coal. Ammonium lignosulphonate produced slightly faster burning than ammonium condensed naphtalene sulphonate dispersant.

They also found that there was not much difference in the burnout and burn rates of the chemically cleaned bituminous coals. A physically-cleaned bituminous coal from a different source (Kentucky Splint Seam) appeared to have a lower burnout than chemical cleaned coals. However, this slurry also had a much larger particle size distribution (8.2 micron mass mean particle size versus 4.6 micron).

The subbituminous coals generally burned slower than bituminous coals in the GE engine. It should be noted, however, that the heating values of these fuels are lower and the injection rates were not adjusted in the GE tests to account for the lower rates of heat addition to the engine. There were also some difference noted in between performance of the various subbituminous coals.

The results of the Cooper/Arthur D. Little fuel evaluations are summarized in Table 5. ${ }^{(75)}$ It was generally noted that the lower speed $400 \mathrm{RPM}$ Cooper engine was not very sensitive to the CWS properties, as long as the slurry did not exhibit flow problems that prevented operation in the engine.

Table 5. CWS Properties Tested ${ }^{(75)}$

\begin{tabular}{||l|l|l|l||}
\hline \hline Effect & Coal Property & Range Tested (3/28/90) & Results \\
\hline $\begin{array}{l}\text { Combustion } \\
\text { Performance }\end{array}$ & $\begin{array}{l}\text { Volatile Content } \\
\text { Rank } \\
\text { Heating Value } \\
\text { Particle Size }\end{array}$ & $\begin{array}{l}27-41 \% \\
\text { Bituminous/subbit. } \\
12-15 \mathrm{kBtu} / \mathrm{b} \text { (dry) } \\
10-85 \mu \mathrm{m} \text { Top Size } \\
3-12 \mu \mathrm{m} \text { Mean Size }\end{array}$ & All Okay \\
\hline $\begin{array}{l}\text { Emissions Control } \\
\text { Cost }\end{array}$ & $\begin{array}{l}\text { Sulfur } \\
\text { Nitrogen }\end{array}$ & $\begin{array}{l}0.7-1.0 \\
1.2-1.8 \%\end{array}$ & $\begin{array}{l}<2 \% \text { Okay } \\
\text { Needs More Testing }\end{array}$ \\
\hline Handling & $\begin{array}{l}\text { Solids Content } \\
\text { Viscosity }\end{array}$ & $\begin{array}{l}48-55 \% \\
200-400 \mathrm{cp}\end{array}$ & All Okay \\
\hline Wear, CWS Cost & Ash Content & $0.5-3.8 \%$ & $-\cdot$ \\
\hline
\end{tabular}

As shown in Table 5, particle-size distributions that have means in the range from 3 to 12 microns, and top sizes up to 85 microns are acceptable. The choice between coal ranks is also open, except that the heating value does have an impact on the injection requirements, and must be considered when designing the injection system. Viscosity in the range of 200-300 centipoise does not appear to be a problem, but $\mathrm{GE}^{(19)}$ reported that increased viscosity results in increased pressure drops in the injection system, and lower injection pressures.

The rheological properties of the CWS fuels affect the sedimentation tendency of the solids during storage, the flow characteristics during transport in piping systems and pumps, and the injection and atomization in diesel engine injection equipment. CWS fuels are generally nonNewtonian, exhibiting non-linear relationships between the shear stress and shear rate, so that the viscosity is variable and dependent on mass loading and the shear rate. It should be noted 
that the apparent viscosities of the CWS fuels are strongly affected by the mass loading of coal in the slurry. Most CWS fuels exhibit a very dramatic increase in the apparent viscosity as the mass loading approaches the 50 percent level, depending on particle size distribution.

The relationship between the apparent viscosity and the shear rate is shown in Figure 14 for slurries formulated at SwRI using physically cleaned coal supplied by AMAX. The results are for three different size distributions, where "AR" designates "as received" with a mean size of 10.2 and top size of 28 microns. "Ground once" (1X) had a mean size of 7.4 and a top size of 18.5 microns, and "ground twice" ( $2 \mathrm{X})$ had a mean size of 5.5 microns and top size of 12.5 microns. The high viscosity at low shear rate is desirable because this minimizes sedimentation. The slurries all exhibited shear thinning in the range from 1 to $30 \mathrm{~s}^{-1}$, and relatively constant viscosity in the range from 30 to $1000 \mathrm{~s}^{-1}$. The low shear rheology is advantageous for storage (high viscosity at no shear) and transport through piping system (shear thinning at low shear rate). The CWS with the larger particles exhibited shear thickening tendencies beyond $1000 \mathrm{~s}^{-1}$, but the CWS with the smaller particles had nearly constant viscosity beyond $10,000 \mathrm{~s}^{-1}$. As will be shown in the next section, the high apparent viscosities of the slurries at high shear rate have significant effects on the injection and atomization characteristics relative to those observed with diesel fuel.

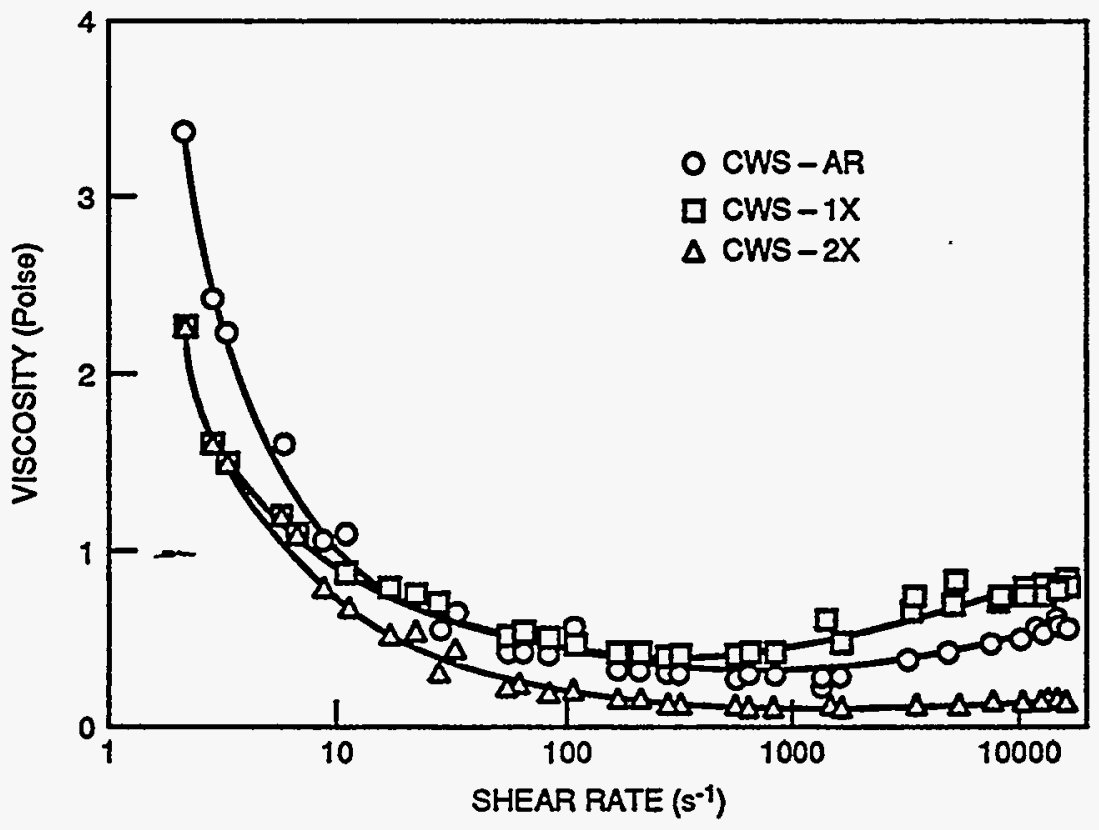

Figure 14. Viscosity Versus Shear Rate for CWS's with Different Mean and Top Particle Sizes

\section{INJECTION CHARACTERISTICS}

Initial efforts at injection system design were aimed at solving the reliability and durability characteristics of the systems. It appears that the shuttle piston design offers the most promise for providing the fuel pressures required for acceptable atomization. The conclusion of the GE engine development work was that an accumulator nozzle design was required in order to achieve acceptable performance in the $1000 \mathrm{rpm}$ GE engine (500 injections/min). Detroit 
Diesel/SwRI and Cooper/Arthur D. Little found that high burnout could be achieved over a very broad range of engine speeds, from 400 to $1900 \mathrm{rpm}$ (200 to 1990 injections/min) using high injection pressures in conventional injection nozzles. It is apparent that the conventional nozzle approach with high injection pressure is acceptable for the lower speed (400 RPM) Cooper engine. Here the engine bore size demands high penetration, the engine speed allows time for this penetration, and the nozzle components are large enough to accommodate more holes. The accumulator concept may improve the performance of the high speed DDC engine (1900 RPM), but it is unclear if the accumulator pressure can be maintained at the higher engine speeds.

Ignition and combustion of any fuel, including CWS, in a diesel engine are highly dependent on the fuel injection characteristics of spray tip penetration rate, spray cone angle (both of these reflect the air entrainment rate), and the drop size distribution in the spray. Drop size distribution and the surrounding air temperature determines the evaporation and heating rates of the fuel. Holve ${ }^{(56)}$ pointed out that fine grinding of coal is not beneficial unless the injection system is capable of producing some drops that are smaller than the larger solid particles in the slurry. He found ${ }^{(76)}$ that the particle size distribution in CWS sprays were larger than the maximum size of the coal particles in the slurry. Morrison ${ }^{(77)}$ also noted that small particle sizes are not always achieved during injection and combustion by having small particles in the slurry. It is theorized that the coal particles agglomerate to form much larger particles, up to three times the size of the original coal particles. ${ }^{(76)}$

Cheng ${ }^{(78)}$ indicated that the combustion efficiency in a rapid compression machine was improved by using increased injection pressure. He theorized that these improvements were due to increased atomization of the slurry in the fuel sprays. The experimental data, presented in the form of high speed movies of the fuel spray, actually indicated a decrease in the jet atomization, an increase in the penetration rate, the occurrence of over-penetration, and the formation of a wall jet. Leonard and Fiske ${ }^{(26)}$ reported similar improvements in combustion efficiency by using a high pressure accumulator injection system. They also theorized that the higher pressure produced increased primary atomization. The actual atomization characteristics in terms of penetration rate, cone angle, and size distribution were not documented in either study. Ryan et al..$^{(9,10)}$ reported that the drop size distribution in slurry sprays were on the order of 50 microns, while the corresponding diesel fuel sprays were in the range of 25 microns.

The engine experiments in the Cooper/Arthur D. Little project indicated that ignition and combustion characteristics were only slightly improved as the fuel injection pressure was increased in the 45-70 MPa range. The GE team observed similar results in their experiments. The higher injection pressures, however, produced correspondingly higher velocities in the injection nozzles and higher wear rates. It was theorized that the primary atomization could be improved by modifications to the design of the nozzle holes, and thus allow the use of lower injection pressure.

Dodge, et al. ${ }^{(73)}$ examined the effects a wide range of different hole geometries on the primary jet breakup and atomization. The hole geometries that were examined are described in Figure 15. The measurements, performed in a high-pressure flow reactor, included cone angle and drop size distribution by laser diffraction, with injection pressures in the range from 

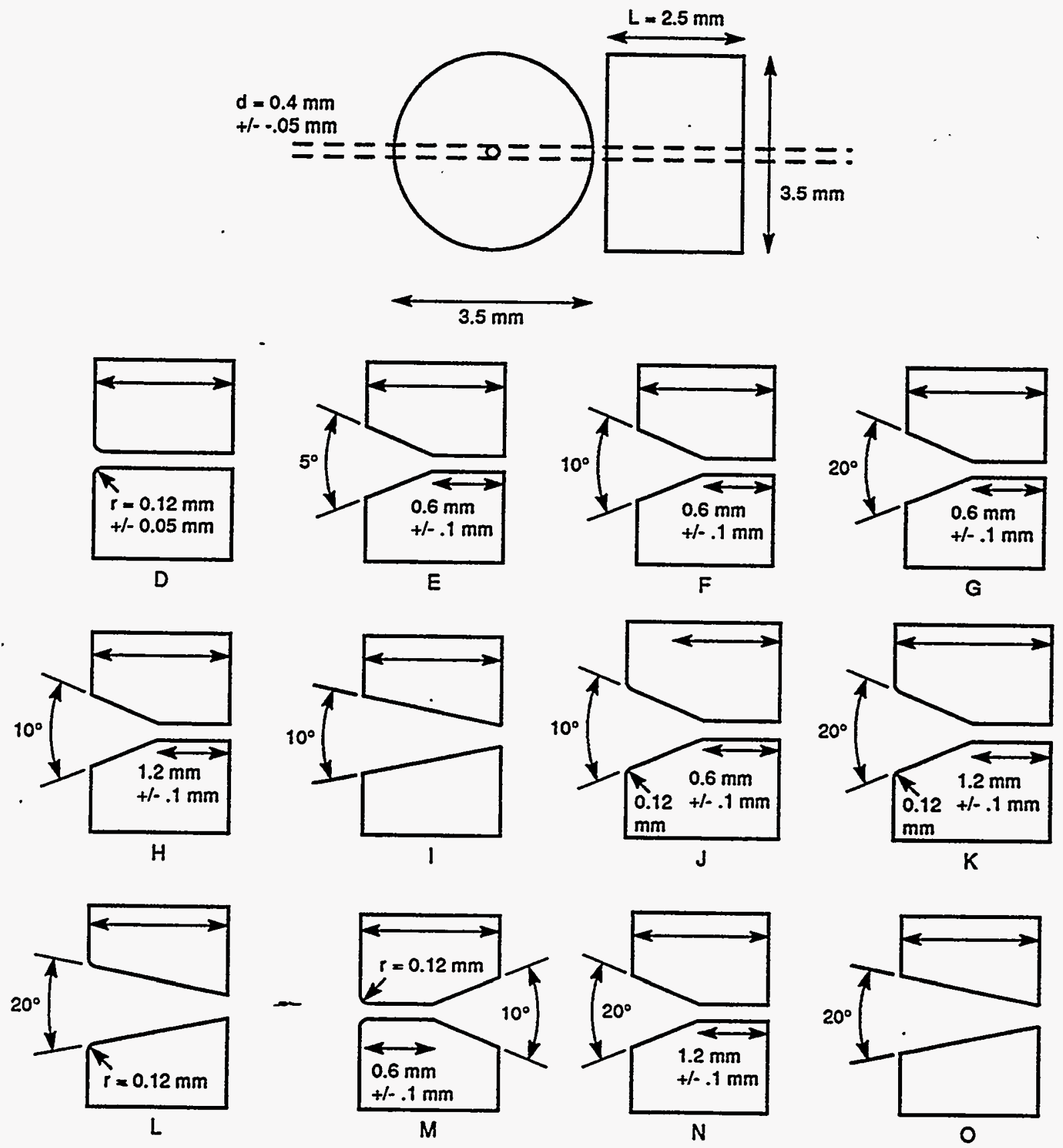

Figure 15. Nozzle Hole Geometries Used in Reference 73 
40 to $100 \mathrm{MPa}$. The results, shown in Figure 16, indicated that the cone angles of the slurries ranged from 2 to 10 degrees, over the pressure range of the experiments, while those for diesel fuel were constant at 15 degrees over the same pressure range. Seshadri et al. ${ }^{(79)}$ reported cone angles of 11 to 16 degrees for CWS and 16 degrees for diesel fuel sprays from a standard GE injection nozzle, using basically the same definition as Dodge et al..$^{(73)}$. Caton ${ }^{(80)}$ reported cone angles of 14 degrees for the high pressure GE accumulator nozzle. The cone angle for these experiments was defined as the arc tangent of the spray width divided by the axial distance of this measurement location from the tip. Dodge et al. ${ }^{(73)}$ used a measurement distance of $177 \mathrm{~mm}$, Seshadri et al. ${ }^{(79)}$ used $80 \mathrm{~mm}$ and Caton et al. ${ }^{(80)}$ used $60 \mathrm{~mm}$.

As shown in Figure 17 from Dodge et al. ${ }^{(73)}$, the mean drop size for the slurry sprays ranged from 25 to 20 microns for various mass loadings of 15 micron mean size coal particles, and from 45 to 30 micron drops for a 52 percent mass loading of 14 micron mean size coal. The maximum coal particle size was 85 microns in these experiments. Kihm et al. ${ }^{(81)}$ reported mean spray drop sizes for CWS in the range from 30 to 100 microns for injection pressure in the range from 28 to $110 \mathrm{MPa}$, but interpretation of these measurements is complicated by the fact that there was evidence in the data (high intensity signal on the inner ring detector of the laser diffraction instrument) of window fouling. Dodge et al. ${ }^{(73)}$ found that the hole geometry has very little effect on the performance in terms of the cone angle and the drop size distribution.

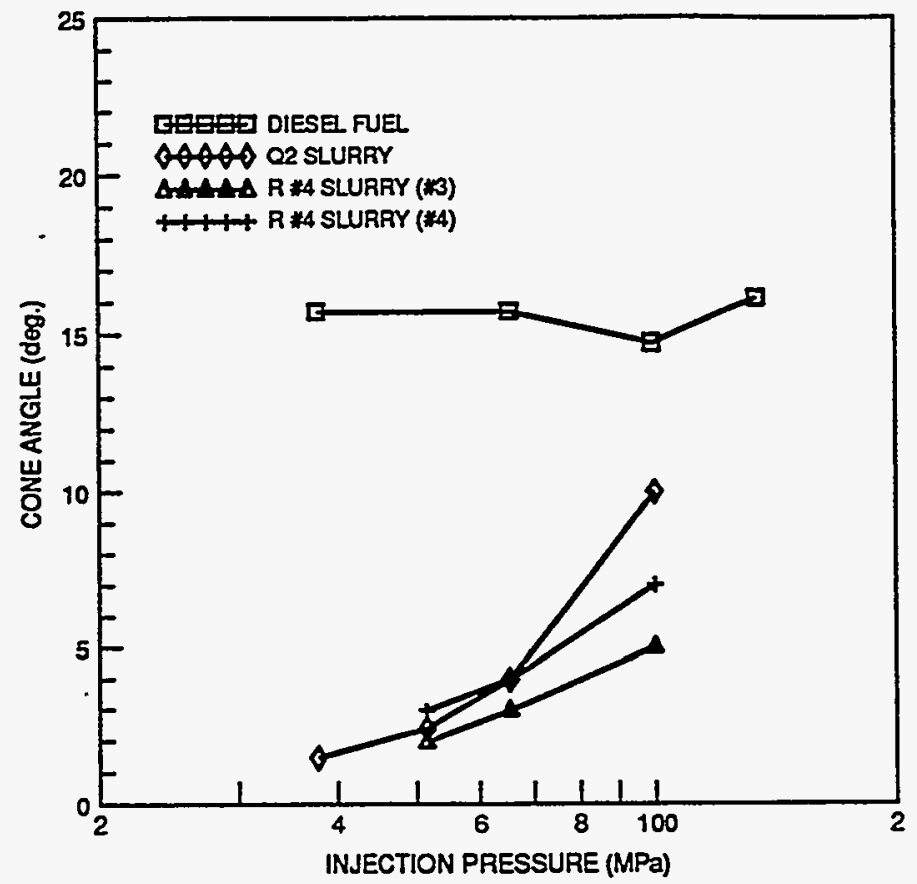

Figure 16: Cone Angles Versus Injection Pressure for Different CWS's 


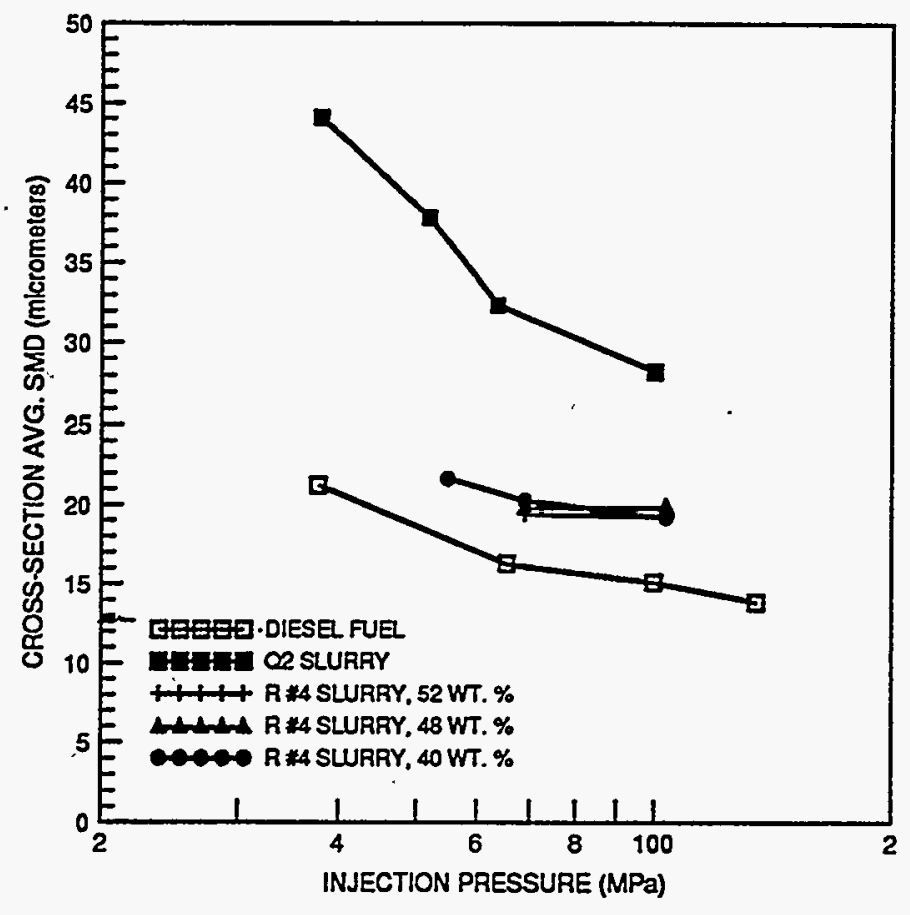

Figure 17. Average SMD of CWS Sprays Versus Injection Pressure

\section{ENGINE WEAR}

Injection system wear problems have been addressed in another section. The other major wear problems in CWS engines occur in the ring and liner areas. The work of Mayville et al. ${ }^{(36)}$, Ives ${ }^{(134)}$, and Schwalb et al. ${ }^{(82,83)}$ in reciprocating wear fixtures indicate the ring and liner wear is a combination of soft abrasive wear, due to the presence of coal in the wear couple, and three-body wear associated with the ash particles that enter the wear region. The three-body wear associated with the presence of the ash particles is a much more significant contributor to the wear rate than the soft abrasive wear, but it should be noted that ring and liner wear would still be a problem if unburned coal enters the wear couple, even if the ash were totally removed from the coal. Increased surface roughness was found to increases the thickness of the hydrodynamic oil film and detergent additives were found to minimize the abrasive wear, suggesting that surface finish and lubricant formulation could be tailored to minimize wear rates. ${ }^{(83)}$

The magnitude of the ring and liner wear problem is demonstrated in Figure 18 from Mayville et al. ${ }^{(37)}$, where the ring wear rates on CWS are compared to that required to achieve diesel fuel durability. Also shown on the figure are the wear rates for other material combinations, indicating that the wear rates are greatly reduced through the use of hard coatings. 


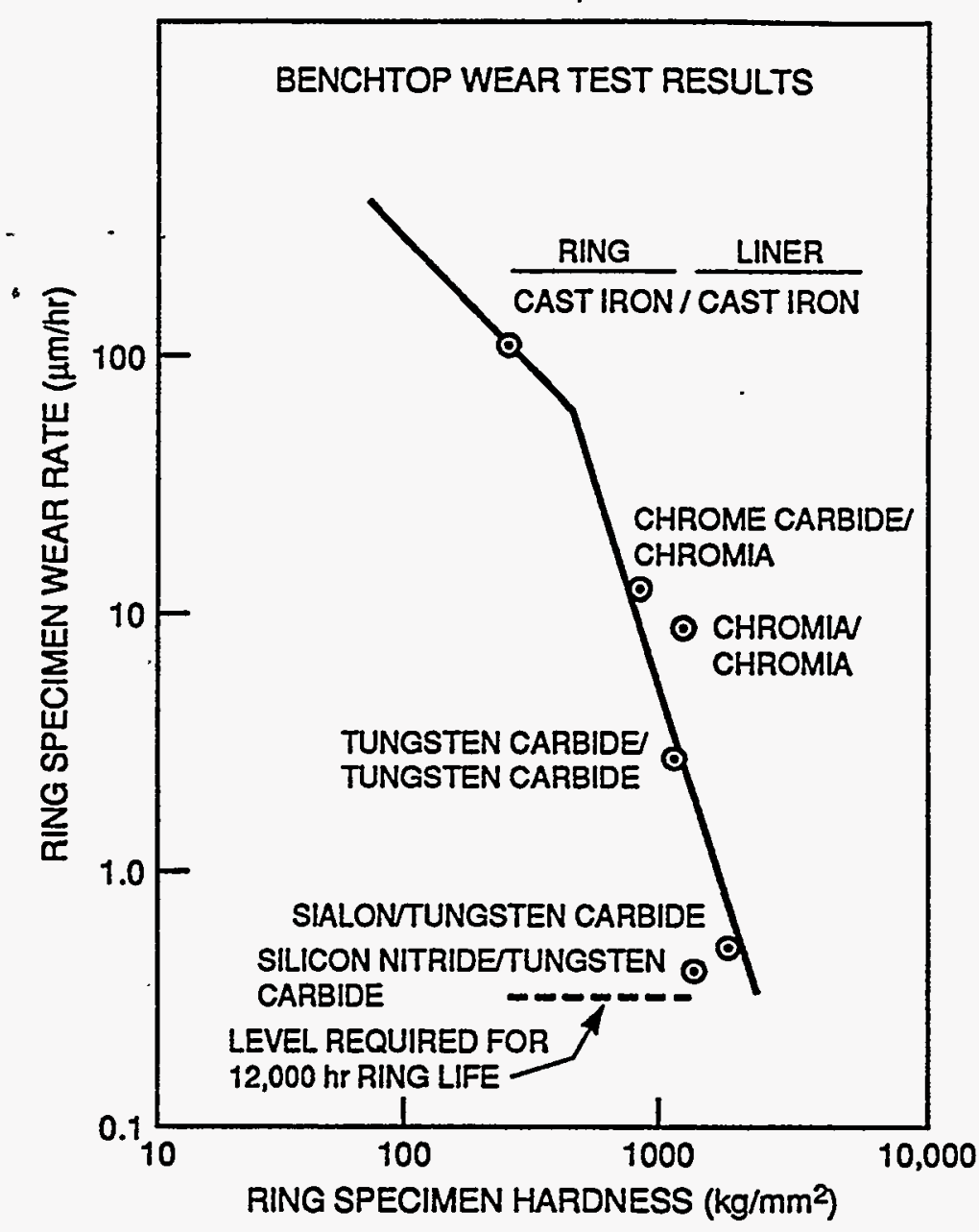

Figure 18. Arthur D. Little Ring and Liner Wear Data ${ }^{(37)}$

The hard coatings were examined in some detail by both the Cooper/Arthur D. Little team and the GE team. The Cooper/Arthur D. Little work, performed by Mayville et al. ${ }^{(84)}$, indicated that tungsten carbide coated ring and liners exhibited acceptable wear characteristics during operation on CWS. This conclusion is illustrated in the results shown in Figure 19, where the end gap change is plotted versus run time for the coated and the standard components. Similar data from the GE team, reported by Flynn et al. ${ }^{(31)}$, are presented in Figures 20 and 21, for the liner and rings, respectively. The material combinations that were examined in the GE project are summarized in Table 6 . The GE team also concluded that the tungsten carbide coatings provided acceptable wear characteristics.

\section{ENGINE MODELING}

The purpose of this section is to review past activities on the modeling of coal-fueled diesel engines. For the most part, these past activities are reviewed in chronological order. For convenience, these activities are discussed in three time periods (with some overlap): (1) - pre-1981, (2) 1981-1990, and (3) 1987-1993. 


\section{Pre-1981 Engine Modeling Activities}

Although significant experimental work on coal-fueled engines was completed prior to 1981 , only a few analytical studies (and no engine cycle simulations) were reported during this time period. The earliest analytical studies were probably those of Nusselt in 1928 and Wentzel in 1931 as reported by Soehngen ${ }^{(1)}$. These studies examined the ignition and combustion processes of coal dust for fixed temperatures, pressures, and oxygen concentrations which were selected to simulate engine conditions. Their work indicated that coal was a relatively slow burning fuel and that a maximum speed of a coal burning diesel would be limited to less than $400 \mathrm{rpm}$.

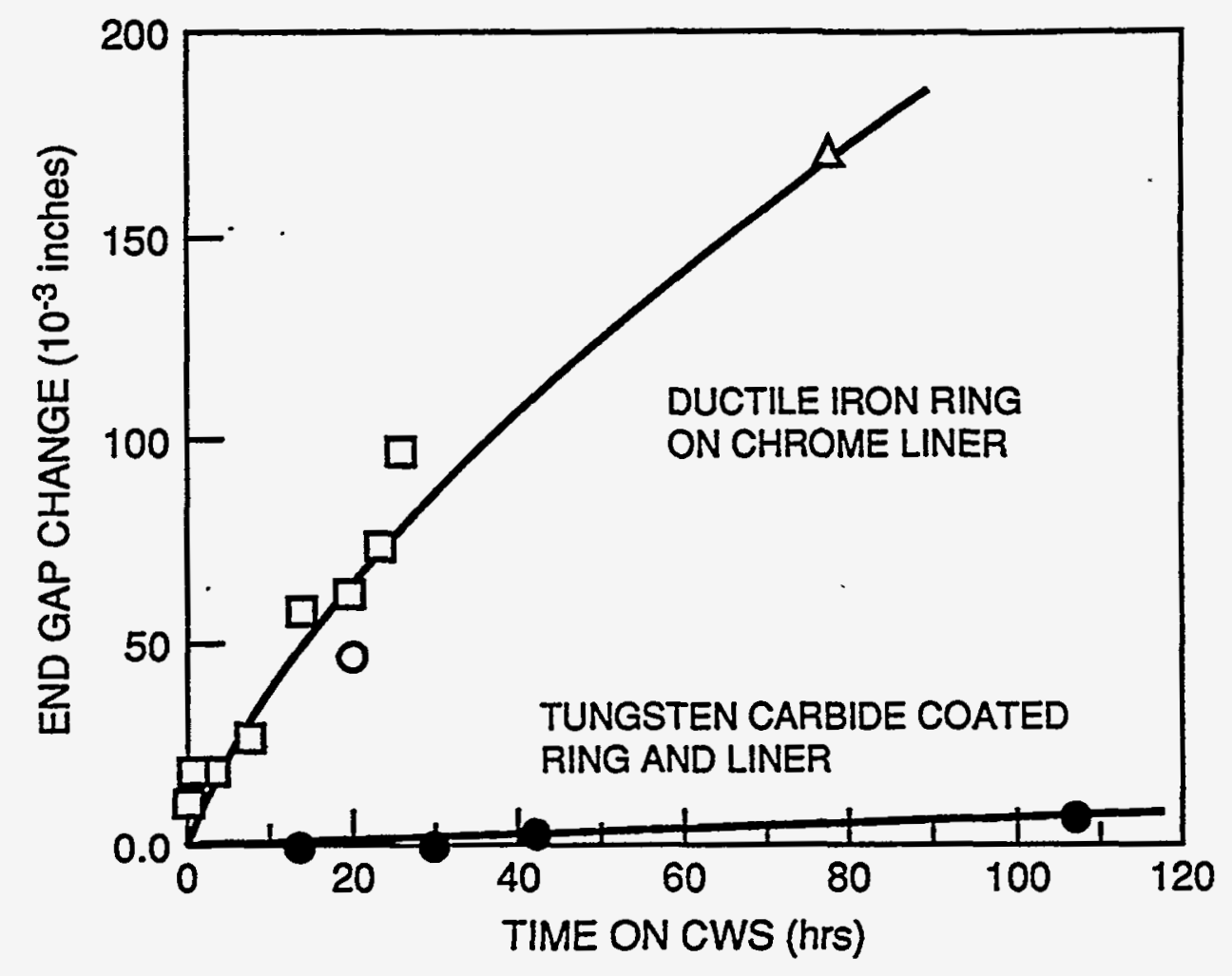

Figure 19. Ring and Liner Wear Rate Data for Conventional and Hard Materials ${ }^{(84)}$ 
a) CYLINDER LINER WEAR

TOP RING REVERSAL

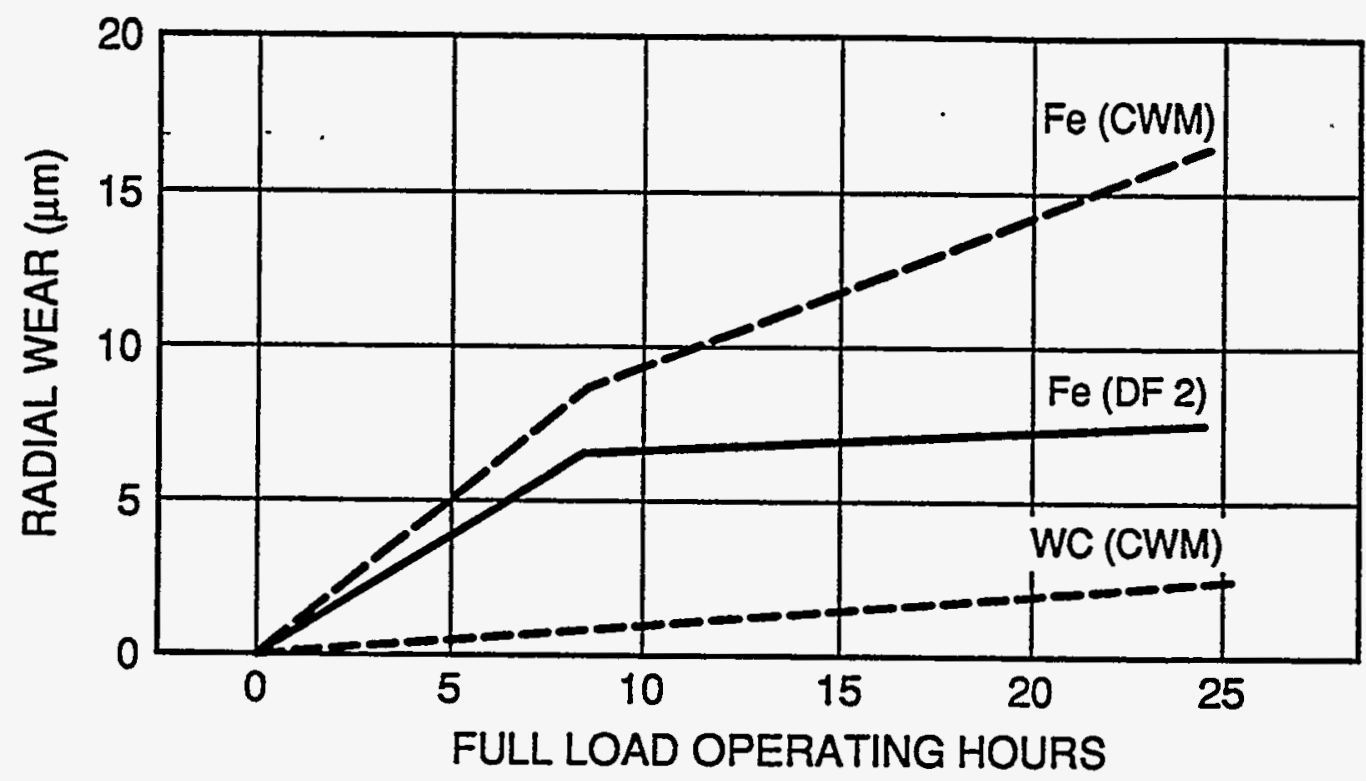

b) CYLINDER LINER WEAR

BOTTOM RING REVERSAL'

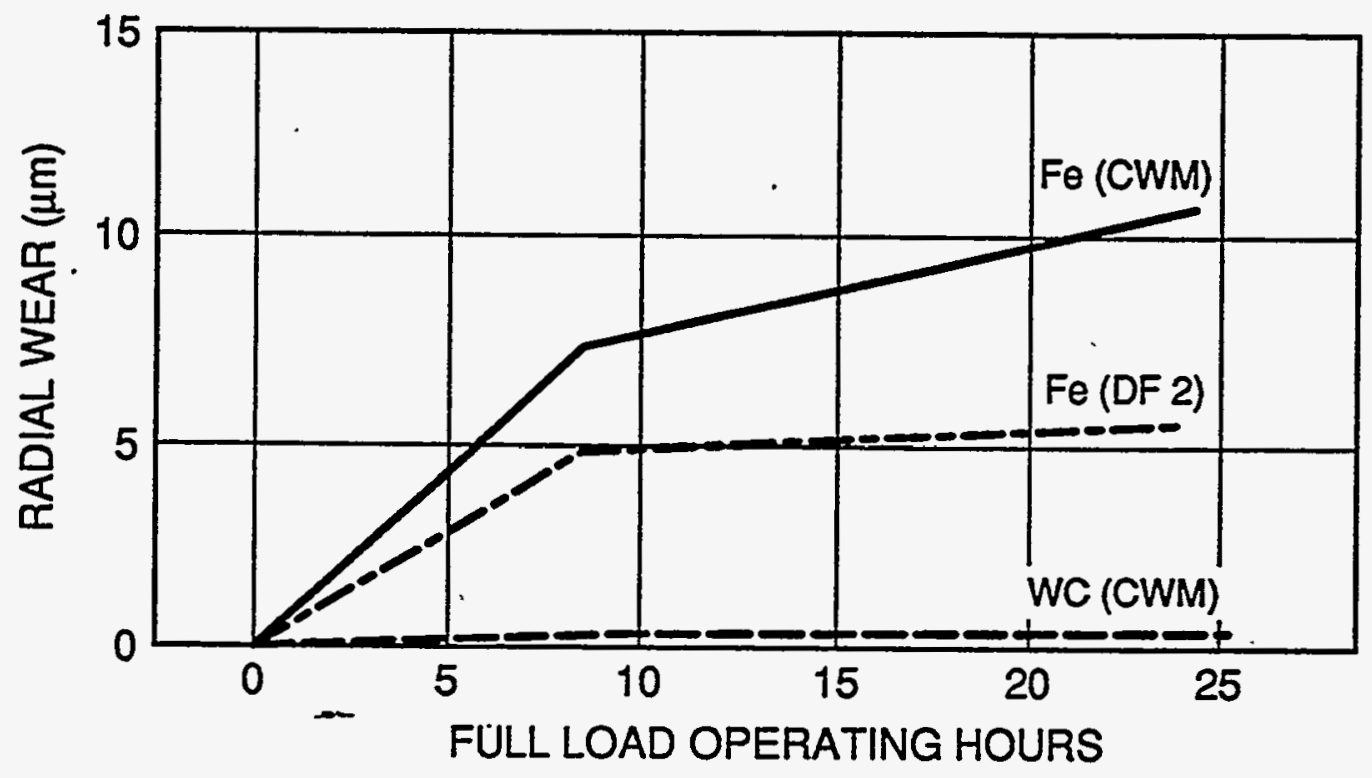

Figure 20. Liner Wear Rates for Various Materials ${ }^{(31)}$ 
a) TOP RING WEAR

DIESEL FUEL AND COAL WATER MIXTURE FUEL

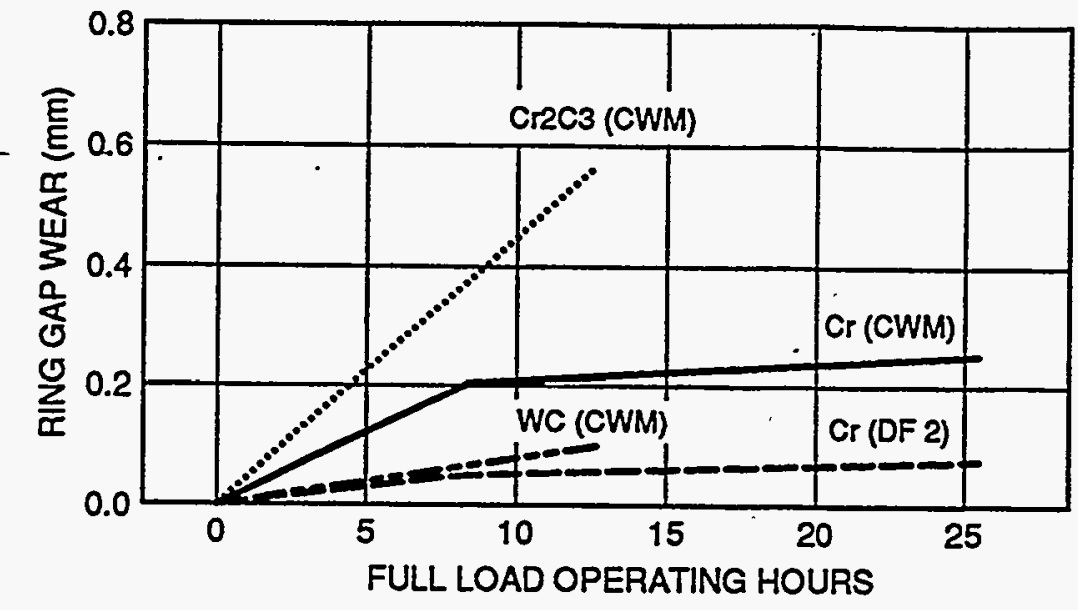

b) MIDDLE RING WEAR

DIESEL FUEL AND COAL WATER MIXTURE FUEL

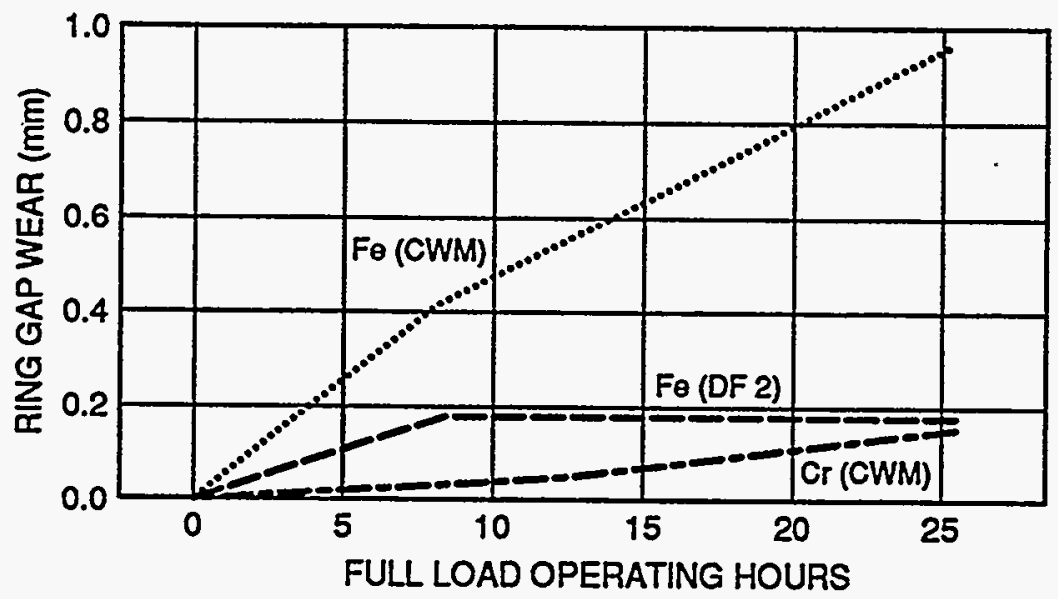

c) OIL RING WEAR

DIESEL FUEL AND COAL WATER MIXTURE FUEL

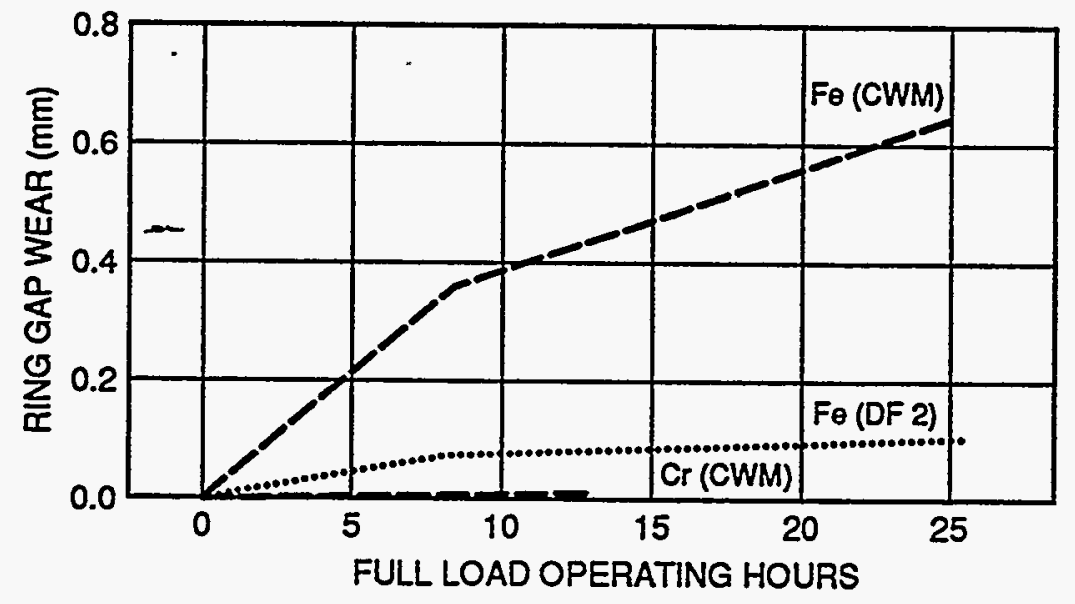

Figure 21. Ring Wear Rates for Various Materials ${ }^{(31)}$ 
Table 6. Yanmar Engine Results ${ }^{(31)}$

\begin{tabular}{|c|c|c|c|}
\hline Run Number & Ring Material & Liner Materlal & $\begin{array}{l}\text { Ring Wear Rate } \\
\mathrm{cc/hr}\end{array}$ \\
\hline \multicolumn{4}{|l|}{ Uncontaminated Runs } \\
\hline 50 & Chrome & Cast Iron & $1.8 \mathrm{E}-5$ \\
\hline 51 & $W C+C o(S T)$ & $W C+C_{0}$ (LPPD) & $1.4 \mathrm{E}-5$ \\
\hline \multicolumn{4}{|l|}{ 2\%-D4 Contamination } \\
\hline 52 & Chrome & Cast Iron & $41.5 \mathrm{E}-5$ \\
\hline 53 & $W C+C o(S T)$ & $W C+C_{0}(L P P D)$ & $55.0 \mathrm{E}-5$ \\
\hline 54 & $W C+C O(P T)$ & $W C+C O(L P P D)$ & $64.0 \mathrm{E}-5$ \\
\hline 56 & $W C+C o(K 96)$ & $W C_{+}+C_{0}(K 703)$ & $0.8 \mathrm{E}-5$ \\
\hline 57 & WC_Co (ST) & $W C+C o(K 703)$ & $3.5 \mathrm{E}-5$ \\
\hline 58 & Chrome & $W C+C o(K 703)$ & $7.1 E-5$ \\
\hline 59 & Chrome & Cast Iron & $28.8 \mathrm{E}-5$ \\
\hline 60 & Cr3C2_Mo (K1008) & $W C+C o(703)$ & 24.5E-5 \\
\hline \multicolumn{4}{|c|}{ Otisca Ash Contaminated } \\
\hline 61 & WC+Co (K96) & $\dot{W} \mathrm{C}+\mathrm{Co}(\mathrm{K} 703)$ & $1.43 E-5$ \\
\hline 62 & $W G+C_{0}(S T)$ & $W C+C o(K 703)$ & $7.00 \mathrm{E}-5$ \\
\hline 63 & Chrome & Cast Iron & $250.00 \mathrm{E}-5$ \\
\hline ST & \multicolumn{3}{|c|}{ Serma Tech Plasma Sprayed } \\
\hline PT & \multicolumn{3}{|c|}{ Plasma Technics Plasma Sprayed } \\
\hline LPPD & \multicolumn{3}{|c|}{ CRD Low Pressure Plasma Deposited } \\
\hline K96 & \multicolumn{3}{|c|}{ Kennametal Monolithic Carbide } \\
\hline K703 & \multicolumn{3}{|c|}{ Kennametal Monolithic Carbide } \\
\hline
\end{tabular}

More recent calculations of particle burning times in an engine cylinder are in rough agreement with each other, although the complexity of the combustion process makes precise determinations difficult. Rich and Walker ${ }^{(4)}$ completed simple coal combustion calculations in addition to actual engine operation. In an effort to reduce the complexity of the mathematical analysis, conditions of constant temperature, pressure and oxygen concentration were assumed. With these simplifications, their results indicated, for example, that a 30 micron diameter particle would require about $10 \mathrm{~ms}$ to completely burn at a pressure of 40.5 bars and a temperature of $2273 \mathrm{~K}$ in an infinite excess air environment. For reference, $10 \mathrm{~ms}$ requires 60 degrees of crank rotation at an engine speed of $1000 \mathrm{rpm}$.

Saxton et al. ${ }^{(85)}$ provided a similar, simple analysis of coal particle combustion in engines but they examined a wider range of fixed engine conditions. Barrett and Saxton ${ }^{(86)}$ presented a subsequent paper that included the effect of time-variable particle temperature. Although physically more meaningful, the calculated combustion times were essentially unchanged. Again, these early studies did not simulate the actual engine cycle. 


\section{Engine Modeling Activities 1981-1990}

The first detailed cycle simulations specifically developed for coal-fueled engines were published during 1982-1984 (Rosegay ${ }^{(87)}$; Caton and Rosegay ${ }^{(12)}$; Rosegay and Caton ${ }^{(5)}$ ). Figure 22 is a schematic of the overall engine system and shows the major components of the thermodynamic model of the cylinder gas. These components include the gas flows into and out of the cylinder, the radiative and convective heat transfers to the cylinder walls, work transfer to the piston, and energy release due to combustion. In these early simulations, a dry, non-volatile coal particle was considered. Since the coal char burn-out was considered the limiting step this was considered a reasonable first approximation. Figure 23 is a schematic of the solid particle combustion model and shows the carbon (char) surface attacked by oxygen and carbon dioxide producing carbon monoxide that is oxidized in the gas-phase away from the surface. In this work, they developed submodels for the combustion, work, heat transfer and mass transfer processes. These submodels were combined with a thermodynamic analysis of the engine to yield instantaneous cylinder conditions and overall indicated engine performance.

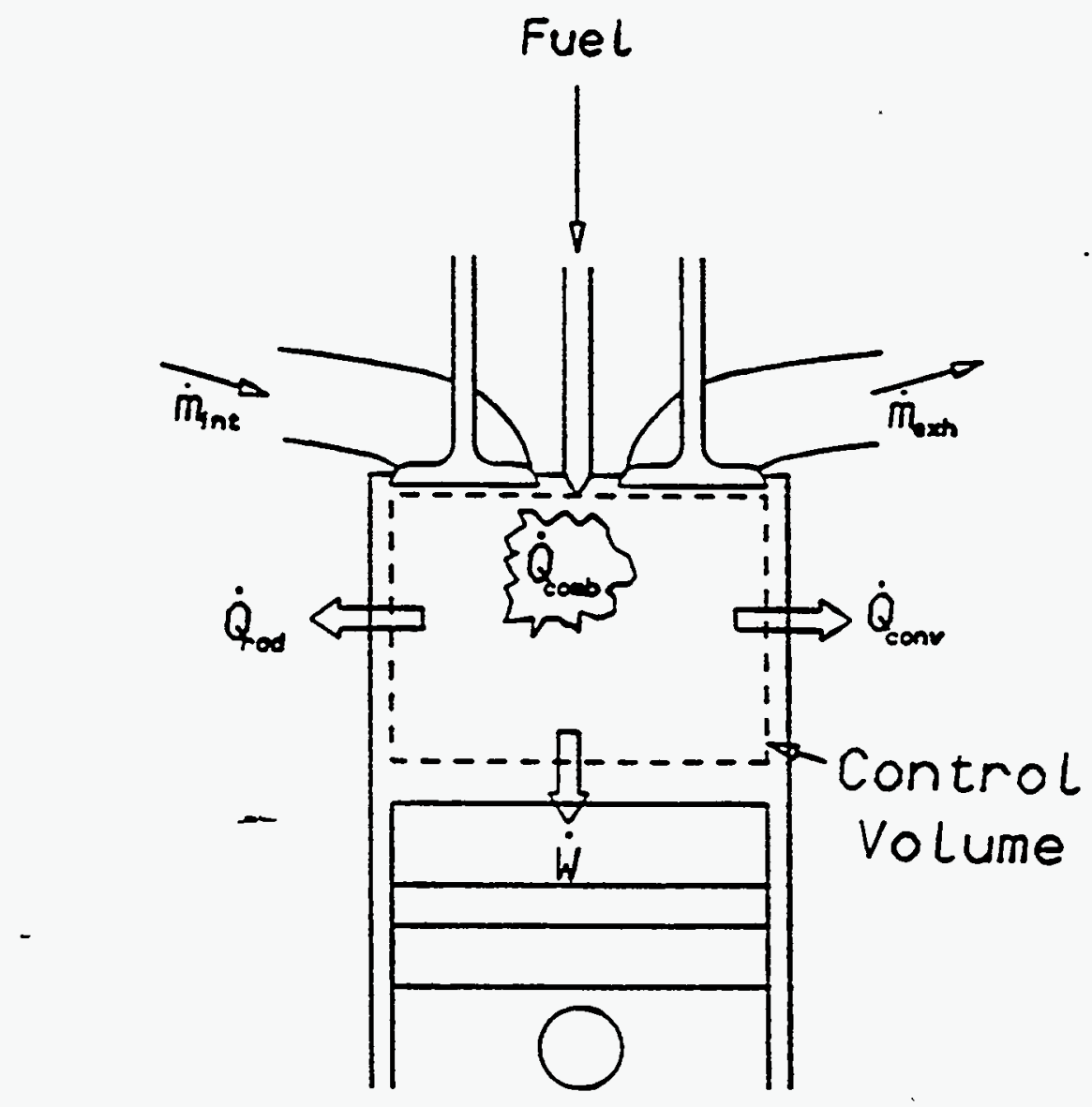

Figure 22. Schematic of Engine Modelling Approach to CWS Combustion 


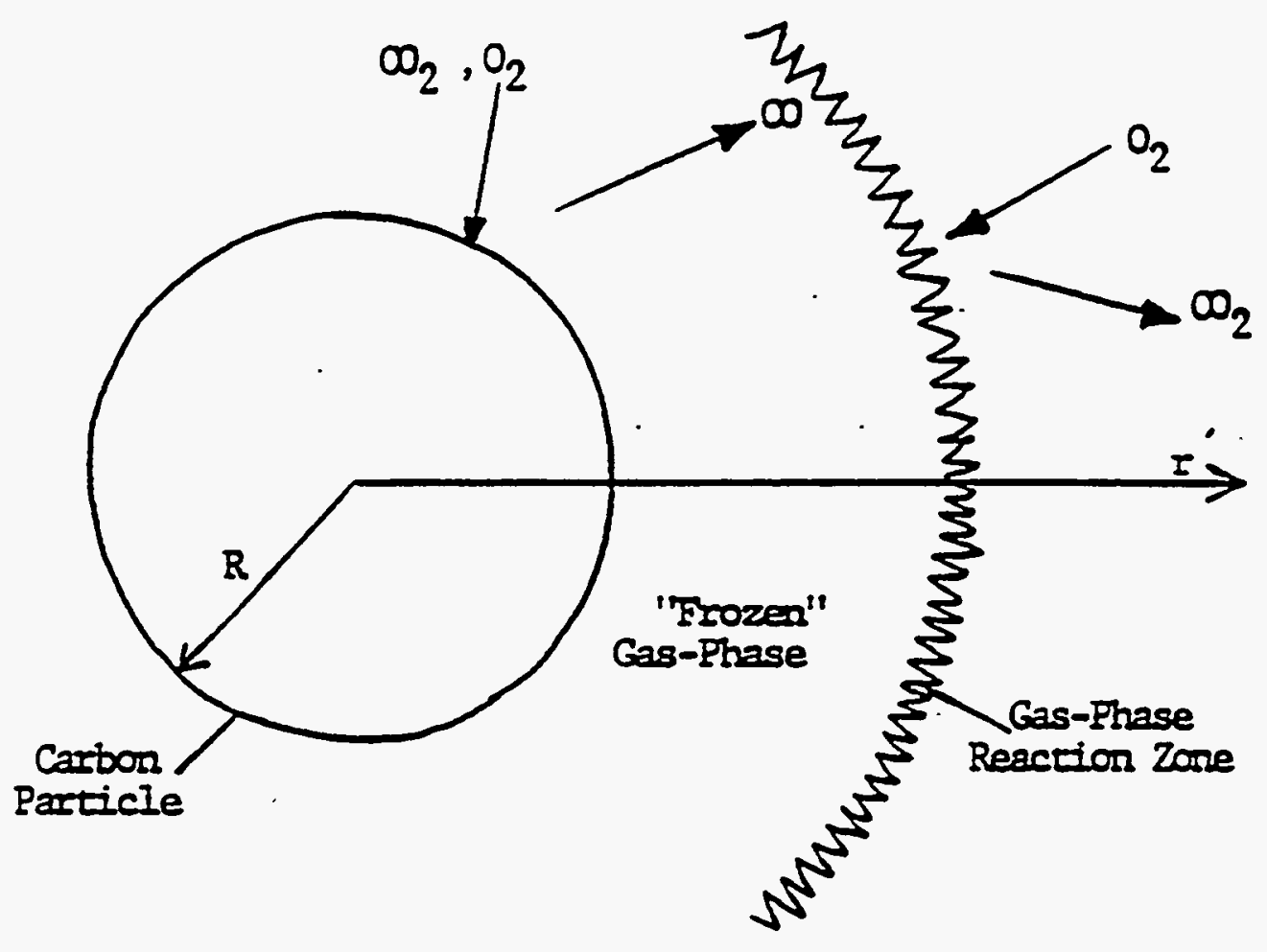

Figure 23. Schematic of the Solid Particle Combustion Model

The effects of engine parameters such as engine speed, injection timing and injection duration and the effect of fuel particle size on engine performance were predicted using the engine model. For example, Figure 24 shows predicted maximum indicated thermal efficiency (MITE), injection timing, and the unburned fuel mass fraction as functions of the initial particle diameter for an engine operating at $800 \mathrm{rpm}$.

To obtain the predicted maximum thermal efficiency for each particle diameter, the injection timing was advanced using the engine model as the diameter increased. As shown, the predicted maximum thermal efficiency decreased and the unburned fuel mass increased as the assumed initial particle diameter increased. For this case, the maximum particle diameter that still predicted maximum thermal efficiency was predicted to be about 20 microns. For an engine operated at $1500 \mathrm{rpm}$, particle sizes equal to or less than about 15 microns provided maximum performance, according to the predictions. The combustion process (and, therefore, engine performance) was primarily limited by diffusion rates, according to the assumptions used. Initial and final reaction rates were, however, limited by the heterogeneous chemical kinetic rates. A submodel for external (pilot) ignition was required due to the initially low reaction rates (for the non-volatile fuel) and short available times. 


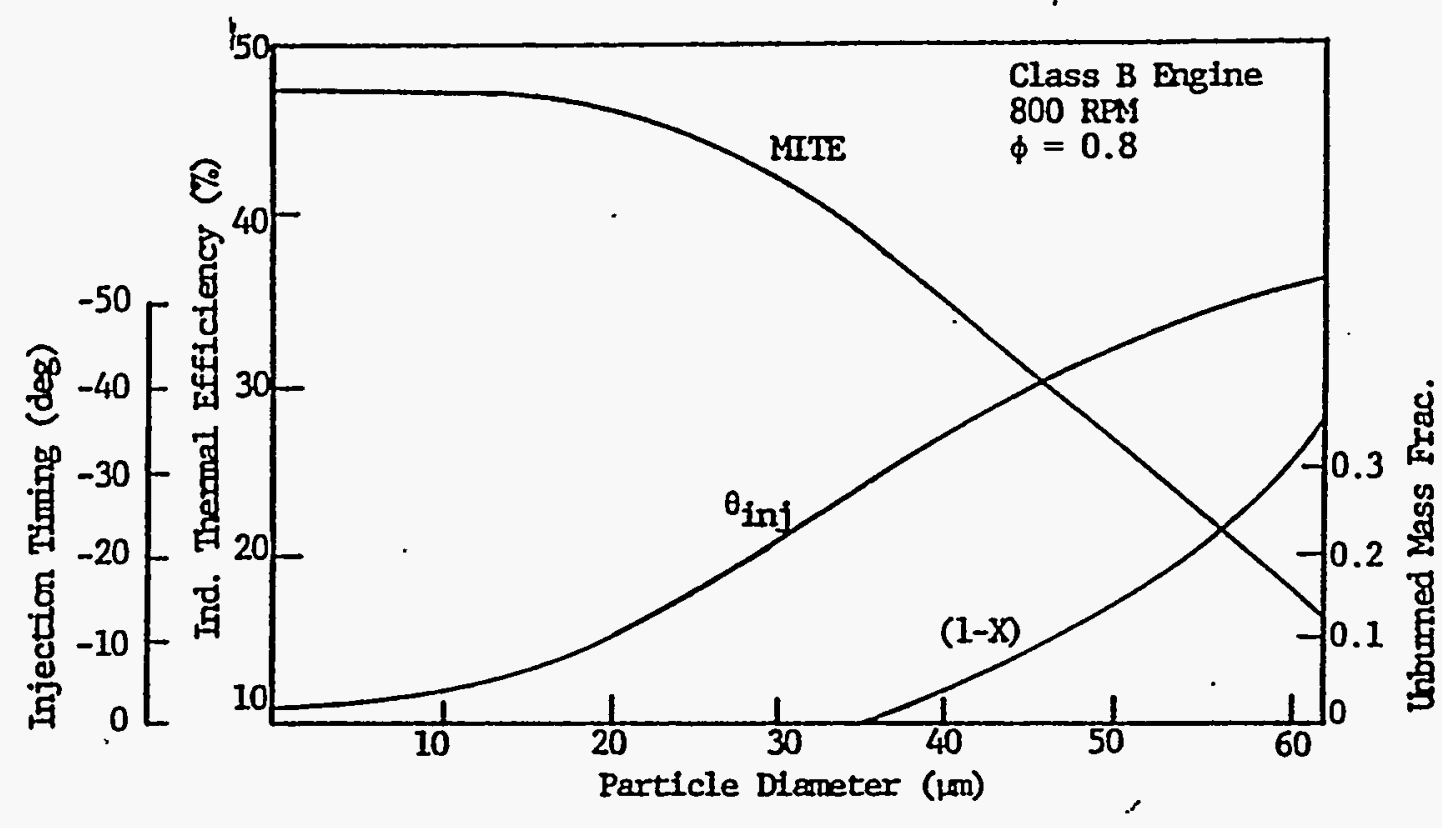

Figure 24. Effect of Particle Size on Thermal Efficiency, Injection Timing, and Unburned Fuel mass Fraction for the Class B Engine

Using the engine cycle simulation described above, Caton $^{(58)}$ reported on the predicted combustion characteristics and overall engine performance of four engines operating on dry, non-volatile coal particles. Four different engine sizes were selected to span the range from low-speed $(100 \mathrm{rpm})$ to high-speed $(1500 \mathrm{rpm})$. For the cases examined, it was predicted that autoignition of the particles did not occur, and a "pilot" fuel of about $10 \%$ of the overall fuel energy was predicted to be needed to insure stable and consistent ignition. After ignition, the particle combustion rates were predominately diffusion limited. Engine thermal efficiency was predicted to be sensitive to engine speed. It was predicted that the high-speed engine operating with 20 microns coal would suffer a 14\% reduction in thermal efficiency as the speed was increased from 1500 to $3000 \mathrm{rpm}$. According to the model, at high speeds, insufficient time is available for complete combustion of the particle fuel.

Bell and Caton ${ }^{(88)}$ added the consideration of volatiles and volatile evolution from the coal particles. Four devolatilization rate expressions for bituminous coal were selected from the literature for use in this study. The coal was modeled as spherical particles composed of a specified fraction of char and volatiles. The volatiles were assumed to jet away from the particle and burn in the gas phase where instantaneous mixing with air was assumed.

The evolution of volatiles from the coal was found to have a significant impact on the ignition and combustion processes in the engine. Figure 25 shows indicated thermal efficiency as a function of the initial (at BDC) gas temperature for four different devolatilization rates and for no devolatilization for a typical locomotive type engine. With rapid devolatilization of the coal, no external energy source was necessary to ignite and completely burn the fuel for an 
initial gas temperature of $450 \mathrm{~K}$ at $\mathrm{BDC}$ (bottom dead center). In contrast, for no volatile evolution, an initial gas temperature of $600 \mathrm{~K}$ was needed to achieve maximum engine performance.

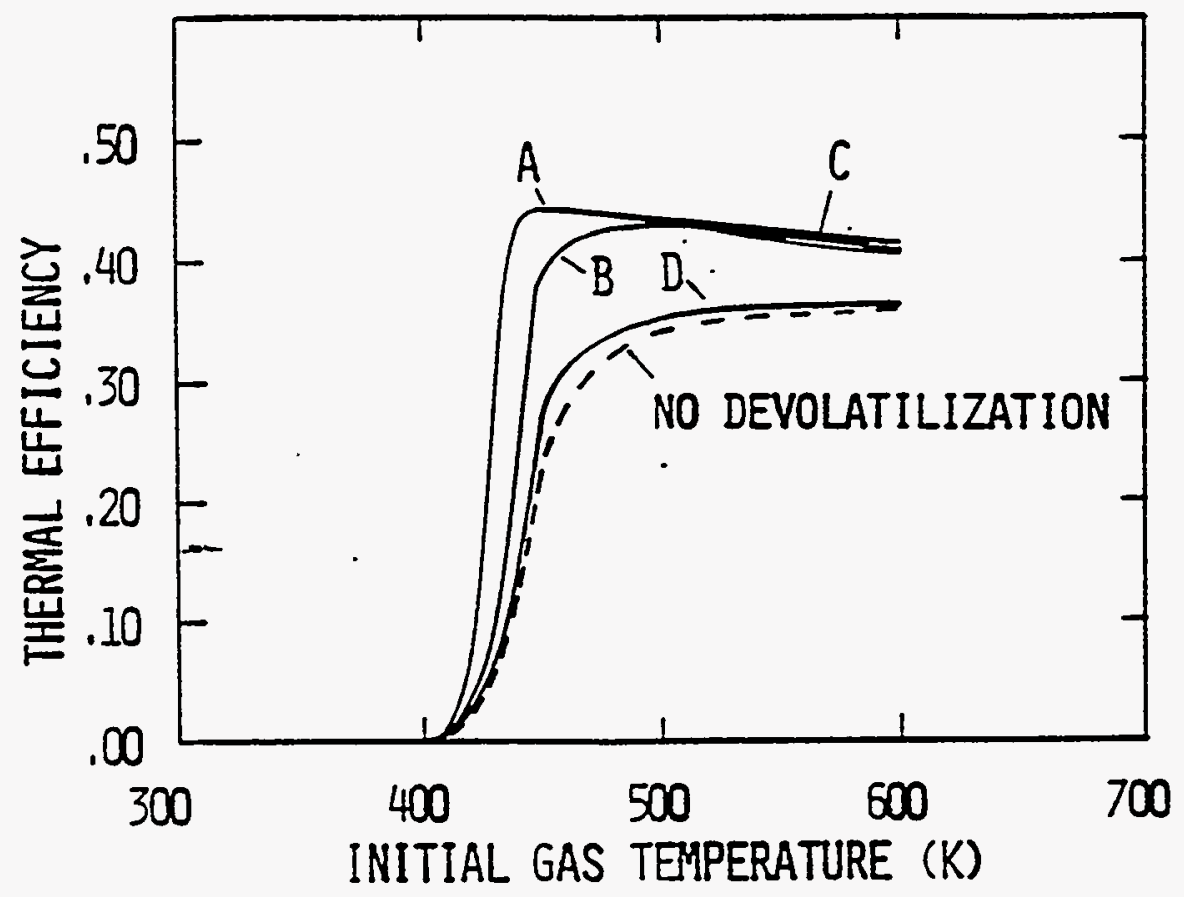

Figure 25. Indicated thermal Efficiency Computed as a Function of the Gas Temperature at BDC

The previous cycle simulations were based only on dry particle fuel. Engine cycle simulations developed for coal slurry fuels were first described by Bell and Caton ${ }^{89,90,91,92)}$. They incorporated liquid droplet evaporation and vaporized fuel combustion. Two submodels for the atomization process were developed and used. The first model assumed separate spherical particles and droplets, and the second assumed concentric droplets around spherical particles. They compared the predicted performance of an engine operating on dry coal particles, dry char particles, coal-water slurries, coal-methanol slurries, coal-diesel slurries, and diesel fuel. Figure 26 shows the predicted indicated thermal efficiency as a function of the initial (at BDC) gas temperature for five different coal fuels for a typical locomotive type engine. The fuels examined were a coal-water mixture (CWM), a dry char, a dry coal (including volatiles), a coal-methanol mixture (CMM), and a coal-oil mixture (COM).

Depending on the fuel, the predicted maximum thermal efficiency under these assumptions ranged from 39 to $49 \%$. The initial (at BDC) cylinder gas temperature necessary to achieve the maximum efficiency for each fuel was dependent on the fuel formulation. For example, for the coal-diesel mixture maximum efficiency was obtained for an initial gas temperature of about $370 \mathrm{~K}$, whereas for the coal-water mixture the maximum efficiency was obtained for an initial gas temperature of about $575 \mathrm{~K}$. This latter, higher temperature was required to provide for the water vaporization and to heat the coal particles to their self-ignition temperature. 


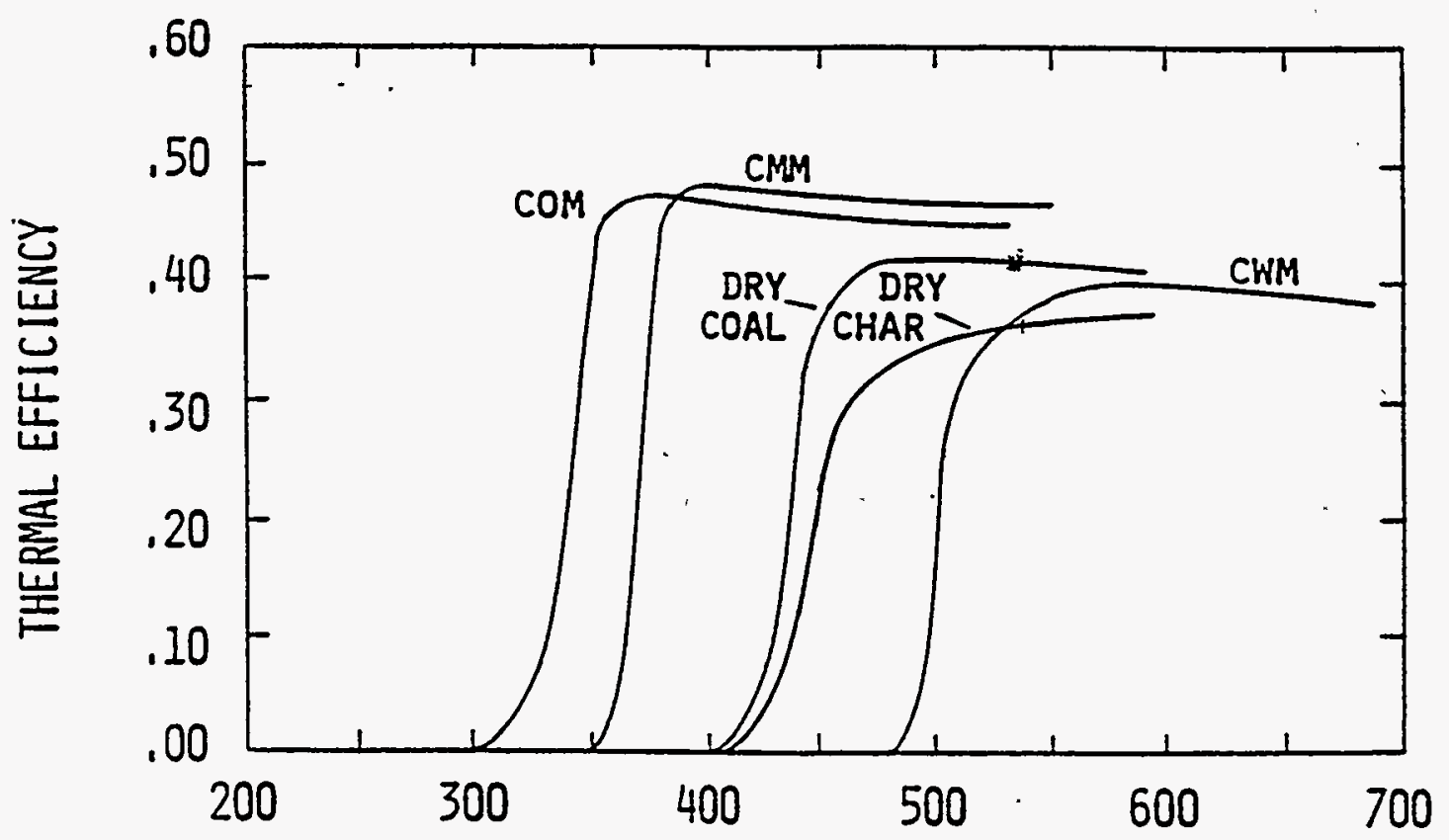

INITIAL GAS TEMPERATURE (K)

Figure 26. Indicated Thermal Efficiency Computed as a Function of the Gas Temperature at BDC for Different Fuels

The previous cycle simulations were based on the simplification that the fuel and air were instantaneously and uniformly mixed in the cylinder to form a homogeneous one-zone region. Several papers were published in 1985 and 1986 that reported the addition of multiple zones in the cylinder to account for fuel stratification and air entrainment into the fuel zones for coal fueled engines. ${ }^{(91,93,94)}$ The intent of these simulations was to include fuel-air stratification in a realistic yet simple manner. This was accomplished by dividing the fuel requirements into a number of packets as the fuel was injected. Each packet is identified by the time of entry into the cylinder and by classification (rich to lean). Once injected, air from the "unburned zone" is entrained into each of the packets or "burning zones," thus allowing fuel-air stratification across the cylinder. The entrained mass is specified by an original entrainment function that is a key feature of the model. ${ }^{(95)}$ This cycle simulation was used to explore the operation of a locomotive engine using coal-water slurry fuels. One of these studies ${ }^{(96)}$ provided results as a function of inlet conditions, particle sizes, fuel additives, and coal properties. As an example, these results included the effect of particle size on ignition and combustion. As the monosize particles were reduced from 30 to 5 microns, the initial gas temperature required for peak efficiency decreased from 530 to $400 \mathrm{~K}$.

This cycle simulation was used in a series of more exhaustive investigations of the ignition and combustion characteristics of coal-water slurry fuels in a locomotive engine. ${ }^{(92,96,97,98)}$ These investigations included comparisons to experimental data for diesel fuel at two engine load conditions. The investigators then used the simulation to examine the details of the ignition and combustion of coal-water slurry fuel in this engine. They reported cylinder pressures, overall heat release rates, droplet and particle diameters, local gas temperatures, particle temperatures, and reaction rates as a function of crank angle for several cases. 
The above work was directed largely toward four-stroke cycle diesel engines using coal fuels. Cycle simulations for two-stroke cycle, coal fueled engines were reported in 1985 and 1986. Kishan and Caton ${ }^{(99)}$ described the results for a medium speed two-stoke cycle, locomotive engine. This study included a detailed scavenging model and considered dry coal particles with no volatiles. The predicted performance results for DF2 were compared to measured diesel fuel operation data to validate the simulation. The potential for a two-stroke cycle locomotive engine to use coal fuel appeared to be favorable. For an initial air temperature of $400 \mathrm{~K}$ and 15 micron monosized particles, the simulation yielded an indicated engine thermal efficiency of $45 \%$.

The above model was improved to include devolatilization and fuel air mixing, and was extended to include a large, low-speed $(120 \mathrm{rpm})$ two-stroke engine ${ }^{(100-102)}$. The simulation results were first compared to experimental data from a large, slow-speed engine using a coal-water slurry fuel. Complete validation of the simulation was not possible due to the lack of detailed experimental data, but comparisons are presented which indicated general agreement between measured and computed values. The simulation was then used to predict the performance of an engine representative of two-stroke cycle locomotive engines.

A study was published by Caton et al. ${ }^{(103)}$ which examined the autoignition of coal-water fuels for engine conditions. They developed a numerical simulation of the ignition and combustion processes of coal-water slurries for engine conditions. ${ }^{(104)}$ Since actual engine data was not available, the authors compared their numerical predictions with data from a constant volume vessel (Leonard and Fiske ${ }^{(60)}$ ). This study provided quantitative information on the overall ignition delays, heterogeneous chemical kinetics, combustion rates, and burn-out characteristics. The use of the heterogeneous chemical kinetics recommended by Smith ${ }^{(105)}$ for coal chars provided good agreement between the computed and measured pressures in the vessel.

Caton et al. ${ }^{(106)}$ expanded their existing cycle simulations to include the calculations of nitric oxide emissions from coal fueled engines. The calculations of the nitric oxide formation and reduction reactions were based on the Zel'dovich ${ }^{(107)}$ mechanism. The computed exhaust nitric oxide concentrations for both diesel and coal-water slurry fuels were in fair agreement with available, limited experimental values from the literature for a locomotive engine (Schmidt ${ }^{(108)}$ ). The exhaust nitric oxide concentrations were lower for the coal-water slurry fuels than for the diesel fuels. These lower concentrations were attributed to the lower gas temperatures due to (1) the water vaporization, and (2) the leaner local mixtures due to the longer ignition delays. In addition, the nitric oxide concentrations for the coal slurry fuels were a strong function of the coal/water mass ratio for the conditions examined. Also, preliminary estimates were completed which suggested the importance of the fuel nitrogen in producing nitric oxide for the coal-water slurry fuels.

In this time period, additional investigators published work on results from cycle simulations. Bell and Choi ${ }^{(109,110)}$ reported on a modified version of the above simulation that was used to explore alternative droplet models and to examine the importance of the carbon-water surface reaction. They reported that including the carbon-water surface reaction did not significantly affect the predicted ignition, combustion, or engine performance. 
Khandare et al. ${ }^{(111)}$ reported on the development and use of a cycle simulation for a coal-dust diesel engine. They assumed that coal particles were inducted into the engine cylinder through the intake manifold. They considered dry, volatile coal particles as the fuel for a pre-chamber diesel engine operating between 400 and $1000 \mathrm{rpm}$. They found that at an engine speed of $550 \mathrm{rpm}$ particles with diameters greater than 75 microns would not significantly burn.

Bell and Choi ${ }^{(112)}$ continued their earlier work on evaluations of fuel atomization for a coal-fueled engine. They examined four different models including secondary atomization for the particles and liquid in an atomized coal-water slurry for a locomotive engine operating at $1050 \mathrm{rpm}$. They concluded that the peak thermal efficiencies were similar for all atomization models, but that the ignition process can be significantly affected by the model.

Modeling studies at Morgantown Energy Technology Center supported engine testing as well as providing assessments on engine performance, emissions, and economic incentives of diesel systems fired with coal-derived fuels $\left(S t o n e^{(113)}\right)$. The primary diesel engine modeling tool was the model developed at Texas A\&M University by Caton and coworkers (see above) for the Morgantown Energy Technology Center. Also, special simulations for gaseous fuels were provided ${ }^{(103)}$ and used. Because diesel engines are part of total systems, the diesel engine modeling work was integrated with modeling of other system units (e.g., gasification, sulfur removal, and heat recovery). The major motivation of this work was to provide estimates of engine performance and assessments of the overall economics when operating with alternative coal fuels.

\section{Engine Modeling Activities 1987-1993}

Several studies were reported between 1987 and 1989 on the development and use of advanced cycle simulations for coal fueled diesel engines. ${ }^{(106,114)}$ Although previous engine cycle simulations provided much needed insight and understanding of the ignition and combustion processes of coal-fueled engines, several important features were lacking in these simulations. For example, the earlier simulations used single, isolated droplet and particle theories for the vaporization and combustion processes. Also, the previous simulations used simple cylinder heat transfer models and provided no estimate of pollutant emissions. Some of the advanced features that were included in this work were (1) a non-steady group evaporation and combustion model for coal slurries, (2) detailed heat transfer and pollutant models, and (3) low heat rejection engine models.

A major component of the above advanced cycle simulations were the group evaporation and combustion models. These group models are rigorous formulations which account for droplet and particle interactions. ${ }^{(114-116)}$ The detailed heat transfer models included fundamental analysis for each engine component (e.g., cylinder head, valve faces, cylinder walls, and piston top) which coupled the gas-to-surface convective heat transfer to the conduction heat transfer through the solid component. Pollutant formation models were developed for nitric oxide, carbon monoxide, and particulates.

The detailed multiple-zoned cylinder heat transfer model was developed using seven zones. $^{(106,117)}$ The geometry, material properties, and coolant conditions could be specified 
independently for each zone. By using a non-steady, one-dimensional, finite-difference analysis of each zone, the model predicts spatial and temporal variations of cylinder wall temperatures. A locomotive engine was examined with this simulation for both diesel and coal-water slurry operation. Good agreement was obtained between the computed and measured cylinder gas temperatures for both diesel and coal-water slurry fuel operation.

The cycle simulation then was used to examine low-heat-rejection engine concepts for coal fueled engines. Five different insulation configurations were examined. Figure 27 shows the indicated thermal efficiency for two cases examined (the base case and a super insulated case) as a function of the initial particle diameter. As shown, one of the findings of this study was that the use of cylinder insulation could allow the use of larger diameter particles compared to no insulation. For the conditions examined, the super insulated case not only provided higher efficiency for any particle diameter, but also was less sensitive to increases in the particle diameter.

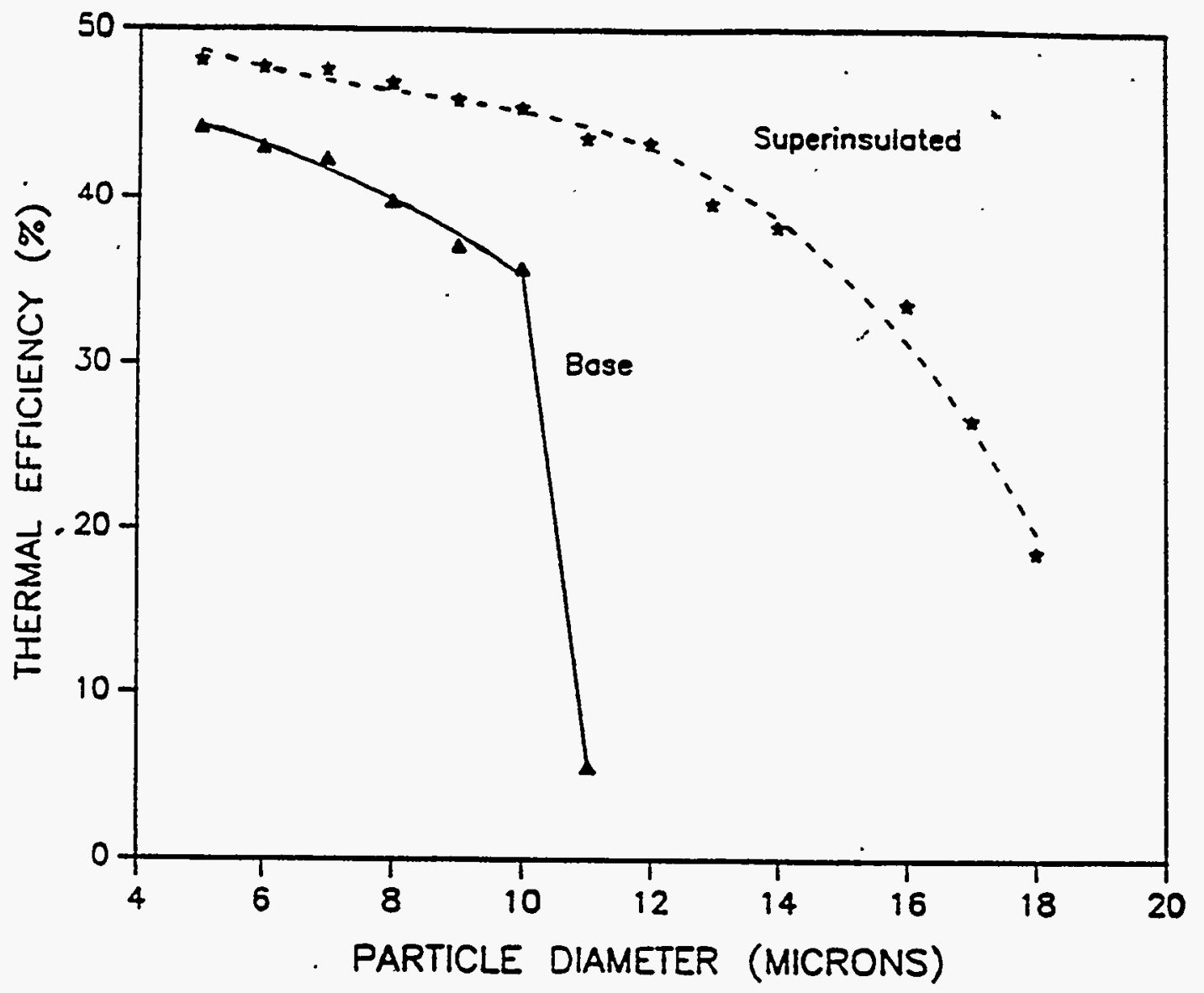

Figure 27. Calculated Indicated Thermal Efficiency Versus Particle Size for Insulated Engines

Several papers were published on the development and use of an advanced cycle simulation that included particle and droplet interactions, i.e., group effects. ${ }^{(118-121)}$ Two major effects were studied: (1) the effect of droplets and particles on the local species concentrations and temperatures, and (2) the effect of exiting carbon monoxide, volatiles and water vapor that block the incoming entrained air. The first effect was found to change the detailed process characteristics and in-cylinder conditions, and moderately affected the overall engine 
performance for the cases studied. The second effect did not significantly affect the in-cylinder processes or the overall performance of the engine for the cases studied.

Wahiduzzaman et al. ${ }^{(13)}$ reported on a comprehensive cycle simulation for a pilot-ignited, coal-water slurry fueled locomotive engine. New and enhanced features of this simulation included a fuel jet development, entrainment and mixing submodel, and a separate submodel of diesel pilot fuel combustion. The combustion model is integrated with an advanced engine design analysis code. The completed simulation was used to explore the effects of fuel characteristics, fuel injection parameters and engine design. variables on engine performance. In addition, the simulation was used to assess the effect of component design modifications on the overall efficiency of the engine and on the degree of coal burn-out.

Preliminary validation of the simulation was reported with limited data, and the comparison of measured and predicted cylinder pressure was good. The simulation was used to explore the relative effects of the injection timings of the coal-water slurry and the diesel pilot fuels. Pilot fuel energy amounts greater than $10 \%$ had little or no effect on improving burn-out, but less than $10 \%$ resulted in decreasing burn-out.

Wahiduzzaman, et al. ${ }^{(14)}$ reported on more complete results using a modified version of the above engine cycle simulation. The most significant modification was a more complete pilot fuel capability. A careful validation of the cycle simulation was completed using nine sets of experimental data for operation with coal-water slurry and diesel pilot fuels. The computed and measured integrated quantities, such as indicated power, were within $7 \%$ of each other. The simulation then was used to complete a parametric study. The parameters that were examined included coal-water slurry and pilot fuel injection timings, fuel temperature, coal-water slurry and pilot fuel properties, injection profiles, plenum pressures and temperatures, valve timings, in-cylinder insulation, and intake swirl. Simulations were completed to generate maps of fuel consumption rates and peak cylinder pressures for each notch (speed and load setting). These maps allow the selection of the best combination of coal-water slurry and pilot fuel injection timing under the constraint of maximum firing pressure. In addition, the simulation was used to explore different operating strategies and the use of in-cylinder insulation and swirl.

Bunker ${ }^{(122)}$, using the above simulation completed some additional computations on the ignition and combustion characteristics of coal-water slurry fuel in a locomotive engine. These computations concentrated on engine operation without pilot to better sort out the effect of the coal fuels. Figure 28 shows the indicated and brake thermal efficiency for to inlet air temperatures ( 350 and $400 \mathrm{~K}$ ) as a function of the initial droplet diameter (lower scale). The corresponding initial diameter of the coal particle agglomerate is shown on the top scale. As shown, as the initial droplet and particle diameter increases efficiency decreases. For the higher inlet air temperature, maximum efficiency is achieved with 20 microns or smaller diameter droplets. 


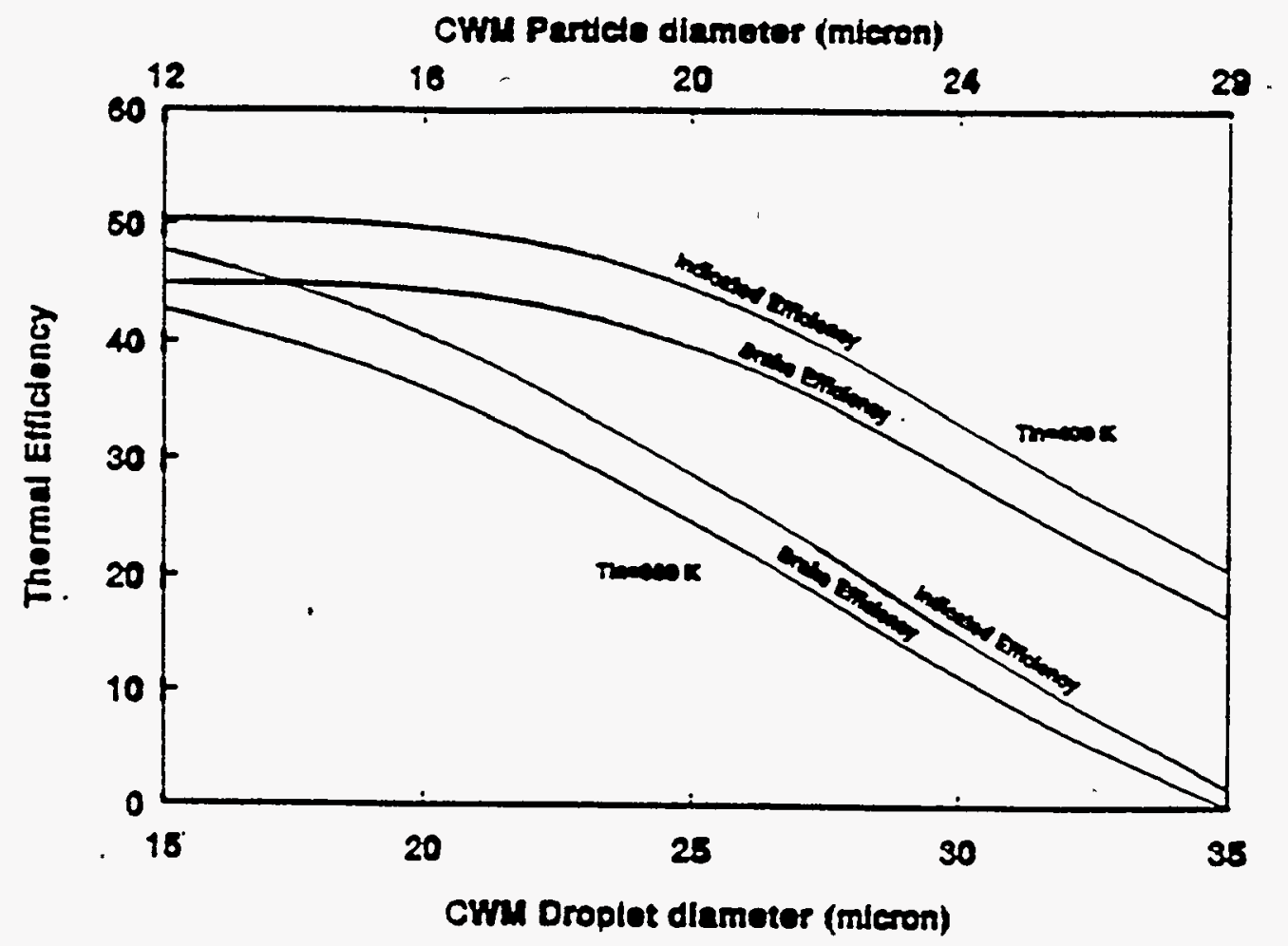

Figure 28. Computed Indicated and Brake thermal Efficiency Versus CWS Drop Size

In this category of advanced models, an initial effort was reported by Gentry ${ }^{(123)}$ and Gentry et al. ${ }^{(124)}$ on the development of a complete multidimensional simulation for coal fuels. This work involved the modification of KIVA (a code for conventional fuels) to include the capability of using coal fuels. The simulation calculated the detailed in-cylinder gas dynamics, spray motion, turbulence parameters, slurry evaporation, devolatilization of the coal particles, char combustion, chemical reactions with heat release, and radiative transfer. They used the simulation to solve one sample problem that was the ignition and combustion of a coal-water slurry in a closed vessel as reported by Leonard and Fiske ${ }^{(60)}$. They reported that the results of the simulation underpredicted vaporization and that the next step in the simulation development should be the improvement of the submodels (including vaporization and devolatilization) and their interaction.

\section{Engine Modeling Summary}

With respect to the technology of coal fueled diesel engines, past activities have included the use of analytical modeling, and the development and use of engine cycle simulations. Prior to 1981, only a few analytical studies were reported on the ignition and combustion of coal particles in engine environments, and no engine cycle simulations were reported. These analytical studies estimated coal particle burn-out times, and compared these times with the available times in an engine at different engine speeds. In general, these studies suggested that for a $1000 \mathrm{rpm}$ engine speed, coal particle diameters would have to be of order 30 microns or less to completely burn within 60 crank angle degrees. 
Beginning in 1982, reports were available on the first detailed engine cycle simulations for coal-fueled, reciprocating engines. These early simulations were developed to examine dry, non-volatile coal particles and were based on a one-zone treatment. Through the 1980s, this simulation continually was improved and enhanced. By the late 1980s, the simulation included capabilities to consider a variety of volatile coals mixed with liquids with combustion occurring in multiple zones each at different mixture strengths.

In 1987, the first of a series of advanced cycle simulations were described. These advanced simulations included group vaporization and combustion effects to account for droplet and particle interactions, detailed heat transfer, and submodels that permitted the computation of emissions. Comprehensive cycle simulations were introduced in 1990 that augmented the above features and provided capabilities for detail design and evaluation for pilot-ignited, coal-water slurry fueled engines. One study reported on the development of a dimensional simulation that included detail treatments of spray development and turbulence.

From the initial elementary beginnings, cycle simulations for coal-fueled engines have evolved into a powerful and comprehensive tool for both diagnostic and design operations. For future coal-fueled engine research and development programs, the parallel use of these cycle simulations with engine development should be most valuable and cost effective. The preferred simulation codes are those developed in the 1987-1993 timeframe described above. 


\section{CWS ENGINE STATUS - 1994}

The use of coal-water-slurry in medium speed diesel engines has been demonstrated to be technically feasible. This conclusion is based upon the use of well formulated coal-water slurries (CWS) in the range of 45-50 weight percent coal loading, using bituminous and subbituminous coals ground to 5-12 micron mean size particles, with a top size limit of 85 microns, and sulfur and ash contents in the range of 1 percent each by mass in the slurry (2\% ash on dry coal basis). Higher ash contents may be usable in the engines, but the technology for coal cleaning has advanced to the point where 2 percent ash (dry coal basis) is reasonable for many bituminous coals. Several hundred hours of engine operation have been achieved in the GE program and over 1100 hours of testing was done in the Cooper/Arthur D. Little program.

When the price differential between natural gas and raw coal increases to about $\$ 2.50$ to $\$ 3 /$ million Btu, the economic factors will appear favorable for use of CWS-diesels after accounting for the system capital costs, fuel, emissions control, parts replacement, and operating costs. It appears that the proven level of exhaust aftertreatment based on test data is adequate to meet current and future emission standards.

The current state of the technology is such that the engine designs can be very well defined for engines that operate in the speed range below $1000 \mathrm{rpm}$ (e.g., GE and Cooper-Bessemer engines). For these engines, the next step is extended engine run times to demonstrate that hard component replacement rates are acceptable. The design details for higher speed engines are not as well defined because the operating experience in these engines is less extensive. The purpose of this section is to outline the details of the current understanding of CWS engines and by doing so, to clearly define the starting point when the fuel economics become more favorable.

\section{Fuel Specification for Coal Slurry}

The coal slurry fuel specification is somewhat dependent on the engine speed, in that the operating experience indicates that the slower $400 \mathrm{rpm}$ engines are much less sensitive to fuel factors than the $1000 \mathrm{rpm}$ engine. The fuel specification in Table 7, therefore, represents an attempt to satisfy the requirements of the $1000 \mathrm{rpm}$ engines, realizing that the fuel will be marginally better than required for operation of the slower engines.

Table 7. CWS Fuel Specification

\begin{tabular}{|l|l|}
\hline Coal & Bituminous \\
\hline Mean Coal Size & $5-12$ Microns \\
\hline Top Particles Size & $15-85$ Microns \\
\hline Ash Content & 1 Percent by Mass (2 percent dry coal) \\
\hline Sulfur & 1 Percent by Mass (2 percent dry coal) \\
\hline Viscosity & 300 Centipoise @ $1000^{-1}$ sec \\
\hline Additive & Dispersant \\
\hline
\end{tabular}




\section{Fuel System Design for Coal Slurry}

Details of the coal slurry fuel system design can be obtained above, or form the cited references. The following are the salient points that are common to all designs and should be considered as the starting point for future work in this area:

Slurry Piping - Smooth pipe, no dead volumes, no rapid changes in flow area

Tank - Continuously recirculating, horizontal-cylindrical tank equipped with a floating suction, and discharge through a manifold with exit holes designed to produce flow with $\mathrm{R}_{\mathrm{e}} \mathrm{xH}=5.7$

Injection Pump - Convention diesel injection pump sized to inject the required amount of slurry to achieve full load and coupled to the engine, supplying diesel fuel pressure pulses to a shuttle piston assembly.

Shuttle Piston Assembly - Convention injection pump barrel and plunger assembly design parameters of surface finish and clearances, titanium nitride coated, sized to displace 150 percent of the required full load slurry flow, and with an L/D of approximately 1 .

Nozzle Holes - Sapphire or diamond compact inserts

Needle Valve Seat - Tungsten Carbide seat insert

Needle Valve and Barrel - Tungsten carbide plasma coated steel

\section{Engine Design for Coal Slurry Fuel}

The results of the METC Program indicate that conventional open chamber, direct injection, low swirl combustion chambers are acceptable for operation on CWS fuels. Combustion efficiencies of 99 percent or higher were routinely demonstrated in these designs, provided the intake air temperature is raised to $135-180^{\circ} \mathrm{C}$. The bowl shape can be either a shallow "Mexican Hat" design, as used in the GE and Detroit Diesel/SwRI projects, or a shallow bowl as used in the Cooper engine.

It is clear that turbocharging is required to achieve acceptable engine efficiency and breathing characteristics, especially with the higher intake air temperatures required for operation on CWS. The intake air temperature should be at least $135^{\circ} \mathrm{C}$ and the pressure should be in the range of $300 \mathrm{kPa}$. While autoignition of coal was demonstrated in the GE, the Cooper, Adiabatics, and the Detroit Diesel engines, positive and repeatable ignition timing control with a pilot is essential for reliable and efficient operation of these a CWS engine. Pilot injection of small quantities of diesel fuel (2-5\% of total fuel energy) appears to be the best method of ignition control. It offers the opportunity for cold starting and operation at the part load conditions, especially idle, where the demonstrated experience on CWS indicates that the engine temperatures drop below the levels required for reliable operation on CWS. 
The rings and liner should be tungsten carbide coated and the lubricant should contain high concentrations of dispersant additive to prevent excessive wear of these components. It appears that filtration of the lube oil using the best available filter technology (pleated paper filter with 5 micron pore size) is sufficient to control wear rates in the rest of the engine. 


\section{REFERENCES}

1. Soehngen, E.E., "Development of Coal-Burning Diesel Engines in Germany," Final Report Prepared for the Energy Research and Development Administration/Office of Fossil Energy, Report No. FE/WAPO/3387-1, August 1976.

2. Tracy, E.W. Jr., "Feasibility Study of the Use of Powdered Coal as a Fuel for Diesel Engines," SwRI Report No. 8-681-1, Southwest Research Institute, November 1957.

3. Marshall, H.P. and C. Shelton, "The Coal Burning Piston Engine," Bulletin of the Virginia Polychemical Institute, Engineering Experimental Station, No. 135, Vol. 53, 1959.

4. Rich, L.L. and M.L. Waker, "Pulverized Coal Burning Diesel Engine," Howard University, Office of the Coal Research, R\&D Report No. 46, USGPO, Washington, DC, 1969.

5. Caton, J.A. and K.H. Rosegay, "A Review and Comparison of Reciprocating Engine Operation Using Solid Fuels," SAE Technical Paper No. 831362, SAE Transactions, Vol. 92, pp. 1108-1124, 1984.

6. Marshall, H.P. and D.C. Walters, Jr., "An Experimental Investigation of a Coal-Slurry Fueled Diesel Engine," SAE Technical Paper No. 770795, 1977.

7. Nydick, S.E., F. Porchet, and H.A. Steiger, "Continued Development of a Coal/Water Slurry-Fired Slow-Speed Diesel Engine: A Review of Recent Test Results," ASME Technical Paper No. 87-ICE-10, also in the Journal of Engineering for Gas Turbines and Power, Vol. 109, pp. 465-476, 1987.

8. Ryan, T.W. III, W.E. Likos, and C.A. Moses, "The Use of Hybrid Fuels in a SingleCylinder Diesel Engine," SAE Technical Paper No. 801380, 1980.

9. Ryan, T.W. III, T.J. Callahan, L.G. Dodge, and C.A. Moses, "Injection, Atomization, and Combustion of Carbon Slurry Fuels," SAE Technical Paper No. 821199, 1983.

10. Ryan, T.W. III and L.G. Dodge, "Diesel Engine Injection and Combustion of Slurries of Coal, Charcoal, and Coke in Diesel Fuel," SAE Technical Paper No. 840119, 1984.

11. Ryan, T.W. II and L.G. Dodge, "Development of Carbon Slurry Fuels for Transportation (Hybrid Fuels - Phase II)," Prepared for National Aeronautics and Space Administration, Lewis Research Center Under Contract DEN3-263 for U.S. Department of Energy Report No. DOE/NASA/0263-1, May 1984. 
12. Caton, J.A. and K.H. Rosegay, "Cycle Simulation of Coal Particle Fueled Reciprocating Internal Combustion Engines," SAE International Off-Highway Meeting, Milwaukee, Wisconsin, September 1983.

13. Wahiduzzaman, S., P.N. Blumberg, R. Keribar, and C.I. Rackmil, "A Comprehensive Model for Pilot-Ignited Coal/Water Mixture Combustion in a Direct-Injection Diesel Engine," ASME ICE-Vol. 12, also in the ASME Transactions, Journal of Engineering for Gas Turbines and Power, Vol. 112, No. 3, pp. 384-390, 1990.

14. Wahiduzzaman, S., P.N. Blumberg, and B.D. Hsu, "Simulation of Significant Design and Operating Characteristics of a Coal Fueled Locomotive Diesel Engine," ASME ICE Vol. 14, Coal Fueled Diesel Engines, 1991.

15. Kakwani, R. and R. Kamo, "Extending and Enhancing the Scientific Base for Advanced Coal-Fueled Power Systems Utilizing Heat Engines," Contract No. DE-AC21-86MC23258, Proceedings of the Annual Coal Fuel Heat Engines and Gas Stream Cleanup Systems Contractors Review Meeting, DOE/METC-88/6094 (DE88001088), pp. 396-408, June 1988.

16. Schwalb, J.A., T.W. Ryan, III, R.M. Kakwani, and R.E. Winsor, "Study of Coal-WaterSlurry Fuel Combustion in a High-Speed Diesel Engine: Part 2, Bench Test Results," ASME Presentation at the Energy-Sources Technology Conference and Exhibition, Houston, Texas, 1993.

17. Greenhalgh, M.L., "High-Pressure Coal Fuel Processor/Engine Development," ASME ICEVol. 14, Coal-Fueled Diesel Engines, pp. 49-55, 1991.

18. Urban, C.M., H.E. Mecredy, T.W. Ryan III, M.N. Ingalls, and B.T. Jett, "Coal-Water Slurry Operation in an EMD Diesel Engine," ASME Technical Paper No. 88-ICE-28, also in the Journal of Engineering for Gas Turbines and Power, Vol. 110, pp. 437-443, 1988.

19. Hsu, B.D. and G.L. Confer, "Progress on the Investigation of Coal-Water-Slurry Fuel Combustion in a Medium Speed Diesel Engine: Part 4 - Fuels Effect," ASME ICE-Vol. 14, Coal-Fueled Diesel Engines, pp. 1-8, 1991.

20. Wilson, R.P. Personal Communication with T.W. Ryan III, June 1989.

21. Schwalb, J.A., T.W. Ryan III, R.M. Kakwani, and R.E. Winsor, "Coal-Water-Slurry Autoignition in a High-Speed Diesel Engine," ASME Presentation at University of West Virginia, 1993. 
22. Likos, W.E. and T.W. Ryan, III, "Combustion Characteristics of Coal Fuels in a High Temperature Diesel Engine," ASME Technical Paper No. 87-ICE-56, 1987.

23. Likos, W.E. and T.W. Ryan, III, "Experiments with Coal Fuels in a High Temperature Diesel Engine," ASME Technical Paper No. 88-ICE-29, also in the Journal of Engineering for Gas Turbines and Power, Vol. 112, No. 3, pp. 376-383, 1990.

24. Ryan, T.W. III, T.J. Callahan, H.E. Mecredy, Q.A. Baker, and B.T. Jett, "Coal Slurry Combustion-Bomb and Small Engine Test Results," ASME Technical Paper No. 87-ICE31, 1987.

25. Ryan, T.W., III, T.J. Callahan, J.A. Schwalb, H.E., Mecredy, C.M. Urban, Q.A. Baker, M. Ingallsand E.R. Banick, "Coal Fueled System Research," Final Report, Subcontract to Allison, P.O. No. H524201, U.S. DOE Contract DE-AC21-85MC22123, Submitted June 27, 1989.

26. Leonard, G.L. and G.H. Fiske, "A Comparison of a Positive Displacement Fuel Injection System With an Accumulator-Based System for Coal-Fueled Diesel Engine Applications," ASME Technical Paper No. 87-ICE-32, 1987.

27. Flynn, P.L., B.D. Hsu, and G.L. Leonard, "Coal Fueled Diesel Engine Progress at GE Transportation Systems," ASME ICE-Vol. 12, also in the ASME Transactions, Journal of Engineering for Gas Turbines and Power, Vol. 112, No. 3, pp. 369-375, 1990.

28. Rao, A.K., R.P. Wilson, E.N. Balles, R.A. Mayville, M.H. McMilliam, and J.A. Kimberley, "Cooper-Bessemer Coal-Fueled Engine System -- Progress Report," ASME ICE-Vol. 7, Coal-Fueled Diesel Engines, pp. 9-17, also in the Journal of Engineering for Gas Turbines and Power Vol. 111, pp. 498-506, 1989.

29. Wilson, R. P., E. Balles, K. Benedek, R. Mayville, K. Rao, and J. Kimberely, "Coal Fueled Diesel Systems Research Coal Fueled Diesel Combustion: Cooper-Bessemer Test Results," Contract No. DE-AC21-85MC22182, Proceedings of the Annual Coal Fuel Heat Engines and Gas Stream Cleanup Systems Contractors Review Meeting, DOE/METC88/6094 (DE88001088), pp. 371-382, 1988.

30. Hsu, B.D., G.L. Leonard, and R.N. Johnson, "Progress on the Investigation of Coal Water Slurry Fuel Combustion in a Medium-Speed Diesel Engine, Part 3 Accumulator Injector Performance," ASME Technical Paper ICE-Vol. 7, Coal-Fueled Diesel Engines, pp. 19-25, also in the ASME Transactins Journal of Engineering for Gas Turbine and Power, Vol. 111 , No. 3, pp. 516-520.

31. Flynn, P.L., G.L. Leonard, and R.L. Mehan, "Component Wear in Coal-Fueled Diesel Engine," ASME Technical Paper No. 89-ICE-15, also in the ASME Journal of Engineering for Gas Turbines and Power, Vol. 111, 3, pp. 521-529, 1989. 
32. Kimberley, J.A., Personel Communication with T.W. Ryan III, 1992.

33. Dunlay, J.B., et. al., "Slow Speed Two Stroke Diesel Engine Tests Using Coal Based Fuels," ASME Paper 81-DGP-12, 1981.

34. Nydick, S.E., "Development of a Coal/Water-Slurry-Fueled Diesel Engine For Industrial Cogeneration," Final and Summary Report Under Contract No. AC02-82CE40539, U.S. DOE/Argonne, IL., Thermo Electron Corp. (Waltham, MA), February 1987.

35. Hsu, B.D., "'Progress on the Investigation of Coal Water Slurry Fuel Combustion in a Medium-Speed Diesel Engine Part 2. Preliminary Full Load Test," ASME Technical Paper No. 88-ICE-5, also in the ASME Transactions, Journal of Engineering for Gas Turbines and Power, Vol. 110, No. 3, pp. 423-430, 1988.

36. Mayville, R.A., A.K. Rao, and R.P. Wilson, "Durable Component Development Progress for the Cooper-Bessemer Coal-Fueled Diesel Engine," ASME ICE-Vol. 14, Coal-Fueled Diesel Engines, pp. 23-27, 1989.

37. Mayville, R.A., A.K. Rao, and R.P., Wilson, "Cooper-Bessemer Coal-Fueled Engine System: Recent Developments in Durable Components," ASME ICE-Vol. 12, Coal Fueled Diesel Engines, pp. 17-22, 1990.

38. Schwalb, J.A., L.G. Dodge, T.W. Ryan III, T.J. Callahan, and R.J. Mannheimer, "CoalWater Slurry Fueled Diesel Engine - Injector Atomization and Wear Tests," Final Report for DOE/METC Contract DE-AC2188MC25124, Arthur D. Little Subcontract 61366, SwRI Project 03-2976, April 1991.

39. Flynn, P.L., R.L. Mehan, G.L. Leonard, and R.N. Johnson, "Hardened Materials in CoalFueled Diesels," Contract No. DE-AC21-88MC23174, Proceedings of the Annual Coal Fuel Heat Engines and Gas Stream Cleanup Systems Contractors Review Meeting, DOE/METC-88/6094 (DE88001088), pp. 211-225, March 1988.

40. Wilson, R.P., et al., "Stationary Coal-Fueled Diesel System," Contract No. DE-AC2188MC25124, Proceedings of the Seventh Annual Coal-Fueled Heat Engines and Gas Stream Cleanup Systems Contractors Review Meeting, DOE/METC90/6110(DE90000480), pp. 3-10, March 1990.

41. Clingenpeel, J.M., M.D. Gurney, and D.B. Eccleston, "A Combustion and Wear Analysis of a Compression-Ignition Engine Using Coal Slurry Fuels," ASME Technical Paper 84DGP-8, 1984.

42. Robben, F., "Coal-Fueled Diesel Engines, " SAE International Off-Highway Meeting and Exposition, SAE Technical Paper No. 831747, 1983.

43. Kamo, R., R.M. Kakwani, M.E. Woods, and L.K. Carpenter, "Introduction of Micronized Coal in the Intake Air of a Medium Speed Adiabatic Diesel Engine," ASME Technical Paper No. 86-ICE-19, 1986. 
44. Murdoch, P.L., M. Pourkashanian and A. Williams, "The Mechanism of Combustion of Coal-Water Slurries," Correspondence to Professor A. Williams, The University of Leeds, Leeds, LS2 9JT, U.K.

45. Seibers, D.L. and T. M. Dyer, "The Autoignition and Combustion of Coal-Water Slurry Under Simulated Diesel Engine Conditions," ASME Technical Paper No. 85-DGP-15, 1987.

46. Sakai, T. and M. Saito, "Single Droplet Combustion of Caol Slurry Fuels," Combustion and Flame, Vol. 51, pp. 141-154, 1983.

47. Szekely, G.A., Jr. and G.M. Faeth, "Combustion Properties of Carbon Slurry Drops," AIAA Journal, Vol. 20, No. 3, p. 422.

48. Wells, W.F., S.K. Kramer, L. D. Smoot, and A.U. Blackham, "Reactivity and Combustion of Coal Chars," Departments of Chemical Engineering and Chemistry, Brigham Young University, Provo, Utah.

49. Liu, D.H., A.M. Zghoul, J. Li, B.S., Tan, K.L. Lockwood, and R.H. Essenhigh, "High Intensity Combustion of Coal With Water Injection," Combustion and Flame, Vol. 63, pp. 49-57, 1986.

50. Law, C.K., H.K. Law, and C.H. Lee, "Combustion Characteristics of Droplets of Coal/Oil and Coal/Oil/Water Mixtures," Energy, 4, 329.

51. McHale, E.T., "Coal-Water Fuel Combustion," Twenty-first Symposium (International) on Combustion, The Combustion Institute, 1986

52. Essenhigh, R.H., "Predicted Burning Times of Solid Particles in an Idealized Dust Flame," Journal of the Institute of Fuel, 34, 1961, pp. 239-244.

53. Essenghigh, R.H. and G.C. Yorke, "Reaction Rates of Single Coal Particles: Influence of Swelling, Shape, and Other Factors," Fuel, Vol. 44, pp. 177-185, 1965.

54. Kanury, A.M., Introduction to Combustion Phenomena, Gordon and Breach Science Publishers ,Second Edition, 1977.

55. Rawlins, D.C., G.J. Germane, P.O. Hedman, and L.D. Smoot, "Laboratory-Scale Combustion of Coal-Water Mixtures, Combustion and Flame 63: 59-72, 1986.

56. Holve, D.J., "Comparative Combustion Studies of Ultrafine Coal/Water Slurries and Pulverized Coal," Proceedings of Second Annual Heat Engines Contractors Meeting, METC, pp. 208-240, May 1985.

57. Petela, R., "Combustion of Mono-Fractional Droplets of Coal-Oil Mixtures," Fuel, Vol. 64, May 1985. 
58. Caton, J.A., "Cycle Simulation of a Coal-Particle-Fueled, Reciprocating, Locomotive Engine," ASME Paper No. 84-DGP-19, 1984.

59. Fu, Y.C., G.T. Bellas, T.D. Brown, J.I. Joubert, and G.F. Walbert, "Combustion Tests of Beneficiated and Micronized Coal-Water Fuels," Seventh International Symposium on Coal Slurry Fuel Preparation and Utilization, May 1985.

60. Leonard, G.L. and G.H. Fiske, "Combustion Characteristics of Coal/Water Mixtures in a Simulated Medium-Speed Diesel Engine Environment," ASME Technical Paper No. 86ICE-15, 1986.

61. Nelson, L.P., W.R. Seker, and P.W. Sampson, "The Combustion Characteristics of Slurried Fuels in Diesel Engines: Detailed Measurements and Analysis," Proceedings of the First Annual Heat Engines Contractors Meeting, DOE/METC/84-31 (DE85001953), METC, pp. 225-234, 1984.

62. Gurney, M.D., "Investigation of Diesel Fuel Injection Equipment Response to Coal Slurry Fuels," Proceedings of the First Annual Heat Engines Contractors Meeting, DOE/METC/84-31 (DE85001953), METC, pp. 221-224, 1984.

63. Brehob, D.D. and R.F. Sawyer, "Compression Ignition of Coal Slurry Fuels," ASME Technical Paper No. 87-ICE-11, 1987.

64. Kakwani, R.M., R. Kamo, R.G. Cutlip, and W.C. Smith, "Combustion Characteristics of Dry-Coal-Powder-Fueled Adiabatic Diesel Engine," ASME ICE-Vol. 7, Coal-Fueled Diesel Engines, pp. 27-34, 1989.

65. Kakwani, R.M., P.R. Badgley, and W.C. Smith, "Development of Fuel Injection and Combustion Systems for Coal-Water-Slurry Fueled Diesel Engines," ASME ICE-Vol. 12, Coal-Fueled Diesel Engines, pp. 41-50, 1990.

66. Hsu, B.D., "Progress on the Investigation of Coal Water Slurry Fuel Combustion in a Medium-Speed Diesel Engine: Part 1. Ignition Studies," ASME Technical Paper No. 88ICE-4, also in the ASME Transactions, Journal of Engineering for Gas Turbines and Power, Vol. 110, No. 3, pp. 415-422, 1988.

67. Hsu, B.D. and P.L. Flynn, "Coal Fueled Diesel Engine Technology Development: GE Single-Cylinder Engine Results, " DOE/METC Contractor Review Meeting, Paper No. 3.1, 1989.

68. Hsu, B.D., G.L. Leonard, and R.N. Johnson, "Progress on the Investigation of Coal-WaterSlurry Fuel Combustion in a Medium-Speed Diesel Engine: Part 3 - Accumulator Injector Performance," ASME ICE-Vol. 7, Coal Fueld Diesel Engines, pp. 52-57, also in the ASME Transactions, Journal of Engineering for Gas Turbines and Power, Vol. 111, No. 3, pp. 516-520, 1989.

69. Hsu, B.D, G.L. Confer, and Z.J. Shen, "Progress on the Investigation of Coal Water Slurry 
Fuel Combustion in a Medium Speed Diesel Engine: Part 5 -- Combustion Studies," ASME ICE-Vol 16, Coal Fueled Diesel Engines, also in the ASME Transactions, Journal of Engineering for Gas Turbines and Power, Vol. 114, No. 3, pp. 515-521.

70. Hsu, B.D., "Coal-Fueled Diesel Engine Development Update at GE Transportation Systems," ASME ICE-Vol 16, Coal Fueled Diesel Engines, pp. 1-10, also in the ASME Transactions, Journal of Engineering for Gas Turbines and Power, Vol. 114, No. 3,pp. 502-508, 1992.

71. Hsu, B.D. and D.P. Branyon, "Progress on the Investigation of Coal Water Slurry Fuel Combustion in a Medium Speed Diesel Engine, Part 6 -- In-Cylinder Combustion Photography Studies," ASME ICE-Vol. 19, Coal-Fueled Diesel Engines, pp. 15-23, 1993.

72. Rao, A.K., C.H. Melcher, R.P. Wilson, E.M. Balles, F.S. Schaub, J.A. Kimberley, "Operating Results of the Cooper-Bessemer JS-1 Engine on Coal-Water Slurry," ASME Paper No. 88-ICE-12, also in the ASME Tranactions, Journal of Engineering for Gas Turbines and Power, Vol. 110, pp. 431-436, 1988.

73. Dodge, L.G., T.J. Callahan, T.W. Ryan, III, J.A. Schwalb, C.E. Benson, and R.P. Wilson, "Injection Characteristics of Coal-Water Slurries in Medium-Speed Diesel Equipment," ASME ICE-Vol 16, Coal Fueled Diesel Engines, also in the ASME Transactions, Journal of Engineering for Gas Turbines and Power, Vol. 114, No. 3, pp. 522-527, 1992.

74. Kakwani, R.M., R.E. Winsor, T.W. Ryan III, S. Wahiduzzaman, R.P. Wilson, Jr., "Study for Coal-Water-Slurry Fuel Combustion in a High-Speed Diesel Engine," ASME ICE-Vol 16, Coal-Fueled Diesel Engines, pp. 25-32, 1992.

75. Wilson, R.P., C.E. Benson, T.W. Ryan III, J.A. Schwalb, L.G. Dodge, and T.J. Callahan, "Coal-Water Slurry Spray Characterization," Contact No. DE-AC21-88MC2124, Proceedings of the Eight Annual Coal-Fueled Heat Engines and Gas Stream Cleanup Systems Contractors Review Meeting, DOE/METC-90/6110 (DE90000480), pp. 263-272, 1991.

76. Holve, D.J., "Combustion Studies of Coal/Water Slurries," Presented at the Spring Meeting of the Western States Section of the Combustion Institute, University of Colorado, Boulder, Colorado, 1984.

77. Morrison, G.F., "Combustion of Coal Liquid Mixtures," Report No. ICTIS/TR24, IEA Coal Research, London, November 1980.

78. Cheng, W.K., Presentation at ASME-ETCE Conference, Dallas, Texas, February 1987.

79. Seshadri, A.K., J.A. Caton, and K.D. Kihn, "Coal-Water Slurry Spray Characterisitcs of a Positive Displacement Fuel Injection System," ASME ICE-Vol. 16, Coal Fueld Diesel Engines, also in the ASME Transactions, Journal of Engineering for Gas Turbines and Power, Vol. 114, No. 3, pp. 528-533, 1992. 
80. Caton, J.A., S.E. Payne, D.P. Terracina, and K.D. Kihm, "Coal-Water Slurry Spray Characterisitcs of an Electronically-Controlled Accumulator Fuel Injection System," ASME ICE-Vol. 19, Coal-Fueled Diesel Engines, pp. 25-32, 1993,

81. Kihm, K.D., D.P. Terracina, S.E. Payne, and J.A. Caton, "Synchronized Droplet Size Measurements for Coal-Water Slurry (CWS) Diesel Sprays of an Electronically-Controlled Fuel Injection System." ASME ICE-Vol. 19, Coal-Fueled Diesel Engines, pp. 33-42, 1993.

82. Schwalb, J.A., T.W. Ryan II, and W.C. Smith, "Lube Oil contamination Induced Wear in Coal-Fueled Diesel Engines," ASME ICE-Vol. 12, Coal-Fueled Diesel Engines, pp. 51$58,1990$.

83. Schwalb J.A. and T.W. Ryan III, "Surface Finish and Particle Size Effects on Wear in Coal-Fueled Diesel Engines," ASME ICE-Vol. 14, Coal-Fueled Diesel Engines, pp. 29-37, 1991.

84. Mayville, R.A., A.K. Rao, R.P. Wilson, "Cooper-Bessemer Coal-Fueled Engine System: Recent Developments in Durable Components," ASME ICE-Vol. 14, Coal Fueled Diesel Engines, pp. 23-27, 1991.

85. Saxton, J., F.A. Creswick, and J.F. Kircher, "Combustion in a Coal Fired Internal Combustion Engine: A Simple Theory," ASME Paper No. 78-Wa/Fu-1, 1978.

86. Barrett, R.E., and J.J.Saxton, "Predicted Burning Times of Nonporous Coal Particles as a Function of Pressure and Particle Size," ASME Paper 80-Wa/Fu-5, 1980.

87. Rosegay, K.H., "A Cycle Simulation of Coal Particle Fueled Receiprocating InternalCombustion Engine," MS Thesis, Texas A\&M University, College Station, 1982.

88. Bell, S.R., and J.A. Caton, "Cycle Simulation for a Reciprocating, Internal-Combustion Engine Using a Coal Slurry Fuel: The Role of Volatiles," 1984 American Flame Research Committee Fall Symposium, Paper No. 4.1, 1984.

89. Bell, S.R., and J.A. Caton, "Cycle Simulation of Reciprocating, Internal-Combustion Engines Using Coal Slurry Fuels," Joint Central and Western States Sections/Combustion Institute Spring Meeting, Paper No. 2-1A, 1985.

90. Bell, S.R., and J.A. Caton, "Analytical Evaluations of Ignition Options for a Coal/Water Slurry Fueled Engine," 1985 American Flame Research Committee Fall Symposium, 1985.

91. Bell, S.R., and J.A. Caton, "Coal-Fueled Diesel Engines: Analytical Evaluations of Ignition Options," The Twenty-First (International) Symposium on Combustion, The Combustion Institute, Pittsburgh, PA, pp. 389-397, 1986.

92. Bell, S.R., and J.A. Caton, "Cycle Simulations of a Coal-Fueled, Reciprocating Internal-Combustion Engine: the Role of Volatiles and Liquid Carriers," Combustion 
Science and Technology, Vol. 50, Nos. 4-6, pp. 185-203, 1986.

93. Caton, J.A., "Coal-Fueled Diesel: Cycle Simulation Study," Proceedings of the Second Annual Heat Engines Contractors' Meeting, U. S. Department of Energy, Morgantown Energy Technology Center, Report No. DOE-METC-85-6023, pp. 250-266, May 1985.

94. Bell, S.R. and J.A. Caton, "Ignition and Combustion Characteristics of Coal Fuels in Diesel Engines," Report No. CF-85-01, Texas A\&M University, Department of Mechanical Engineering, September 1985.

95. Bell, S.R., "Development of a Cycle Simulation for a Coal-Fueled, Direct-Injected, Internal Combustion Engine," Texas A\&M University, Department of Mechanical Engineering, Ph.D., December 1986.

96. Bell, S.R., and J.A. Caton, "Numerical Simulation of a Coal-Fueled, Compression-Ignition Engine," Fuel, Vol. 67, pp.474-481, April 1988.

97. Caton, J.A., S. Bell, S. Kishan, D. Richardson, "Coal-Fueled Diesel: Cycle Simulation Study," Contract No. DE-AC21-84-MC21175, Proceedings of the Third Annual Heat Engines "Contractors Meetine, DOE/METC-86/6041 (DE86001086), pp. 308-319, May 1986.

98. Caton, J.A. and S.R. Bell, "Coal-Fueled Diesel: Cycle Simulation," Final Report, U.S. Department of Energy, Contract No. DE-AX21-84MC21175, Report No. DE87003352, December 1986.

99. Kishan, S., and J.A. Caton, "Simulation of a Two-Stroke Cycle, Locomotive Engine Using Diesel or Coal Fuels," Joint Central and Western States Sections/Combustion Institute Spring Meeting, Paper No. 1-1A, 1985.

100. Kishan, S., "Simulation Study of Two-Stroke Cycle Compression-Ignition Engines," Texas A\&M University, Department of Mechanical Engineering, MSME, May 1985.

101. Kishan, S., S.R. Bell, J.A. Caton, "Two-Stroke Cycle Engine Simulations: A Sensitivity Study," Report No. CF-85-04, Texas A\&M University, Department of Mechanical Engineering, 1985.

102. Kishan, S., S.R. Bell, and J.A. Caton, "Numerical Simulations of Two-Stroke Cycle Engines Using Coal Fuels," ASME Technical Paper No. 86-ICE-13, also in the ASME Transactions, Journal of Engineering for Gas Turbines and Power, Vol. 108, No. 4, pp. 661-668, 1986.

103. Caton, J.A., "GFSIM: Coal-Fueled Diesel Cycle Simulation with Provisions for Gas Fuels," Final Report, U. S. Department of Energy, Contract No. DE-AH21-87MC05095, 1987.

104. Koncke, K.F., "Calculations of Ignition Characteristics of Coal-Water Slurry Fuels for 
Engine Conditions: Comparison of Numerical Predictions with Existing Experimental Results," Texas A\&M University, Department of Mechanical Engineering, Diplomarbeit Degree (the German equivalent of a U. S. Master of Science degree), June 1986.

105 Smith, I.W., "The Kinetics of Combustion of Pulverized Semi-Anthracite in the Temperature Range 1400-2200 K, " Combustion and Flame, Vol. 17, p. 421, 1971.

106. Caton, J.A., and K. Annamalai, "Performance and Emissions of Coal-Fueled Engines Using Group Combustion Theory," Proceedings of the Annual Heat Engines and Gas Stream Cleanup Systems Contractors Review Meeting, U. S. Department of Energy, Morgantown Energy Technology Center, Report No. DOE-METC-87-6077, pp. 190-196, 1987.

107. Zel'dovich, J., "The Oxidation of Nitrogen in Combusions and Explosions," Acta Physico Chemica, USSR, Vol. 21, pp. 577-628, 1946.

108. Schmidt, J.F., "An Engine Cycle Simulation with Thermal Nitric Oxide Computations for Coal-Fueled Diesel Engines," Texas A\&M University, Department of Mechanical Engineering, Diplomarbeit, 1987.

109. Bell, S.R., and G.H. Choi, "A Comparison of Numerical Atomization Models for a Coal-Fueled Engine," Proceedings of the Central States Section/Combustion Institute Spring Technical Meeting, May 1988.

110. Bell. S.R., and G.H. Choi, "Numerical Evaluation of the Carbon-Water Reaction in a Coal-Water Fueled Engine," ASME ICE-Vol. 7, Coal-Fueled Diesel Engines, pp. 35-42, 1989.

111. Khandare, S.S., R.D. Garg, and R.R. Gaur, "Cycle Simulation of Volaile Coal-Fuel Diesel Engine Using Coal-Dust Induction System, ASME ICE-Vol. 7, Coal-Fueled Diesel Engines, pp. 62-74, 1989.

112. Bell, S.R., and G.H. Choi,, "Numerical Evaluation of Fuel Atomization in a Coal Fueled Engine," ASME ICE-Vol. 12, Coal-Fueled Diesel Engines, pp. 69-76, 1990.

113. Stone, K.R., "Modeling Diesel Performance with Alternative Fuels," Proceedings of the Fifth Annual Heat Engines Contractors Meeting, U. S. Department of Energy, Morgantown Energy Technology Center, Report No. DOE-METC-88-6094, pp. 140-149, 1988.

114. Annamalai, K., J.A. Caton, J. Roth, W. Ryan, and J. Schmidt, "Performance and Emissions of Coal-Fueled Engines Using Group Combustion Theory," Interim Report, U. S. Department of Energy, Contract No. DE-AC21-86MC23256, November 1987.

115. Ryan, W., K. Annamalai, and J.A. Caton, "Group Ignition of a Spherical Cloud of Coal Particles," Eastern States Section/The Combustion Institute, Paper No. 87-09, November 1987. 
116. Ryan, W., K. Annamalai, and J.A. Caton, "Relation Between Group Combustion and Drop Array Studies," Proceedings of the Central States Section/Combustion Institute Spring Technical Meeting, Paper No. 20, pp. 261-267, 1989

117. Ryan, W., K. Annamalai, and J.A. Caton, "Relation Between Group Combustion and Drop Array Studies," Combustion and Flame, Vol. 80, pp. 313-321, 1990.

118. Roth, J.M., "Cycle Simulation for Coal-Fueled Engines Using Low-Heat-Rejection Concepts," Texas A\&M University, Department of Mechanical Engineering, ASME, 1988.

119. Caton, J.A., and K. Annamalai, "Performance and Emissions of Coal-Fueled Engines Using Group Combustion Theory," Proceedings of the AR\&TD Direct Utilization, and Instrumentation and Diagnostic Contractors Review Meeting, U. S. Department of Energy, pp. 31-40, 1987.

120. Branyon, D.P., "Development and Use of an Advanced Coal-Fueled Diesel Cycle Simulation with Group Effects," Texas A\&M University, Department of Mechanical Engineering, ASME Paper 831362, 1989.

121. Branyon, D.P., J.A. Caton, and K. Annamalai, "Coal Fueled Diesel Cycle Simulation: The Role of Group Effects," ASME ICE-Vol. 12, Coal-Fueled Diesel Engines, pp. 77-84, also in the ASME Transactions, Journal of Engineering for Gas Turbines and Power, Vol. 112, No. 3, pp.391-397, 1990.

122. Bunker, B., "Development and Implementation of an Engine Cycle Simulation," Texas A\&M University, Department of Mechanical Engineering, 91-92 University Undergraduate Fellows Program, MEEN 485H, May 1992.

123. Gentry, R.A., "Numerical Analysis of Coal-Fired Diesel Engines," Technical Paper Presented at Third Annual Heat Engines Contractors Meeting, DOE/METC, Report No. DOE/METC/86-6041, May 1986.

124. Gentry, R.A., B.J. Daly, and A.A. Amsden, "KIVA COAL: A Modified Version of the KIVA Program for Calculating the Combustion Dynamics of a Coal-Water Slurry in a Diesel Engine Cylinder," Los Alamos National Laboratory Report No. LA-11045-MS, December 1987.

125. Kakwani, R.M., et al., "Coal-Fueled, High-Speed Diesel Engine Development, Final Report," DOE/MC/27222/3624 (DE9400093), September 1993.

126. Greenhalgh, M.L., "High-Pressure Coal Fuel Processor Development - Task 1 Proof-ofPrincipal Testing," DOE/MC/25141-3339 (DE93000276) Topical Report, November 1992.

127. Greenhalgh, M.L., "High-Pressure Coal Fuel Processor Development," DOE/MC/251413340 (DE93000277), Final Report, December 1992. 
128. Johnson, R.N., and Haydon, H.L., "Coal-Fueled Diesel Technology Development, Fuel Injection Equipment for Coal-Fueled Diesel Engines," Topical Report, DOE/MC/231743672 (DE9400-4088), January 1994.

129. Johnson, N., Lee, M., and White, R.H., "Coal-Fueled Diesel Technology Development, Nozzle Development for Coal-Fueled Diesel Engines," Topical Report, DOE/MC/23174-3673 (DE9400-4089), January 1994.

130. Mehan, R.L., Gray, D.M., "Improved Materials for Durable Rings, Liners, and Injection Nozzles," Topical Report, DOE/MC/23174-3366 (DE9300-0283), December 1991.

131. VanKleunen, W., et al., "Coal-Fueled Diesel Technology Development, Emissions Control," Topical Report, Parts 1 and 2, DOE/MC/23174-3699 (DE94004096), January 1994.

132. Cohen, M.R., et al., "Emission R\&D at GE/CRD Coal-Fueled Diesel Technology Development, Methods for $\mathrm{SO}_{2}$ and $\mathrm{NO}_{\mathrm{x}}$ Removal from Coal-Diesel Exhaust," Topical Report, DOE/MC/23174-3551 (DE94000076), October 1993.

133. Kakwani, R.M., et al., "Coal-Fueled High-Speed Diesel Engine Development, Final Report," DOE/MC/27222-3624 (DE94000093), September 1993.

134. Ives, L.K., "Abrasive Wear by Coal-Fueled Diesel Engine and Related Particles," NISTIR 4811, ORNL/Sub/83-21322/01, September 1992.

135. Rao, A.K., and Wilson, R.P., "Coal-Diesel Technology Looks Good for Clean Coal 5," Modern Power Systems, February 1994. 


\section{APPENDIX A}

COAL FUELED DIESEL REVIEW BIBLIOGRAPHY 


\section{BIBLIOGRAPHY}

A Report by the Coal Task Group of the Energy Resources Subcommittee of the National Petroleum Councils Committee on U.S. Energy Outlook, "U.S. Energy Outlook - Coal Availability," 1973.

Adiabatics, Inc., "Tribological Consideration in Coal Burning Diesel Engine," Coal-Fueled Diesel Systems Research Final Report, AI Report N. FR85155-288.

Aghan, R.L. and L.E. Samuels, "Mechanisms of Abrasive Polishing," Wear, Vol. 16, 1970, pp. 293-301.

Allen, T., Particle Size Measurement, Chapman and Hall, New York, p. 139.

Ames, B.N., J. McCann, E. Yamasaki, "Methods for Detecting Caracinogens and Mutagens With the Salmonella/Mmmalin Microsome Mutagenicity Test," Muta Res 31:347-364, 1975.

Anderson, D.P., "Wear Particle Atlas (Revised)," Prepared for Advanced Technology Office Support Equipment Engineering Department, Naval Air Engineering Center, Lakehurst, New Jersey, Report NAEC-92-163, 1982.

Andreussi, P., L. Tognotti, M. Graziadio, and G. DeMichele, "Atomization of Coal-Water Fuels by a Pneumatic Nozzle: Characteristics of the Spray," Aerosol Science and Technology 13:35-46 (1990).

Andrews, M.J. and F.V. Bracco, "On the Structure of Turbulent Dense Spray Jets," Encyclopedia of Fluid Mechanics, Vol. 3, 1988.

Annamalai, K. and S.C. Ramalingaim, "Group Combustion of Char/Carbon Particles," Combustion and Flame, Vol. 70, 1987, pp. 307-332.

Annamali, K., S. Ramlinam, T. Dahah, and D. Chi, "Group Combustion of a Cylindrical Cloud Char/Carbon Particles," Transactions of the ASME J. of Heat Transfer, Vol. 190, 1988, pp. 190-200.

Annamali, K., J.A. Caton, J. Roth, W. Ryan, and J. Schmidt, "Performance and Emissions of Coal-Fueled Engines Using Group Combustion Theory," Interim Report, U.S. Department of Energy, Contract No. DE-AC21-86MC23256, November 1987. 
Annand, W.J.D., "Heat Transfer in the Cylinder of Reciprocating Internal Combustion Engines," Proc. Instn. Mech. engrs., Vol. 177, No. 36, 1963

Anson, D., S.A. Barber, H.F. Feldmann, and M.D. Gurney, "Development Plan for a Coal/Water Slurry Fired Diesel Engine for Cogeneration Applications," DOE Contract No. AC0286CE40747, July 1987.

Arai, M., M. Tabata, H. Hiroyasu, and M. Shimizu, "Disintegrating Process and Spray Characterization of Fuel Jet Injected by a Diesel Nozzle," SAE Technical Paper No. $840275,1984$.

Archard, J.F., "Wear Theory and Mechanisms," Wear Control Handbook M.B. Peterson and W.O. Winer, eds., 1980, ASME, pp. 35-80, New York.

Archard, J.F., "Contact and Rubbing of Flat Surfaces," J. Appl. Phys., Vol. 24, 1953, pp. 981988.

Argonne National Laboratory, "An Assessment of the Natural Gas Base in the United States," Prepared for U.S. DOE Office of Policy and Planning, May 1988.

Arthur D. Little, "Coal-Fueled Diesel Systems Research," Final Report for DOE Contract No. DE-AC21-85MC22182, NITS/DE9000479, September 1988.

Arthur D. Little, "Coal-Fueled Diesel Systems for Stationary Power Applications," Topical Report for DOE Contract No. DE-AC21-85MC22182, September 1986.

Ayers, W.J. Jr., L.D. Strickland, R.A. Wojewodka, and Jay R. Leep, "Diesel Engines, Liquid Fossil Fuels, A Scoping Study," Contract No. PTPA No. 925, Proceedings of the Annual Coal Fuel Heat Engines and Gas Stream Cleanup Systems Contractors Review Meeting, DOE/METC-88/6094 (DE88001088), June 1988, pp. 383-395.

Badgley, P., R. Kamo, A. Holmes, and S. Kumar, "Fluidic Coal Feed System," Contract No. DEAC-86MC23006, Proceedings of the Annual Coal Fuel Heat Engines and Gas Stream Cleanup Systems Coñtractors Review Meeting, DOE/METC-88/6094 (DE88001088), June 1988, pp. 334-345.

Badgley, P., D. Doup, and R. Kamo, "Innovative Coal-Fueled Diesel Engine," Contract No. DEAC21-88MC25132, Proceedings of the Seventh Annual Coal-Fueled Heat Engines and Gas Stream Cleanup Systems Contractors Review Meeting, DOE/METC-90/6110 (DE90000480), March 1990, pp. 216-226, also Final Report, submitted to DOE . 
Badgley, Patrick, Douglas Doup, and Roy Kamo, "Innovative Coal-Fueled Diesel Engine Injector," Contract No. DE-AC21-88MC25132, Advance Research and Technology Development, Direct Utilization, and Instrumentation and Diagnostics Contractors' Review Meeting, CONF-900981--(DE91006344), METC/PETC, September 16-18, 1990, pp. 377386.

Badgley, P.R. and D.C. Doup, "Combustion Optimization of High-Speed Coal-Water-Slurry Fueled Diesel Engine," ASME ICE-Vol. 14, Coal-Fueled Diesel Engines, Presented at the Fourteenth Annual Energy-Sources Technology Conference and Exhibition, Houston, Texas, January 20-23, 1991, pp. 17-22.

Balles, E.N., "Single-Cylinder Coal-Diesel Engine Results," Proceedings of the Sixth Annual Coal-Fueled Heat Engines and Gas Stream Cleanup Systems Contractors Review Meeting, U.S. Department of Energy, Morgantown, West Virginia, DOE/METC-89/6101, March 1989.

Balles, E.N., "Coal-Fuel Diesel Combustion: Cooper Bessemer Test Results," presented at the Annual Coal Fuel Heat Engines and Gas Stream Cleanup Systems Contractors Review Meeting, June 14-16, 1988, Morgantown, W.V.

Balles, E.N., K.R. Benedek, R.P. Wilson, and A.K. Rao, "Analysis of Cylinder Pressure and Combustion Products from an Experimental Coal-Fueled Diesel Engine," ASME ICE Division Technical Conference, New Engine Technology for Cogeneration, ICE-Vol. 2, October 1987, pp. 75-82.

Balles, E.N., R.P. Wilson, K. Benedek, R. Mayville, K. Rao, F. Schaub, and J. Kimberley, "CoalFueled Diesels: Technology Development, Single-Cylinder Coal Diesel Engine Results," in Proc. Sixth Annual Coal-Fueled Heat Engines and Gas Stream Cleanup Systems Contractors' Review Meeting, Morgantown, WV, March, 1989.

Balles, E.N., R.P. Wilson, A.K. Rao, and C.H. Melcher, "Coal-Fueled Diesel Engine for Power Generation," ASME, Presented at the Joint Power Generation Conference and Exhibition, Dallas, Texas, October 1989.

Balles, E.N., et al., "Single Cylinder Coal-Diesel Engine Technology Development: GE Single Cylinder Engine Results." DOE/METC Contractors Review Meeting, Paper No. 3.3, Morgantown, WV, Aarch 1989.

Barber, G.C., J.C. Lee, and K.C. Ludema, "Materials and Surface Finish Effects in the Breakingin Process of Engines," Transactions of the ASME, Vol. 109, 1987, pp. 380-387.

Baranescu, G.S., "A New System for the Delivery and Combustion Control of Coal Slurries in Diesel Engines," SAE Technical Paper No. 890446, Feb. 1989. 
Barrett, R.E. and J.J. Saxton, "Predicted Burning Times of Nonporous Coal Particles as a Function of Pressure and Particle Size," ASME Paper 80-Wa/Fu-5, 1980.

Barth, H.G., Modern Methods of Particle Size Analysis, Wiley and Sons, New York, 1984, pp. 135-172.

Baxter, L.L., D.R. Hardesty and E. Parsons, "Combustion Research for Advanced Heat Engines," Contract No. FWP Number: 0642, Advance Research and Technology Development, Direct Utilization, and Instrumentation and Diagnostics Contractors' Review Meeting, CONF-900981--(DE91006344), METC/PETC, September 16-18, 1990, pp. 397-406.

Bell S.R. and J.A. Caton, "Coal-Fueled Diesel Engines: Analytical Evaluations of Ignition Options," Twenty-First Symposium (International) on Combustion, The Combustion Institute, 1986, 1986, pp. 389-397.

Bell, S.R. and G.H. Choi, "Numerical Evaluation of the Carbon-Water Reaction in a Coal-Water Fueled Engine," ASME ICE-Vol. 7, Coal-Fueled Diesel Engines, Presented at the Twelfth Annual Energy-Sources Technology Conference and Exhibition, Houston, Texas, January 22-25, 1989, pp. 35-42.

Bell, S.R. and J.A. Caton, "Cycle Simulation of Reciprocating, Internal-Combustion Engines Using Coal-Slurry Fuels," Technical Paper presented at the Spring States Section/Combustion Institute Meeting, Paper 2-1A, April 1985.

Bell, S.R., "Development of a Cycle Simulation for a Coal-Fueled, Direct-Injected, Internal Combustion Engine," PhD. Dissertation, Texas A\&M University, 1986.

Bell, S.R., and J.A. Caton, "Analytical Evaluations of Ignition Options for a Coal/Water Slurry Fueled Engine," American Flame Research Committe Fall Symposium, October 1985c.

Bell, S.R. and J.A. Caton, "Cycle Simulations of a Coal-Fueled Reciprocating, InternalCombustion Engine: The Role of Volatile and Liquid Carriers," Journal of Combustion Science and Technology, Vol. 55, 1986. pp. 185-203.

Bell, S.R. and J.A. Caton, "Cycle Simulations of a Coal-Fueled Reciprocating, InternalCombustion Engine: The Role of Volatile," American Flame Research Committe Fall Symposium, Paper \$o. 4.1, October 1984.

Bell, S.R., and J.A. Caton, "Ignition and Combustion Characteristics of Coal Fuels in Diesel Engines," Report No. CF-85-01, Texas A\&M University, Department of Mechanical Engineering, September 1985b.

Bell, S.R., "Development of a Cycle Simulation for a Coal-Fueled, Direct-Injection, Internal Combustion Engine," PhD Dissertation, Texas A\&M University, College Station, 1986. 
Bell, S.R. and G.H. Choi, "A Comparison of Numerical Atomization Models for a Coal-Fueled Engine," Presented at the Central States Section Meeting of the Combustion Institute, Indianapolis, Indiana, May 1988.

Bell, S.R. and J.A. Caton, "Numerical Simulation of a Coal-Fueled, Compression-Ignition Engine," Journal of Fuel, Vol. 67, 1988, pp. 478-481.

Bell, S.R. and G.H. Choi, "Numerical Evaluation of Fuel Atomization in a Coal-Fueled Engine," ASME ICE-Vol. 12, Coal-Fueled Diesel Engines, Presented at the Thirteenth Annual Energy-Sources Technology Conference and Exhibition, New Orleans, Louisiana, January 14-18, 1990, pp. 69-75.

Bendat, J.S. and A.G. Piersol, Random Data Analysis and Measurement Procedure, 2nd Edition, pp. 428-434, Wiley-Interscience, New York, 1986.

Bendick, R.C., F.P. Dorchak, N.F. Rekos, and H.A. Webb, Proceedings of the 6th Annual CoalFueled Heat Engines and Gas Stream Cleanup System Contractors Review Meeting, Morgantown WV, 1989.

Benedek, K., et al., "Injection and Combustion Studies of CWS in a Diesel Environment," ADL/MIT, Proceedings of the Annual Heat Engines and Gas Stream Cleanup Systems Contractors Review Meeting, DE/METC-87/6077, April, 1987.

Benedek, K.R., "Coal-Fueled Diesel Systems for Stationary Power Applications: Coal Water Slurry Injection and Combustion Experiments," Task 2 - Topical Report prepared by ADL and MIT under DOE Contract No. DE-AC-85-MC22181, September, 1987.

Benedek, K.R., K.T. Menzies, S.A. Johnson, R.P. Wilson, K.A. Rao, and F.S. Schaub, "Emission Characteristics and Control Technology for Stationary Coal-Fueled Diesel Engines," ASME ICE Division Technical Conference, Engine Emissions Technology for the 1990's, ICE Vol. 4, pp. 169-176, also in the ASME Journal of Enginering for Gas Turbines and Power, Vol. 111, 3, 1989, pp. 507-515, October 1988.

Benedek, K.R., J. McCullough, K. Rao, and W. Cheng, "Coal Fuel Diesel Engines for Stationary Power," Contract No. DE-AC21-85MC22182, Proceedings of the Third Annual Heat Engines Contractors Meeting. DOE/METC-86/6041 (DE86001086), May 1986, pp. 9-20.

Benson, C.E., T.W. Ryan III, J.A. Schwalb, L.G. Dodge, T.J. Callahan, "Cal-Water Slurry Spray Characterization," Proceedings of the Eighth Annual Coal-Fueled Heat Engines an Gas Stream Cleanup Systems Contractors Review Meeting, U.S. Department of Energy, Morgantown Energy Technology Center, accepted for publication, July 1991.

Berbezier, I., J.M. Martin, and Ph. Kapsa, "The Role of Carbon in Lubricated Mild Wear," Tribology International, Vol. 19, No. 3, 1986, pp. 115-122. 
Bhasin, A.K., et al. "Manufacture and Testing of Ultra-Clean Coal-Water Slurry Fuels for DirectFired Gas Turbines," Final Report prepared for DOE/METC, Report No. DOE/MC/2070016365, August 1984.

Blizzard, Donald T., "Heat Engines: Tomorrow's Clean Coal Technology, Coal Fueled Diesels Overview," Proceedings of the Annual Coal Fuel Heat Engines and Gas Stream Cleanup Systems Contractors Review Meeting, DOE/METC-88/6094 (DE88001088), June 1988, pp. 7-10.

Blizzard, D.T., F.S. Schaub, and J.G. Smith, "Development of the Cooper-Bessemer Clean Burner Gas-Diesel (Dual-Fuel) Engine." ASME ICE Division Technical Conference, Fuels. Controls, and Aftertreatment for Low Emissions Engines, ICE-Vol. 15, October 1991, pp. 87-97.

Bonne, M.A., "Development of Instrumentation and Analysis Techniques for Diesel Engine Combustion and Heat Transfer Studies", M.S. Thesis, Department of Mechanical Engineering, University of Illinois at Urbana-Champaign, Urbana, 1989.

Borman, G.L., "Mathematical Simulation of I.C. Engine Processes \& Performance Including Comparison With Experiments," Ph.D. Thesis, University of Wisconsin, 1964.

Bortz, S.J., V. Roman, G.R. Offen, "Hydrate and Process Parameters Controlling $\mathrm{SO}_{2}$ Removal During Hydroxide Injection Near $1000^{\circ} \mathrm{F}$," Presented at First Annual FGD Control Technologies Conference, St. Louis Mo., October 1988.

Bortz, S.J., V.P. Roman, R.J. Yang, and G.R. Offen, "Coal-Fueled Diesels: Technology Development Single Cylinder Coal Diesel Engine Results," Proceedings of the Sixth Annual Coal-Fueled Heat Engines and Gas Stream Cleanup Systems Contractors Review Meeting, DOE/METC-89/6101, 1989.

Bowan, C.T., "Kinetics of Pollutant Formation and Destruction in Combustion," Prgress in Energy and Combustion Science, Vol. 1, pp. 33-45, 1975.

Bracco, F.V., "Structure of High Speed Full Cone Sprays," Recent Advances in Aerospace Sciences, $1985 \mathrm{~b}$.

Bracco, F.V., "Modeling of Engine Sprays," SAE Technical Paper No. 850394, 1985.

Branyon, D.P., "Development and Use of an Advanced Coal-Fueled Diesel Cycle Simulation with Group Effects," ASME Paper 831362, 1989. 
Branyon, D.P., J.A. Caton, and K. Annamalai, "Coal Fueled Diesel Cycle Simulation: The Role of Group Effects," ASME ICE-Vol. 12, Coal-Fueled Diesel Engines, also in the ASME Transactions, Journal of Engineering for Gas Turbines and Power, Vol. 112, No. 3 pp. 391-397. Presented at the Thirteenth Annual Energy-Sources Technology Conference and Exhibition, New. Orleans, Louisiana, January. 14-18, 1990, pp. 77-84.

Brehob, D.D. and R.F. Sawyer, "Compression Ignition of Coal Slurry Fuels," ASME Technical Paper No. 87-ICE-11, Energy-Sources Technology Conference and Exhibition, Dallas, Texas, February 15-20, 1987.

Buckley, D.H., Surface Effects in Adhesion, Friction, Wear, and Lubrication, Elsevier Scientific Publishing Co., New York, 1981.

Bunker, B., "Development and Implementation of an Engine Cycle Simulation," Texas A\&M University, Department of Mechanical Engineering, 91-92 University Undergraduate Fellows Program, MEEN 485H, May 1992.

Butcher, T., W. Slegeir, and R. Sapienze, "Additives for Heat Engine Coal Slurry Fuels," Proceedings of the First Annual Heat Engines Contractors Meeting, DOE/METC/84-31 (DE85001953), METC, November 1984, pp. 121-125.

Byam, J.W. and K.E. Markel, Editors, Proceedings of the Annual Heat Engines and Gas Stream Cleanup Systems Contractors Review Meeting, Morgantown Energy Technology Center, Morgantown, West Virginia, 1987.

Cameron, A. and G. Pumphrey, "Assessment of Bore Polishing Properties of Lubricating Oils by Bench Tests," Esslingen Conference, W. Germany, Testing and Evaluation of Motor Oils, 1983:

Carpenter, L.K. and F.W. Crouse Jr., (1985a), "Coal-Fueled Diesels, Fossil Energy Activities," ASME Technical Paper presented at the 1985 ASME Energy-Sources Technology Conference/Diesel and Gas Engine Symposium, Paper 85-DGP-18, February 1985.

Carpenter, L.K., F.W. Crouse, Jr., and J.S. Halow, (1985b), "Coal-Fueled Turbines: Deposition Research," ASME Technical Paper presented at the 1985 Gas Turbine Conference, Paper 85-GT-213, (1985b) March 1985.

Carpenter L.K. and F.W. Crouse, Jr., "Coal-Fueled Diesels: Progress and Challenges," ASME Technical Paper No. 86-ICE-6, Presented at the Energy-Sources and Technology Conference and Exhibition, New Orleans, LA., February 23-27, 1986.

Caton, J.A., S. Kishan, and S.R. Bell, "Numerical Simulations of Two-Stroke Cycle Engines Using Coal Fuels," Ninth Annual Energy Sources Technology Conference and Exhibition, ASME Internal Combustion Engine Division Symposium, ASME Technical Paper No. 86ICE-13, February 25, 1986. 
Caton, J.A. and S.R. Bell, "Cycle Simulation for a Reciprocating, Internal Combustion Engine Using a Coal Slurry Fuel: The Role of Volatile", American Flame Research Committee Fall Symposium, Paper No. 4.1, October 1984.

Caton, J.A. and S.R. Bell, "Cycle Simulation of Reciprocating, Internal Combustion Engines Using Coal Slurry Fuels," Joint Central and Western States Sections/Combustion Institute Spring Meeting, Paper No. 1-1-A, April 1985.

Caton, J.A. and S.R. Bell, "Analytical Evaluation of Ignition Options for a Coal/Water Slurry Fueled Engine" American Flame Research Committee Fall Symposium, October 1985.

Caton, J.A. and K. Rosegay, "Cycle Simulation of Coal Particle Fueled Reciprocating Internal Combustion Engines," SAE International Off-Highway Meeting, Milwaukee, Wisconsin, Sept. 12-15, 1983.

Caton, J.A., K.D. Kihm, A.K., Seshadri, and G. Zicterman, "Micronized-Coal-Water Slurry Sprays From a Diesel Engine Positive Displacement Fuel Injection System," Proceedings of the Spring Technical Meeting of the Central States Section of the Combustion Institute, Paper No. 58, April 1991, pp. 361-366, Nashville, TN.

Caton, J.A. and K.H. Rosegay, "A Review and Comparison of Reciprocating Engine Operation Using Solid Fuels," SAE Technical Paper No. 831362, SAE Transactions, Vol. 92, pp. 1108-1124, 1984.

Caton, J.A., S. Bell, S. Kishan, and D. Richardson, " Coal-Fueled Diesel: Cycle Simulation Study," Contract No. DE-AC21-84-MC21175, Proceedings of the Third Annual Heat Engines Contractors Meeting, DOE/METC-86/6041 (DE86001086), May 1986, pp. 308-319.

Caton, J.A., "Cycle Simulation for a Coal-Fueled Diesel Engine," Proceedings of the First Annual Heat Engines Contractors Meeting, DOE/METC/84-31 (DE85001953), METC, November 1985, pp. 245-258.

Caton, J.A., "GFSIM: Coal-Fueled Diesel Cycle Simulation with Provisions for Gas Fuels," Final Report, U.S. Department of Energy, Contract No. DE-AH21-87MC05095, December 1987.

Caton, J.A., A.K. Seshadri, and K.D. Kihm, "Spray Tip Penetration and Cone Angles for CoalWater_Slurry Using a Modified Medium-Speed Diesel Engine Injection System," Proceedings of the Spring Technical Meeting of the Central States Section of the Combustion Institute, pp. 453-458, Columbus, $\mathrm{OH}$. 
Caton, J.A., and S.R. Bell, "Coal-Fueled Diesel: Cycle Simulation Study," Contract No. DEAC21-84MC21175, Proceedings of the Second Annual Heat Engines Contractors Meeting, DOE/METC-85/6023 (DE85008595), May. 1985, pp.'250-266, Final Report No. DE87003352, December 1986.

Caton, J.A., and K.D. Kihm, "Coal-Ẇater Slurry Atomization Characteristics," Contract No. DEAC21-88MC23174, Proceedings of the Eight Annual Coal-Fueled Heat Engines and Gas Stream Cleanup Systems Contractors Review Meeting, DOE/METC-90/6110 (DE90000480), July 1991, pp. 273-282.

Caton, J.A., J. Schmidt, J. Roth, F. Bachman, and K. Annamalai, "Nitric Oxide Emissions from a Coal-Fueled Engine: Numerical Results," ASME Technical Paper No. 88-ICE-22, Energy-Sources Technology Conference and Exhibition, New Orleans, LA, January 10-14, 1988.

Caton, J.A., S.E. Payne, D.P. Terracina, and K.D. Kihm, "Coal-Water Slurry Spray Characteristics of an Electronically-Controlled Accumulator Fuel Injection System," ASME ICE-Vol. 19. Coal-Fueled Diesel Engines --1993, Presented at the 16th Annual Energy-Sources Technology Conference and Exhibition, Houston, Texas, January 31February 4, 1993, pp. 25-32.

Caton, J.A. and K. Annamalai, "Performance and Emissions of Coal-Fueled Engines Using Group Combustion," Contract No. DE-AC21-86MC23256, Proceedings of the Annual Coal Fuel Heat Engines and Gas Stream Cleanup Systems Contractors Review Meeting, DOE/METC-88/6094 (DE88001088), Proceedings of the Sixth Annual Coal-Fueled Heat Engines and Gas Stream Cleanup Systems Contractors Review Meeting, U.S. Dept. of Energy, Morgantown Energy Technology Center Report No. DOE-METC-89-6101, pp. 346-357, March 1989..

Caton, J.A., "Cycle Simulation of a Coal-Particle-Fueled, Reciprocating, Locomotive Engine," ASME Technical Paper No. 84-DGP-19.

Cenco-du Nouy Tensiometers, "Surface and Interfacial Tensions by the Ring Method," Bulletin 101, Central Scientific Co. (CENCO)

Chappell, M.S. and E.P. Cockshatt, "Gas Turbine Cycle Calculations: Thermodynamic Data Tables for Air and Combustion Products for Three Systems of Units," National Research Council, Canada, Aeronautical Report LR-579, August 1974.

Chatterjee, "The System in Release of Volatile From Coal and Char-I: Rapid Thermal Process," Journal of Mines, Metals and Fuels, March 1972.

Chatwani, A.U. and F.V. Bracco, "Computation of Dense Spray Jets," International Conference on Liquid Atomization and Spray Systems (ICASS-85), Paper 1B/1/1, 1985. 
Chehroudi, B. and F.V. Bracco, "On the Intact Core of Full Cone Sprays," SAE Technical Paper No. $850126,1986$.

Cheng, W.K., Presentation of ASME-ETCE Conference, Dallas, Texas, February 1987.

Chigier, N. and P.L. Meyer, Presented at the Sixth International Symposium on Coal Slurry Combustion and Technology, FL, 1984.

Chittenden, R.J., D. Dowson, J.A. Dunn, and C.M. Taylor, "A Theoretical Analysis of Isothermal EHL Concentrated Contracts - Parts I and II," Proc. R. Soc. Lond. A387, 1985, pp. 245269 and pp. 271-294.

Chiu, W.H. and F.M. Liu, "Group Combustion of Liquid Droplets," Combustion and Science Technology, Vol. 17, 1977, pp. 127-142.

Clark, A.E., F.W. Stringer, and J.S. Clarke, "The Spontaneous Ignition of Hydro-Carbon Fuels in a Flowing Stream," I. Mech. E. Symposium on Diesel Engine Combustion, 1970.

Clingenpeel, J.M., M.D. Gurney, and D.B. Eccleston, "A Combustion and Wear Analysis of a Compression-Ignition Engine Using Coal Slurry Fuels," Energy-Sources Technology Conference, ASME Technical Paper 84-DGP-8, 1984.

Close, T.M., W. Cheng, and K.R. Benedek, "CWS Spray Characteristics in a High Pressure Environment," Eight International Symposium on Coal Slurry Fuels, 1986.

"Coal Fueled Diesel Systems Research, Final Report," U.S. DOE Contract No. DE-AC2186MC22123, Adiabatics, Inc., Report No. FR85155-288.

Cohen, J.M., "Operation of Diffraction-Based Droplet Sizing Instruments at Extreme Condition," Proc. Institute of Liquid Atomization and Spray Systems, (ILASS), Irvine, CA , pp. 104108.

Cook, C., E. Gal, M. Mengel and W. Van Kleunen, "Coal-Fueled Diesel Emissions Control Technology Development," ASME ICE-Vol. 19. Coal-Fueled Diesel Engines -1993, Presented at the Sixteenth Annual Energy-Sources Technology Conference and Exhibition, Houston, Texas, January 31-February 4, 1993, pp. 9-14.

Correa, S.M. and M. Sichel, "The Boundary Layer Structure of a Vaporizing Fuel Cloud," Combustion and Science Technology, Vol. 28, 1982, pp. 121-130.

Crouse, F.W. Jr., "Proceedings of the First Annual Heat Engines Contractors Review Meeting," Topical Report prepared by DOE/METC. Report No. DOE/METC/84-31, November 1984.

Crouse, F.W. Jr, "Proceedings of the Second Annual Heat Engines Contractors Review Meeting," Topical Report prepared by DOE/METC, Report No. DOE/METC/85-6023, May 1985. 
Crouse, F.W. Jr., "Proceedings of the Third Annual Heat Engines Contractors Review Meeting," Topical Report prepared by DOE/METC, Report No. DOE/METC/86-6041, May 1986.

Cummins, L., "Birth of the Diesel Dynasty," Diesel Progress, 50th Anniversary Supplement, July 1985, pp. $12-30$.

Czichos, H. and K.H. Habig, "Wear of Medium Carbon Steel: A Systematic Study of the Influences of Materials and Operating Parameters, Wear, Vol. 110, 1986, pp. 389-400.

Danyluk, S. and R. Reaves, "Influence of Fluids on the Abrasion of Silicon by Diamond, "Wear, Vol. 77, 1982, pp. 81-87.

Davini, P., "Reduction of Nitrogen Oxides With Ammonia: The Activity of Certain Soots," Fuel, 67, 24, 1988.

Dellefield, R.J. and H.A. Webb, "Proceedings of the Annual Coal-Fueled Heat Engines and Gas Stream Cleanup Systems Contractors Review Meeting," Topical Report prepared by DOE/METC, Report No. DOE/METC/88-6094, June 1988.

Delyagin, G.N., "General Laws of Coal-Particle Combustion," UDC 662.611:662.66.001.5, (00105082/83/1904-0475), Plenum Publishing Corporation, 1984.

Demski, R.J., et al., "Simultaneous Removal of $\mathrm{SO}_{2}$ and $\mathrm{NO}_{x}$ from Flue Gas Employing a Fluidized-Bed Copper Oxide Process," Presented at the Pittsburgh Coal Conference, Pittsburgh Pennsylvania, September 1983.

Dent, J.C., "A Basis for the Comparison of Various Experimental Methods for Studying Spray Penetration," SAE Technical Paper No. 710571, 1971.

Dickinson, B. and J.A. Caton, "Settling Properties of Coal-Water Slurries," Report No. CF-91-02, Texas A\&M University, Department of Mechancial Engineering, March 1991.

Dobner, S., "Modelling of Entrained Bed Gasification: The Issues," Electric Power Research Institute Memo, 1976.

Dodge, L.G., T.J. Callahan, T.W. Ryan, III, J.A. Schwalb, C.E. Benson, and R.P. Wilson, "Injection Characterístics of Coal-Water Slurries in Medium-Speed Diesel Equipment," ASME ICE-Vol 16, also in the ASME Transactions, Journal of Engineering for Gas Turbines and Power, Vol. 114, No. 3, July 1992, pp. 522-527.

Dodge, L.G., "Representation of Average Drop Sizes in Sprays," Journal of Propulsion and Power, Vol. 4, 1988, pp. 490-496.

Dodge, L.G. "Change of Calibration of Diffraction - Based Particle Sizers in Dense Sprays," Optical Engineering, Vol. 23 (6), 1984, pp. 626-630. 
Doup, D.C. and P.R. Badgley, "Novel Injector Techniques for Coal-Fueled Diesel Engines," ASME ICE-Vol 16, Coal-Fueled Diesel Engines, Presented at the Energy-Sources Technology Conference and Exhibition, Houston, Texas, January 26-30, 1992, pp. 63-67.

Dowson, D. and G.R. Hịgginson, Elastohydrodynamic Lubrication, Pergamon Oxford, 1977.

Drummond, C.J. and R.E. Tisher, "Duct Injection Technologies for $\mathrm{SO}_{2}$ Control," Presented at First Combined FGD and Dry $\mathrm{SO}_{2}$ Control Symposium, St. Louis, Missouri, 1988.

Ducowicz, J.K., "A Particle Fluid Numerical Model for Liquid Sprays," Journal of Computational Physics, Vol. 35, 1980.

Dunlay, J.B., J.P. Davis, H.A. Steiger, and M.K. Eberle, "Performance Tests of a Slow Speed, Two-Stroke Diesel Engine Using Coal Based Fuels," U.S. Department of Energy Report TE-7905-267-80, June 1980.

Dunlay, J.B., et al., "Slow Speed Two-Stroke Diesel Engine Tests Using Coal Based Fuels," ASME Paper 81-DGP-12, 1981.

Dunn-Rankin, D. and A.R. Kerstein, Combustion and Flame, 69: 193-209, (1987).

Dunn-Rankin, D. and A.R. Kerstein, "Influence of Ash on Particle Size Distribution Evolution During Coal Combustion," Combustion and Flame, Vol. 74, 1988, pp. 207-218.

Elkotb, M.M., "Fuel Atomization for Spray Modelling," Prog. Energy Combustion Sci., Vol. 8, 1982, pp. 61-91.

Elliot, M.A., "Chemistry of the Coal Utilization," Second Supplementary Volume.

Essenhigh, R.H., "Predicted Burning Times of Solid Particles in an Idealized Dust Flame," Journal of the Institute of Fuel, 34, 1961, pp. 239-244.

Essenghigh, R.H. and G.C. Yorke, "Reaction Rates of Single Coal Particles: Influence of Swelling, Shape, and Other Factor," Fuel, Vol. 44, pp. 177-185, 1965.

Felton, P.G., A.A. Hamidi, and A.K. Aigal, "Measurement of Drop Size Distribution in Dense Sprays by Laser Diffraction," ICLASS-85, Paper IVA/4/1, 1985.

Final Report, "Coal Fueled Diesel Systems Research ," U.S. DOE Contract No. DEAC2185MC22123, Allison P.O. No. H524201 Southwest Research Institute (SwRI) Project No. 02-8632, Feb. 10, 1989. 
Final Report of an Industrial Slow-Speed Diesel Cogeneration Application in the Chemical Industry, DOE/CS/40279-T1 (DE86005627), Work Performed Under Contract No. FC0179CS40279 for U.S. Department of Energy, Office of Industrial Programs by Thermo Electron Corporation, Waltham, Massachusetts.

Fitzsimmons, B. and H.D. Clevenger, "Contaminated Lubricants and Tapered Roller Bearing Wear," ASLE Transactions, Vol. 20, 2, 1975, pp. 97-107.

Flynn, P.L., "Coal Fueled Diesel Technology Development," Proceedings of the Sixth Annual Coal Fueled Heat Engines and Gas Stream Cleanup Contractors Review Meeting, ed. R.C. Bedick, DOE/METC-89/6101, (DE89000952), 1989, pp. 79-90.

Flynn, P.L., R. McDowell, G. Confer, and S. Basic, "12-Cylinder Coal-Fired Engine Design," Contract No. DE-AC21-88MC23174, Proceedings of the Seventh Annual Coal-Fueled Heat Engines and Gas Stream Cleanup Systems Contractors Review Meeting, DOE/METC-90/6110 (DE90000480), March 1990, pp. 440-441.

Flynn, P.L., G.L. Leonard, and R.L. Mehan, "Component Wear in Coal-Fueled Diesel Engines," ASME Technical Paper No. 89-ICE-15, Energy-Sources Technology Conference and Exhibition, Houston, Texas, January 22-25, 1989 also in the ASME Journal of Engineering for Gas Turbines and Power, Vol. 111, 3, 1989, pp. 521-529.

Flynn, P., E. Gal, E.A. Samuel, and M. Cohen, "Coal Fueled Diesel Technology Development Emissions: A Status Report," Contract No. DE-AC21-88MC23174, Proceedings of the Seventh Annual Coal-Fueled Heat Engines and Gas Stream Cleanup Systems Contractors Review Meeting, DOE/METC-90/6110 (DE90000480), March 1990, pp. 206-215.

Flynn, P.L.; B.D. Hsu, G.L. Leonard, and C.S. Cook, "Coal Fueled Diesel Technology Development," Contract No. DE-AC21-88MC23174, Proceedings of the Annual Coal Fuel Heat Engines and Gas Stream Cleanup Systems Contractors Review Meeting. DOE/METC-88/6094 (DE88001088), June 1988, pp. 79-90.

Flynn, P.L. and B.D. Hsu, "Coal Fueled Diesel Technology Developments," Proceeding of the Sixth Annual Coal-Fueled Heat Engines and Gas Stream Cleanup Systems, Morgantown, West Virginia, DOE/METC-89/6101, 1989, pp. 79-90, SAE Technical Paper No. 881159, August 1988.

Flynn, P.L., B.D. Hsu, G.L. Leonard, and C.S. Cook, "Coal-Fueled Diesel Locomotives Overview," Contract No. DE-AC21-88MC23174, Proceedings of the Seventh Annual Coal-Fueled Heat Engines and Gas Stream Cleanup Systems Contractors Review Meeting, DOE/METC-90/6110 (DE90000480), March 1990, pp. 11-22. 
Flynn, P.L., B.D. Hsu, and G.L. Confer, "Coal-Fueled Diesel Engine Performance--Fuels Effect," Contract No. DE-AC21-88MC23174, Proceedings of the Seventh Annual Coal-Fueled Heat Engines and Gas Stream Cleanup Systems Contractors Review Meeting, DOE/METC-90/6110 (DE90000480), March 1990, pp. 262-271.

Flynn, P.L., R.L. Mehan, G.L. Leonard, and R.N. Johnson, "Hardened Materials in Coal-Fueled Diesels," Contract No. DE-AC21-88MC23174, Proceedings of the Annual Coal Fuel Heat Engines and Gas Stream Cleanup Systems Contractors Review Meeting, DOE/METC88/6094 (DE88001088), March 1988, pp. 211-225.

Flynn, P.L., B.D. Hsu, and G.L. Leonard, "Coal Fueled Diesel Engine Progress at GE - Transportation Systems," ASME ICE-Vol. 12, also in the ASME Transactions, Journal of Engineering for Gas Turbines and Power, Vol. 112, No. 3, 1990, pp. 369-375.

Fu, Y.C., G.T. Bellas, T.D. Brown, J.I. Joubert, and G.F. Walbert, "Combustion Tests of Beneficiated and Micronized Coal-Water Fuels," 7th International Symposium on Coal Slurry Fuel Preparation and Utilization, May 21-24, 1985.

Func. E. and E. Rabinozwicz, "Abrasiveness of Fine Grain Particles in Slurry Machinery," Processings Seventh Technical Conference on Slurry Transporation, Lake Tahoe, Nevada, 1983.

Fusaro, R.L. and D.L. Schrubens, "Tribological Properties of Coal Slurries," NASA Technical Memorandum 89930, Oct. 5-8, 1987.

Gahr, K.H. and H. Zum, "Modelling of Two-Body Abrasive Wear," Wear, Vol. 124, 1988, pp. 87-103.

Gal, E., C.S. Cook, M. Cohen, W. Van Kleunen, and R. Hamilton, "Coal Fueled Diesel Emissions Control Technology Development: A Status Report," Proceedings of the Eight Annual Coal-Fueled Heat Engines and Gas Stream Cleanup Systems Contractors Review Meeting, Morgantown, West Virginia, July 1991.

Gal, E., P. Flynn, E. Samuel, and M. Cohen, "Coal-Fueled Diesel Technology Development Emissions: A Status Report, Proceedings of the Seventh Annual Coal-Fueled Heat Engines and Gas Stream Cleanup Systems Contractors Review Meeting, Morgantown, West Virginia.

Gaur, R.R., "Digital Simulation of Four Stroke High Speed Diesel Engine With Turbo-Charger for Wide Range Matching and Optimization," Ph.D. Thesis, 1977.

Gaydos, P.A., "Characterization of Oil Particulate from the Cooper JS1 Engine Operating on Coal/Water Slurry," Topical Report to Arthur D. Little, June 12, 1989. 
General Electric Company, R\&D Center, "Coal-Fueled Diesel: Technology Development," DOE/MC/22181-2694, NTIS/DE89000984, Springfield Virginia: National Technical Information Service., 1989.

Gentry, R.A., "Numerical Analysis of Coal-Fired Diesel Engines," Technical Paper presented at Third Annual Heat Engines Contractors Meeting, DOE/METC, Report No. DOE/METC/86-6041, May 1986.

Gentry, R.A., B.J. Daly, and A.A. Amsden, "KIVA COAL: A Modified Version of the KIVA Program for Calculating the Combustion Dynamics of a Coal-Water Slurry in a Diesel Engine Cylinder," Los Alamos Naitonal Laboratory Report No. LA-11045-MS, December 1987.

Gong, Y., L. You, and X. Liang, "An Investigation on Droplet Size Distribution and Evaporation of Diesel Fuel Sprays at High Injection Pressure by Using Laser Diagnostic Technique," SAE Technical Paper No. 920090, 1992.

Greenhalgh, M.L., "High-Pressure Coal Fuel Processor/Engine Development," ASME ICE-Vol. 14, Coal-Fueled Diesel Engines, Presented at the Fourteenth Annual Energy-Sources Technology Conference and Exhibition, Houston, Texas, January 20-23, 1991, pp.49-55.

Greenhalgh, M.L., "Preliminary. Test Data and Systems Analysis of a High-Pressure Coal Fuel Processor/Engine System Concept," ASME ICE-Vol 16, Coal-Fueled Diesel Engines, Presented at the Energy-Sources Technology Conference and Exhibition, Houston, Texas, January 26-30, 1992, pp. 17-23.

Greenhalgh, M.L., D.R. Orr, Dr. C. Wen, and S. Montafia, "Coal-Gas-Fueled Diesels for Locomotives and High Pressure Fuel Processor Design," Contract No. DE-AC2188MC25141, Proceedings of the Annual Coal Fuel Heat Engines and Gas Stream Cleanup Systems Contractors Review Meeting, DOE/METC-88/6094 (DE88001088), June 1988, pp. 91-98.

Greenhalgh, M.L., C.S. Wen, and R.E. Wright, "High-Pressure Coal Fuel Processor Development," Contract DE-AC21-88MC25141, Proceedings of the Eight Annual CoalFueled Heat Engines and Gas Stream Cleanup Systems Contractors Review Meeting, DOE/METC-90/6110 (DE90000480), July 1991, pp. 247-255.

Gülder, O., "Temporally and Spatially Resolved Drop Sizing of Dense Diesel Sprays," Proc. Institute of Liquid Atomization and Spray Systems (ILASS), Pittsburgh, PA, 1988, pp.7881.

Gurney, M.D., "Investigation of Diesel Fuel Injection Equipment Response to Coal Slurry Fuels," Proceedings of the First Annual Heat Engines Contractors Meeting, DOE/METC/84-31 (DE85001953), METC, November 1984, pp. 221-224. 
Gurney, M.D., "Development of Fuel Specifications of Coal Slurry Fuels for Diesel Engines--A Preliminary Report," Proceedings of the First Annual Heat Engines Contractors Meeting, DOE/METC/84-31 (DE85001953), METC, November 1984, pp. 214-220.

Gurney, M.D., "Coal Slurry Guidelines for Diesel Engines," Contract No. DE-AC03-84BC99882, Proceedings of the Second Annual Heat Engines Contractors Meeting. DOE/METC85/6023 (DE85008595), May 1985, pp. 335-349.

Gurney, M.D., "Combustion of Coal Slurry Fuels in a Diesel Engine," Two Volume Final Report prepared for DOE/METC, November 1984.

Gurney, M.D., J.M. Clingenpeel, and D.B. Eccleston, "Coal Slurry Fuels Viscosity Effects," Contract No. DE-AC03-84BC99882, Proceedings of the Advanced Research and Technology Development (AR\&TD) Direct Utilization Contractors Review Meeting, DOE/METC-85/6027 (DE85013718), METC/PETC, August 1985, pp. 43-49.

Gurney, M.D., J.M. Clingenpeel, and D.B. Eccleston, "A Program to Examine the Use of Coal Slurry Fuels in Diesel Engines," Energy-Sources Technology Conference, ASME Technical Paper 84-DGP-9, 1984.

Hammond, D.C. Jr., "Deconvolution technique for line-of-sight optical scattering measurements in axisymmetric sprays," Applied Optics, Vol. 20, 1981, p. 493.

Hanse, D.J., "Coal-Oil Mixtures As A Diesel Fuel," Master of Science Thesis, University of North Carolina, 1949.

Hapeman, M.J. and S.D. Savkar, "Economic Assessment of Coal-Burning Diesel Locomotives," ASME Technical Paper No. 86-ICE-14, Presented at the Energy-Sources and Technology Conference and Exhibition, New Orleans, LA., February 23-27, 1986, also in the Joint IEEE and ASME Railroad Conference Proceedings, April, 1987.

Hardesty, D. and L. Baxter, "Combustion Research for Advanced Heat Engine Power Systems," FTPA No. 0642.000, Proceedings of the Annual Coal Fuel Heat Engines and Gas Stream Cleanup Systems Contractors Review Meeting, DOE/METC-88/6094 (DE88001088), June 1988, pp. 163-172.

Harris, T.A., Rolling Bearing Analysis, 2nd Ed., John Wiley \& Sons, 1984.

Hay, N. and P.L. Jones, "Comparison of the Various Correlations for Spray Penetration," SAE Technical Paper No. 720776, 1972.

Hesling, D.M., "A Study of Typical Bore Finishes and Their Effects on Engine Performance," 1963 Annual Meeting, ASLE, New York, 1963. 
Heywood, J.B., "Internal Combustion Engine Fundamentals," McGraw-Hill Book Company, 1988, pp. 535.

Hiroyasu, H. and T. Kadota, "Development and Use of Spray Combustion Modeling to Predict Diesel Engine Efficiency and Pollutant Emissions," Bulletin of JSME, Vol. 26, No. 214, 1983.

Hiroyasu, H., "Diesel Engine Combustion and Its Modeling," Diagnostics and Modeling of Combustion in Reciprocating Engines, COMODIA 85, Proceedings of Symposium, Tokyo, pp. 53-75, Sept. 1985.

Hiroyasu, H, and T. Kadota, "Fuel Droplet Size Distribution in Diesel Combustion Chamber," SAE Transactions, Paper No. 740715, 1974.

Hiroyasu, H. and M. Arai, "Structures of Fuel Sprays in Diesel Engines," SAE Technical Paper No. $900475,1990$.

Hiroyasu, H., "Experimental and Theoretical Studies on the Structure of Fuel Spray as in Diesel Engines," Proc. ICLASS-91, Gaithersburg, MD, pp. 17-31, 1991.

Holmes, A.B., "Fluidic Fuel Feed System," Proceedings of the Annul Heat Engines and Gas Stream Cleanup Systems Contractors Review Meeting, DOE/METC (DE87001072), April 1987.

Holve, D.J., "Combustion Studies of Coal/Water Slurries," Presented at the Spring Meeting of the Western States Section of the Combustion Institute, University of Colorado, Boulder, Colorado, April 2-3, 1984.

Holve, D.J., "Comparative Combustion Studies of Ultrafine Coal/Water Slurries and Pulverized Coal," Proceedings of Second Annual Heat Engines Contractors Meeting, METC , pp. 208-240, May 1985.

Holve, D.J., K. Gomi, and T.H. Fletcher, Combustion Science and Technology, 52: 269 291(1987).

Holve, D.J. and P.L. Meyer, Combustion Science and Technology, 52: 243-268, (1987).

Horton, C.E., "Coal-Fueled Diesels: Systems Research," Fourth Annual Coal-Fueled Heat Engine and Gas Stream Cleanup Systems Contractors Review Meeting, Morgantown, WV, June 16, 1988.

Howard, J.B. and R.H. Essenhigh, "Mechanism of Solid Particle Combustion With Simultaneous Gas Phase Volatile Combustion," Eleventh Symposium of Combustion,pp. 399-408, 1967. 
Hsu, B.D., "Ignition Study of Coal Water Slurry Fuel in GE-7FDL Engine," Proceedings of the Annual Coal-Fueled Heat Engines and Gas Stream Cleanup Systems Contractors Review Meeting, ed. J.W. Byam, Jr., and K.E. Markel, Jr., DOE/METC-87/6077, NTIS/DE87001072, 1987, pp. 450-464.

Hsu, B.D., "Coal-Fuel Diesel Combustion: General Electric Test Results," Proceedings of the Annual Coal-Fueled Heat Engines and Gas Stream Cleanup Systems Contractors Review Meeting, ed. R.J. Dellefield and H.A. Webb,

Hsu, B.D., "Coal-Fuel Diesel Combustion: GE Single Cylinder Engine Results," Proceedings of the Sixth Annual Coal-Fueled Heat Engines and Gas Stream Cleanup Systems Contractors Review Meeting, ed. R.C. Bedick, T.P. Dorchak, N.F. Rekos, and H.A. Webb, DOE/METC-89/6101 NTIS/DE89000952, 1989, pp. 169-175.

Hsu, B.D., "Coal-Fuel Diesel Engine Performance - Fuels Effect," Proceedings of the Seventh Annual Cal-Fueled Heat Engines and Gas Stream Cleanup Systems Contractors Review Meeting, ed. H.A. Webb, N.F. Rekos, V.P. Kothari, and R.C. Bedick, DOE/METC90/6110, NTIS/DE90000480, 1990, p-. 262-271.

Hsu, B.D., G.L. Leonard, and C.S. Cook, "Coal-Fueled Diesel Locomotives Overview," Proceedings of the Seventh Annual Coal-Fueled Heat Engines and Gas Stream Cleanup Systems Contractors Review Meeting, ed. H.A. Webb, N.F. Rekos, V.P. Kothari, and R.C. Bedick, DOE/METC-90/6110, NTIS/DE90000480, 1990, pp. 11-22.

Hsu, B.D. and P.L. Flynn, "Preliminary Study of Using Coal-Water Slurry Fuel in GE-7DL Medium Speed Diesel Engine," Proceedings of the 18th International Congress on Combustion Engines, Tianjin, China, 1989, pp. 1295-1313.

Hsu, B.D., R.E. McDowell, G.L. Confer, and S.L. Basic, "Coal-Fueled Diesel Locomotive Test," Contract No. DE-AC21-88MC23174, Proceedings for the Ninth Annual Coal-Fueled Heat Engines, Advanced Pressurized Fluidized-Bed Combustion (PFBC), and Gas Stream Cleanup Systems Contractors Review Meeting, DOE/METC-93/6129 (DE93000232), October 1992, pp. 39-50.

Hsu, B.D. and P.L. Flynn, "Coal Fueled Diesel Engine Technology Development: GE Single Cylinder Engine Results," DOE/METC Contractor Review Meeting, Paper No. 3.1, March 1989.

Hsu, B.D., "Progress on the Investigation of Coal Water Slurry Fuel Combustion in a MediumSpeed Diesel Engine: Part 1. Ignition Studies," ASME Technical Paper No. 88-ICE-4, also in the ASME Transactions, Journal of Engineering for Gas Turbines and Power, Vol. 110, No. 3, pp. 415-422, January 1988. 
Hsu, B.D., "Heat Release, Cycle Efficiency and Maximum Cylinder Pressure in Diesel Engine The Use of an Extended Air Cycle Analysis," SAE Transactions, pp. 4.766-4.778, 1984.

Hsu, B.D., R.E. McDowell, S.L. Basic, and G.L. Confer, "Proof-of-Concept Testing of a Medium Speed 12-Cylinder Coal-Fueled Diesel Engine," Contract No. DE-AC21-88MC23174, Proceedings of the Eight Annual Coal-Fueled Heat Engines and Gas Stream Cleanup Systems Contractors Review Meeting, DOE/METC-90/6110 (DE90000480), pp. 283-292, July 1991.

Hsu, B.D., A.K. Kalafala, and C.S. Cook, "Coal-Fueled Diesel Locomotives Overview," Contract No. DE-AC21-88MC23174, Proceedings of the Eight Annual Coal-Fueled Heat Engines and Gas Stream Cleanup Systems Contractors Review Meeting, DOE/METC-90/6110 (DE90000480), pp. 72-80, July 1991.

Hsu, B.D., "'Progress on the Investigation of Coal Water Slurry Fuel Combustion in a MediumSpeed Diesel Engine Part 2. Preliminary Full Load Test," ASME Technical Paper No. 88ICE-5, also in the ASME Transactions, Journal of Engineering for Gas Turbines and Power, Vol. 110, No. 3, pp. 423-430, 1988.

Hsu, B.D., "Coal-Fueled Diesel Engine Development Update at GE Transportation Systems," ASME ICE-Vol 16, pp. 1-10, also in the ASME Transactions, Journal of Engineering for Gas Turbines and Power, Vol. 114, No. 3, pp. 502-508, 1992, in Coal-Fueled Diesel Engines, ASME, Vol. 16-ICE, 1992, pp. 1-9.

Hsu, B.D. and D.P. Branyon, "Progress on the Investigation of Coal Water Slurry Fuel Combustion in a Medium Speed Diesel Engine, Part 6 -. In-Cylinder Combustion Photography Studies," ASME ICE-Vol. 19. Coal-Fueled Diesel Engines--1993, Presented at the 16th Annual Energy-Sources Technology Conference and Exhibition, Houston, Texas, pp. 15-23, January 31-February 4, 1993.

Hsu, B.D, G.L. Confer, and Z.J. Shen, "Progress on the Investigation of Coal Water Slurry Fuel Combustion in a Medium Speed Diesel Engine: Part 5 -- Combustion Studies," ASME ICE-Vol 16, also in the ASME Transactions, Journal of Engineering for Gas Turbines and Power, Vol. 114, No. 3, pp. 515-521.

Hsu, B.D., G.L. Leonard, and R.N. Johnson, "Progress on the Investigation of Coal Water Slurry Fuel Combustion iñ a Medium-Speed Diesel Engine, Part 3 Accumulator Injector Performance," Coal-Fueled Diesel Engines, edited by M.H. McMillian and H.A. Webb, ASME Technical Paper ICE-Vol. 7, pp. 19-25, also in the ASME Transactins Journal of Engineering for Gas Turbine and Power, Vol. 111, No. 3, pp. 516-520, 1989.

Hsu, B.D. and G.L. Confer, "Progress on the Investigation of Coal-Water-Slurry Fuel Combustion in a Medium Speed Diesel Engine: Part 4 - Fuels Effect," ASME ICE-Vol. 14, CoalFueled Diesel Engines, Presented at the Fourteenth Annual Energy-Sources Technology Conference and Exhibition, Houston, Texas, January 20-23, 1991, pp. 1-8.

Bibliography 20 
Huh, J-C, G-Y Lee, and O-Y Yang, "An Experimental Study on Initial Behavior of Diesel Fuel Spray Characteristics," Proc. ICLASS-91, Gaithersburg, MD, 1991, pp. 283-290.

Hurst, B.E., "Thermal DeNO ${ }_{x}$ Technology Update," Presented at 1985 Joint Symposium on Stationary_Combustion $\mathrm{NO}_{\bar{\tau}}$ Control, Boston, Mssachusetts, 1985.

Im, C. and R.A. Wolfe, "Conceptual Design and Economic Analysis for the Manufacture of an Ultra-Clean Coal/Water Mixture," Topical Report prepared by United Coal for DOE/METC, Report No. DOE/MC/20122-11722, February 1985.

Imai, M. H. Teramoto, Y. Shimauchi, and E. Tonegawa, "Effect of Oil Supply on Fretting Wear," Wear, 110, pp. 227-225.

Ives, L.K., M.B. Peterson, and E.P. Whitenton, "NIST-3-Mechanisms of Galling and Abrasive Wear," Semi-Annual Progress Report for the U.S. DOE Fossil Energy Advanced Research and Technology Development Fossil Energy Materials Program, 1988.

Janczak, K.J. and M.R. Wisniewski, "Influence of Surface Roughness Parameters on Elastohydrodynamic Film Thickness," Wear, Vol. 115, 1987, pp. 75-82.

Jawad, B., E.S. Gulari, and N.A. Henein, "Penetration of Intermittent Fuel Sprays by an Optical Obscuration Technique," ASME Technical Paper No. 87-WA/HT-15, 1987.

Johnson K.L., Contact Mechanics, Cambridge University Press, Cambridge, 1985.

Johnson, S.A., C.L. Senior, C.K. Katz, and R.P. Wilson, "Cooper-Bessemer Coal-Fueled Engine System-Progress Report," ASME ICE-Vol. 7, January 1989, p. 9.

Johnson, S.A., C.L. Senior, C.K. Katz, and R.P. Wilson, "Development of NO Control Technlogies for Coal-Fueled Stationary Diesel Power Plants," Stationary Sources $\mathrm{NO}_{x}$ Symposium, San Francisco, CA, March 1989.

Jones, R.B., C.B. McCouet, C. Morley, and K. King, "Maceral and Rank Influences on the Morphology of Coal Char," Fuel, Vol. 64, 1985, pp. 1406-1467.

Kakwani, R.M., "Innovative Coal-Fueled Diesel Engine Injector," Final Report to be Submitted to $\mathrm{DOE}$.

Kakwani, R.M., R.E. Winsor, J.A. Schwalb, T.W. Ryan III, and S. Wahiduzzaman, "Coal-Fueled High-Speed Diesel Engine Development," Contract No. DE-AC21-90MC27222, Proceedings of the Ninth Annual Coal-Fueled Heat Engines, Advanced Pressurized Fluidized-Bed Combustion (PFBC), and Gas Stream Cleanup Systems Contractors Review Meeting. DOE/METC-93/6129 (DE93000232), October 1992, pp. 51-52. 
Kakwani, R.M., R.E. Winsor, T.W. Ryan II, S. Wahiduzzaman, and R.P. Wilson, "Study for Coal-Water-Slurry Fuel Combustion in a High-Speed Diesel Engine," ASME ICE-Vol 16, Coal-Fueled Diesel Engines, Presented at the Energy-Sources Technology Conference and Exhibition, Houston, Texas, January 26-30, 1992, pp. 25-32.

Kakwani R.M., P.R. Badgley, and W.C. Smith, "Development of Fuel Injection and Combustion Systems for CWS-Fueled Diesel Engines," ASME ICE-Vol. 12, 1990, pp. 41-50.

Kakwani, R. and R. Kamo, "Extending and Enhancing the Scientific Base for Advanced CoalFueled Power Systems Utilizing Heat Engines," Contract No. DE-AC21-86MC23258, Proceedings of the Annual Coal Fuel Heat Engines and Gas Stream Cleanup Systems Contractors Review Meeting, DOE/METC-88/6094 (DE88001088), June 1988, pp. 396408.

Kakwani, R.M., R.E. Winsor, R. Straub, T.W. Ryan III, S. Wahiduzzaman, and R.P. Wilson, "Coal-Fueled High-Speed Diesel Engine Development," Contact No. DE-AC2190MC27222, Proceedings of the Eight Annual Coal-Fueled Heat Engines and Gas Stream Cleanup Systems Contractors Review Meeting, DOE/METC-90/6110 (DE90000480), July 1991, pp. 293-300.

Kakwani, R. and R. Kamo, "Extending and Enhancing the Scientific Base for Advanced CoalFueled Power Systems Utilizing Heat Engines," Contract No. DE-AC21-86MC23258, Proceedings of the Annual Coal Fuel Heat Engines and Gas Stream Cleanup Systems Contractors Review Meeting, DOE/METC-88/6094 (DE88001088), June 1988, pp. 236249.

Kakwani, R.M. and R. Kamo, "Combustion Characteristics of Dry-Coal-Powder-Fueled Adiabatic Diesel Engine," 1988 ETCE, New Orleans, also in the ASME Publication ICE-Vol. 7, NTIS/DE89000978, DOE/MC/232558, January 1989, pp. 27-34.

Kakwani, R.M., R. Kamo, R.G. Cutlip, and W.C. Smith, "Combustion Characteristics of DryCoal-Powder-Fueled Adiabatic Diesel Engine," ASME ICE-Vol. 7, Coal-Fueled Diesel Engines, Presented at the Twelfth Annual Energy-Sources Technology Conference and Exhibition, Houston, Texas, January 22-25, 1989, pp. 27-34.

Kakwani, R.M., P.R. Badgley, and W.C. Smith, "Development of Fuel Injection and Combustion Systems for Coal-Water-Slurry Fueled Diesel Engines," ASME ICE-Vol. 12, Coal-Fueled Diesel Engines, Presented at the Thirteenth Annual Energy-Sources Technology Conference and Exhibition, New Orleans, Louisiana, January 14-18, 1990, pp. 41-50.

Kamo, R., R.M. Kakwani, M.E. Woods, and E. Valdmanis, "Combustion Characteristics of Coal Fuels in Adiabatic Diesel Engines," ASME Technical Paper No. 86-ICE-19, Proceedings of the Third Annual Heat Engines Contractors Meeting, DOE/METC-86/6041 (DE86001086), May 1986, pp. 257-270, also Final Report submitted to DOE, Contract No. DE-AC21-84MC21099. 
Kamo, R., R.M. Kakwani, M.E. Woods, and L.K. Carpenter, "Introduction of Micronized Coal in the Intake Air of a Medium Speed Adiabatic Diesel Engine," ASME Technical Paper No. 86-ICE-19, Presented at the Energy-Sources and Technology Conference and Exhibition, New Orleans, LA., February 23-27, 1986.

Kamo, R., A.B. Holmes, P. Badgley, and S. Kumar, "Coal Fuel Fluidic Injector for Diesel Engines," Contract No. DE-AC21-85MC24056, Proceedings of the Annual Coal Fuel Heat Engines and Gas Stream Cleanup Systems Contractors Review Meeting, DOE/METC88/6094 (DE88001088), June 1988, pp. 200-(see pages 89-106).

Kamo, R., R.M. Kakwani, and L.K. Carpenter, "Combustion Characteristics of Powdered Coal Fueled Adiabatic Engine," Paper Number D104, Proceedings, CIMAC Conference, Warsaw, Poland, 1987.

Kamo, R. and E. Valdmanis, "Tribological Properties of Some Selected Materials in a Coal-Fired Environment," Journal of the Society of Tribologists and Lubrication Engineers, Vol. 45 No. 7, 1988, pp 417-423.

Kamo, R. and J. Wurm, "Combustion Characteristics of Coal Fuels in Adiabatic Diesel Engines," Proceedings of the Second Annual Heat Engines Contractors Meeting, DOE/METC85/6023 (DE85008595), May 1985, pp. 325-334.

Kamo, R. and R.M. Kakwani, "Combustion Characteristics of Coal Fuels in Adiabatic Diesel Engines," Proceedings of the Third Annual Heat Engines Contractors Meeting, Morgantown Energy Technology Center, Morgantown, West Virginia, 1986.

Kanakia, M.D. and S.J. Lestz, "Fuel System Component Wear With JP-8," Interim Report BFLRF No. 262, U.S. Army Belvoir Research, Development and Engineering Center, Materials, Fuels and Lubricants Laboratory, Fort Belvoir, VA, Contract No. DAAK70-87-C-0043, May 1989.

Kanury, A.M., Introduction to Combustion Phenomena, Gordon and Breach Science Publishers, second edition, 1977.

Kayaba, T., K. Hokkirigawa, and K. Kato, "Analysis of the Abrasive Wear Mechanism by Successive Observations of Wear Processes in a Scanning Electron Microscope," Wear, Vol. 110, 1986, pp. $419-430$.

Keller, D.M., Jr., "Coal Refining by Physical Methods for the Preparation of Coal Slurries with Less Than One Weight Percent Ash," Presented at the Fifth International Symposium on Coal Slurry Combustion and Technology, Tampa, Florida, April 1983.

Khandare, S.S., R.D. Garg, and R.R. Gaur, "Investigation on the Use of Solid Fuels for Diesel Engine," SAE Technical Paper No. 872094, International Fuels and Lubricants Meeting and Exposition, Toronto, Ontario, Canada, November 2-5, 1987. 
Kihm, K.D., J.A. Caton, A. Seshadri, and G. Zicterman, "On Coal-Water Slurry Diesel Injector Sprays," Proc. 5th International Conference on Liuqid Atomization and Spray System (ICLASS), Vol. 2, p. 32.

Kihm, K.D and J.A. Caton, "Apparent Viscosity of Coal Water Slurry Fuels," Report No. CF-9103, Combustion and Fuels Research Laboratory, Department of Mechanical Engineering, Texas A\&M University, 1991.

Kihm, K.D., D.P. Terracina, S.E. Payne, and J.A. Caton, "Synchronized Droplet Size Measurements for Coal-Water Slurry (CWS) Diesel Sprays of an Electronically-Controlled Fuel Injection System," ASME ICE-Vol. 19. Coal-Fueled Diesel Engines --1993, Presented at the 16th Annual Energy-Sources Technology Conference and Exhibition, Houston, Texas, January 31-February 4, 1993, pp. 33-42.

Kihm, K.D. and J.A. Caton, "Particle Size Characteristics from Digitally Processed Images of Scanning Electron Microscope (SEM) Photographs of Coal-Water Slurry Samples," Technical Report CF-91-01, Mechanical Engineering, Texas A\&M University, June 1991.

Kihm, K.D. and J.A. Caton, "Synchronization of a Laser Fraunhofer Diffraction Drop sizing Technique with Intermittent Spray Systems," Applied Optics, Vol. 31, No. 23, 1992, pp. 1914-1916.

Kimberley, J.A., Personel Communication with Tom Ryan III, 1992

Kishan, S., "Simulation Study of Two-Stroke Cycle Compression-Ignition Engines," Texas A\&M University, Department of Mechanical Engineering, MSME, May 1985.

Kishan, S. and J.A. Caton, "Simluation of a Two-Stroke Cycle, Locomotive Engine Using Diesel or Coal Fuels," Joint Central and Western States Sections/Combustion Institute Spring Meeting, Paper No. 1-1A, April 1985.

Kishan, S., S.R. Bell, J.A. Caton, "Two-Stroke Cycle Engine Simulations: A Sensitivity Study," Report No. CF-85-04, Texas A\&M University, Department of Mechanical Engineering, December 1985.

Kishan, S., S.R. Bell, and J.A. Caton, "Numerical Simulations of Two-Stroke Cycle Engines Using Coal Fuels," Ninth Annual Energy-sources Technology Conference and Exhibition, American Society of Mechanical Engineers, Internal Combustion Engine Division Symposium, Paper No. 86-ICE-13, February 1986, also ASME Transactions---Journal of Engineering for Gas Turbines and Power, Vol. 108, No. 4, pp. 661-668, October 1986. 
Khandare, S.S., R.D. Garg, and R.R. Gaur, "Cycle Simulation of Volatile Coal-Fuel Diesel Engine Using Coal-Dust Induction System," Coal-Fueled Diesel Engines 1989, Eds. H.A. Webb and M.H. McMillian, ICE-Vol. 7, Energy-sources Technology Conference and Exhibition, American Society of Mechanical Engineers, Internal Combustion Engine Division Symposium, Houston, Texas, pp. 62-74, January 1989.

Kobhayashi, H., J.B. Howard, and A.F. Sarofim, "Coal Devolatilization at High Temperatures," Sixteenth International Symposium on Combustion, The Combustion Institute, 1977.

Koch, R.L., "Coal-Fueled Diesel Systems Research," Contract No. DE-AC21-85MC22123, Proceedings of the Third Annual Heat Engines Contractors Meeting, DOE/METC-86/6041 (DE86001086), May 1986, pp. 31-40.

Koch, R.L., "GM Diesel Overview," Annual Heat Engines and Gas Stream Cleanup Systems Contractors Review Meeting, Morgantown, WV, April 1987.

Koch, R.L., C.E. Horton, T. Uzkan, Dr. T.W. Ryan, II, and R. Kamo, "Coal-Fueled Diesels: Systems Research Diesel Engine Tests Using Coal-Water Slurry," Contract No. DE-AC2185MC22123, Proceedings of the Annual Coal Fuel Heat Engines and Gas Stream Cleanup Systems Contractors Review Meeting, DOE/METC-88/6094 (DE88001088), June 1988, pp. 176-187.

Koch, R.L., "Coal-Fueled Diesel Systems Research," Contract No. DE-AC21-85MC22123, . Proceedings of the Second Annual Heat Engines Contractors Meeting. DOE/METC85/6023 (DE85008595), May 1985, pp. 288-291.

Kock, R.L., C.E. Curry, D.L. Mason, and J.D. Slezinger III, "Commercialization Considerations for a Coal-Fueled Diesel Locomotive," ASME Technical Paper No. 86-ICE-5, Presented at the Energy-Sources and Technology Conference and Exhibition, New Orleans, LA., February 23-27, 1986.

Kock, R.L., C.E. Horton, Dr. T. Uzkan, T.W. Ryan III, and R. Kamo, "Coal-Fueled Diesels: Systems Research," Contract No. DE-AC21-85MC22123, Proceedings of the Annual Coal Fuel Heat Engines and Gas Stream Cleanup Systems Contractors Review Meeting, DOE/METC-88/6094 (DE88001088), June 1988, pp. 350-360.

Koncke, K.F., "Calculations of Ignition Characteristics' of Coal-Water Slurry Fuels for Engine Conditions: Comparison of Numerical Predictions with Existing Experimental Results," Texas_A\&M University, Department of Mechanical Engineering, Diplomarbeit*, June 1986.

Krazinski, J.L. and R.E. Holtz, "The Coal-Fueled Diesel Technology Assessment Study: Combustion of Coal-Based Fuels in Diesel Engines," ANL/MCT--87-3, DE88 008149, Argonne National Laboratory/METC, December 1985. 
Krishna, C.R., "Slurry Atomization -- A Brief Review," Contract No. DE-AC02-76CH00016 (Informal Report No. BNL 32952--DE83 014436), U.S. DOE, July 1982.

Krishna, C.R., P. Marnell, and T. Butcher, "Atomization Characteristics of Coal Slurries," First Quarterly Report (September 1 - November 30, 1981), Contract No. DOE/TIC--2006853 (DE82 006853), Brookhaven National Laboratory, Upton, NY.

Kruse, K., "Lignin-Augmented Bituminous Coal Depolymerization: A Route to Clean Fuels," Final Technical Report, Center for Research on Sulphur in Coal, 1991.

Lai, M.-C., V.W. Wong, W.K. Cheng, T.U., Yu, and J.M. Beer, "Injection and Combustion of Coal-Water Slurry in a Diesel Environment," Final Report Energy Lab., Massachusetts Institute of Technology, Cambridge, MA, 1987b.

Lai, M.-C., B. Zhou, W.K. Cheng, V.W. Wong, and K.R. Benedek, "Parametric Studies of CoalWater Slurry Combustion in a Rapid Compression Machine, ASME Paper No. 87-ICE-9, Energy-Sources Technology Conference and Exhibition, Dallas, Texas, February, 1986.

Lamey, S.C., E.E. Childers, and J.K. Wachter, "Characterization of Emissions From METC's Diesel Engine Combusting Advanced Fuels," Proceedings of the Seventh Annual CoalFueled Heat Engines and Gas Stream Cleanup Systems Contractors Review Meeting, DOE/METC-90/6110 (DE90000480), March 1990, pp. 234-238.

Law, C.K., H.K. Law, and C.H. Lee, "Combustion Characteristics of Droplets of Coal/Oil and Coal/Oil/Water Mixtures," Energy, 4, 329.

Lefebvre, A.H., Atomization and Sprays, Hemisphere Publishing Co., New York, Ch. 2, 1989.

Leonard, G.L. and G.H. Fiske, "A Comparison of a Positive Displacement Fuel Injection System with an Accumulator-Based System for Coal-Fueled Diesel Engine Applications," ASME Technical Paper No. 87-ICE-32, Energy-Sources Technology Conference and Exhibition, Dallas, Texas, February 15-20, 1987.

Leonard, G.L. and B.D. Hsu, "Coal-Fuel Diesel Combustion: General Electric Test Results," Contract No. DE-AC21-85MC22181, Proceedings of the Annual Coal Fuel Heat Engines and Gas Stream Cleanup Systems Contractors Review Meeting. DOE/METC-88/6094 (DE88001088), June 1988, pp. 361-370.

Leonard, G.L, and G.H. Fiske, "Combustion Characteristics of Coal/Water Mixtures in a Simulated Medium-Speed Diesel Engine Environment," ASME Technical Paper No. 86ICE-15, Energy-Sources and Technology Conference and Exhibition, New Orleans, LA, February 23-27, 1986. 
Leonard, G., B. Hsu, and P. Flynn, "Coal-Fueled Diesel Technology Development," Final Report, Work Performed Under Contract No. DE-AC21-85-MC22181 for U.S. DOE Office of Fossil Energy by General Electric Company, Research and Development Center, DOE/MC/22181-2694 (DE89000984).

Leonard, G.L. and N.F. Rekos, "Coal-Fuel Diesel Combustion: General Electric Test Results," Contract No. DE-AC21-85MC22181, Proceedings of the Annual Coal Fuel Heat Engines and Gas Stream Cleanup Systems Contractors Review Meeting, DOE/METC-88/6094 (DE88001088), June 1988, pp. 409-418.

Libby, P.A., and T.R. Blake, "Theoretical Study of Burning Carbon Particles," Journal of Combustion and Flame, 36, (1979), pp. 139-169.

Libby, P.A. and T.R. Blake, "Burning of Coal Particles in the Presence of Water Vapor," Journal of Combustion and Flame, Vol. 41, 1981, pp. 123-147.

Libby, P.A., "Ignition, Combustion, and Extinction of Carbon Particles," Journal of Combustion and Flame, 38, (1980), pp. 285-300.

Liddle, S.G, C.A. Di Bella, and L. Yang, "An Assessment of Advanced Coal-Fired Locomotive Concepts: Performance, Cost, and Market," Koh Systems Inc., Report DOE/MC/22012-3, October 1987.

Likos, W.E., T.W. Ryan III, and E.N. Balles, "Coal-Fuel Diesel Combustion: Cooper Bessemer Test Results," Presented at the Annual Coal Fuel Heat Engines and Gas Stream Cleanup Systems Contractors Review Meeting, Morgantown, WV., June 1988.

Likos, W.E. and T.W. Ryan, III, "Experiments with Coal Fuels in a High Temperature Diesel Engine," ASME Technical Paper No. 88-ICE-29, Energy-Sources Technology Conference and Exhibition, New Orleans, LA, January 10-14, 1988, also in the Journal of Engineering for Gas Turbines and Power, Vol. 112, No. 3, 1990, pp. 376-383, 1990.

Likos, W.E. and T.W. Ryan, III, "Combustion Characteristics of Coal Fuels in a High Temperature Diesel Engine," ASME Technical Paper No. 87-ICE-56, Energy-Sources Technology Conference and Exhibition, Dallas, Texas, February 15-20, 1987.

Lilly, L. C.R., Diesel Reference Book, Butterworth and Co., 1984, pp. 10/1-10/7.

Lindsey, T.H., et al., "Allison's Coal Fueled Gas Turbine "Proof of Concept" Program." Contract No. DE-AC21-86MC23165, Proceedings of the Annual Coal Fuel Heat Engines and Gas Stream Cleanup Systems Contractors Review Meeting, DOE/METC-88/6094 (DE88001088), June 1988, pp 27-39. 
Lindsey, T, C. Wilkes, J. Petraits, R. Wenglarz, R. Bourke, and K. Caraker, "Coal-Fueled Gas Turbines for Cogeneration Application," Proceedings of the Sixth Annual Coal-Fueled Heat Engines and Gas Stream Cleanup Systems Contractors Review Meeting, U.S. DOE, 89/6101, March 1989.

Liu, D.H., A.M. Żghoul, J. Li, B.S. Tan, D.L. Lockwood, and R.H. Essenhigh, "High Intensity Combustion of Coal With Water Injection," Combustion and Flame, Vol. 63, pp. 49-57, 1986.

Lustgarten, G.A. and K. Aeberli, "Improved Liner and Ring Wear Properties of Two-Stroke Diesels," Diesel and Gas Turbine Worldwide, Vol. 20, No. 3, 1988, pp. 45-48.

Marshall, H.P. and C. Shelton, "The Coal Burning Piston Engine," Bulletin of the Virginia Polytechnical Institute, Engineering Experimental Station, No. 135, Vol. 53, 1959.

Marshall, H.P. and D.C. Walters, Jr., "An Experimental Investigation of a Coal-Slurry Fueled Diesel Engine," SAE Technical Paper No. 770795, Passenger Car Meeting, Detroit Plaza, Detroit, Michigan, September 1977.

Marshall, H.P., S.M. Bhat, S.T. Mulvaney, and J.F. Sevelli, "Performance of a Diesel Engine Operating on Raw Coal-Diesel Fuel Slurries," SAE Technical Paper No. 810253, International Congress and Exposition, February 1981.

Martin, J.K. and T. Ahmad, "Heat Release Characteristics of an Open-Chamber Diesel Engine Employing a Wall-Wetting Combustion System," SAE Technical Paper No. 860420, 1986.

Martinelli, L., R.D. Reitz, and F.V. Bracco, "Comparisons of Computed and Measured Dense Spray Jets," AIAA Progress in Astr. and Aero Series, 95, 1984.

Mathews, K.J. and P.J. Street, Presented at the Sixth International Symposium on Coal Slurry Combustion and Technology, Florida, 1984.

Mayville, R.A., A.K. Rao, R.P., Wilson, "Cooper-Bessemer Coal-Fueled Engine System: Recent Developments in Durable Components," ASME ICE Division Technical Conference, Coal Fueled Diesel Engines--1990, ICE-Vol. 14, pp. 23-27, January 1991.

Mayville, R.A., A.K. Rao, and R.P. Wilson, "Durable Component Development Progress for the Cooper-Bessemer Coal-Fueled Diesel Engine," Coal-Fueled Diesel Engines, edited by J.A. Caton_and H.A. Webb, ASME Technical Paper No. ICE-Vol. 14, pp. 23-27, 1989.

Mayville, R.A., A.K. Rao, R.P. Wilson, Jr., "Cooper-Bessemer Coal-Fueled Engine System: Recent Developments in Durable Components," ASME ICE-Vol. 12, Coal-Fueled Diesel Engines, Presented at the Thirteenth Annual Energy-Sources Technology Conference and Exhibition, New Orleans, Louisiana, pp. 17-22, January 14-18, 1990. 
Mayville, R.A., "Abrasive Concentration Effects on Wear Under Reciprocating Conditions," The International Conference on Wear of Materials--1989, Denver, Colorado, pp. 83-87, April 1989.

Mayville, R.A., R.P. Wilson, S.A. Barber, and C.H. Melcher, "Wear Reduction Progress for Stationary Power Coal-Fueled Diesel Engines," in Proc. Sixth Annual Coal-Fueled Heat Engine and Gas Stream Cleanup Sytems Contractors' Review Meting, Morgantown, WV, (1989a), March 1989.

McDowell, R.E., S.L. Basic and G.L. Confer, "Design and Operation of a Coal Fueled 12 Cylinder Medium Speed Diesel Engine," Presented to the DOE/METC Heat Engines and Gas Stream Cleanup Systems Contractors Review Meeting, Morgantown, WV, July 1991.

McDowell, R.E., S.L. Basic, and G.L. Confer, "Design and Operation of a Medium Speed 12Cylinder Coal-Fueled Diesel Engine," ASME ICE-Vol 16, Coal-Fueled Diesel Engines, Presented at the Energy-Sources Technology Conference and Exhibition, Houston, Texas, pp. 33-38, January 1992.

McHale, E.T., "Coal-Water Fuel Combustion," Twenty-first Symposium (International) on Combustion, The Combustion Institute, 1986.

McLean, W.J., D.R. Hardesty, and J.H. Pohl, "Direct Observations of Pulverized Coal Particles in a Combustion Environment," Paper No. 80-11, Central States Section Meeting, The Combustion Institute, Louisiana State University, March 1980.

McMillian, M.H. and H.A. Webb, "Coal-Fueled Diesels: Systems Development," ASME ICEVol. 7, Coal-Fueled Diesel Engines, Presented at the Twelfth Annual Energy-Sources Technology Conference and Exhibition, Houston, Texas, January 22-25, ASME ICE-Vol. 7, 1989, pp. 1-8, also in the ASME Journal of Engineering for Gas Turbines and Power, 111,3 , pp. 485-490, 1989.

McMillian, M.H. and E.H. Robey, "Preliminary Test of Fuel-Bound Nitrogen-Doped Diesel Fuel in a Single Cylinder Diesel Engine," Paper presented at the Fourteenth Annual ASME Energy-Sources Technology Conference and Exhibtion, 1991.

McMillian, M.H., S.W. Richardson, E.H. Robey, and C.E. Romero, "METC Research on CoalFired Diesels," Proceedings of the Ninth Annual Coal-Fueled Heat Engines, Advanced Pressurized Fluidized-Bed Combustion (PFBC), and Gas Stream Cleanup Systems Contractors Review Meeting, DOE/METC-93/6129 (DE93000232), October 1992, pp. 304. 
McMillian, M.H., D.S. Benedict, C.E. Romero, and E.H. Robey, "METC In-House Coal-Fueled Diesel Research: Overview," Proceedings of the Eight Annual Coal-Fueled Heat Engines and Gas Stream Cleanup Systems Contractors Review Meeting, DOE/METC-90/6110 (DE90000480), July 1991, pp. 256-262, also in the ASME Journal of Engineering for Gas Turbine and Power, Vol. 111, 3, 1989, pp. 485-490.

Mechanical Engineers' Handbook, (Myer Kutz, ed.) John Wiley and Sons Inc., New York, 1986.

Mecredy, H.E. and B.T. Jett, "A Comparison of the Combustion Characteristics of Three Coal Slurry Fuels," METC Annual Heat Engines and Gas Stream Cleanup Systems CRM, April 1987.

Mehan, R.L., "The Wear of Selected Materials in Mineral Oil Containing a Solid Contaminant," Wear, Vol. 124, pp. 65-85, 1988.

Mehan, R.L., P.L. Flynn, and A.W. Giammarise, "Evaluation of Piston Ring Materials in Oil Contining an Abrasive Using a Ring-on-Block Test Machine," Wear, 1990.

Melton, R.B., Jr., "Diesel Fuel Injection Viewed as a Phenomena," SAE Technical Paper No. $710132,1971$.

Miles, B.H., G.B., King, and P.E. Sojka, "Malvern Particle Size Measurements in Media with Time Varying Index of Refraction Gradients," Proc. Institute of Liquid Atomization and Spray Systems (ILASS), Irvine, CA, pp. 156-160, 1989.

Milne, C.R. and D.W. Pershing, "Time Resolved Rate Measurements for Sized Sorbents," Presented at the Pittsburgh Coal Conference, Pittsburgh, Pennsylvania, September 1987.

Misra, A. and I. Finnie, "Correlations Between Two-Body and Three-Body Abrasion and Erosion of Metals," Wear, Vol. 68, 1981, pp. 33-39.

Mitchell, R.S. and H.J. Gluskoter, "Mineralogy of Ash of Some American Coals: Variations With Temperature and Source," Fuel, Vol. 55, 1976, pp. 90-96.

Mitchell, R.E., and W.J. McLean, "On the Temperature and Reaction Rate of Burning Pulverized Fuels," Sandia Report No. SAND82-8657 (UC-90 Printed November 1982), Presented at the Nineteenth Interrational Symposium on Combustion, Haifa, Israel, August 8-13, 1982.

Mitchell, R.S. and H.J. Gluskoter, "Mineralogy of Ash of Some American Coals: Variations With Temperature and Source," Fuel, Vol. 55, pp. 90-96.

Mochida, I., M. Ogaki, H. Fujitsu, Y. Yoshinobu and S. Ida, "Catalytic Activity of Coke Activated With Sulfuric Acid for the Reduction of Nitric Oxide," Fuel, 62, 1983, p. 867. 
Morel, T. and R. Keribar, "A Model for Predicting Spastically and Time Resolved Convective Heat Transfer in Bow-in-Piston Combustion Chambers," SAE Paper No. 850204, 1985.

Morel, T., R. Keribar, and P.N. Blumberg, "A New Approach to Integrating Engine Performance and Component Design Analysis Through Simulation," SAE Paper No. 880131, 1988.

Morel, T. and R. Keribar, "Heat Radiation in D.I. Diesel Engines," SAE Technical Paper No. $860445,1986$.

Morrison, G.F., "Combustion of Coal Liquid Mixtures," Report No. ICTIS/TR24, IEA Coal Research, London, November 1983.

Morrison, L.H., "The Coal Dust Engine Details of the Design," Power, Vol. 68, 1928, pp. 746748.

Murdoch, P.L., M. Pourkashanian and A. Williams, "The Mechanism of Combustion of Coal-Water Slurries," Correspondence to Professor A. Williams, The University of Leeds, Leeds, LS2 9JT, U.K.

Nakahira, T, M. Komori, M. Nishida, and K. Tsujimura, "The Shock Wave Generation Around the Diesel Fuel Sprays with High Pressure Injection," SAE Technical Paper No. 920460, 1992.

Nelson, L. P., W. R. Seker, and P. W. Sampson, "The Combustion Characteristics of Slurried Fuels in Diesel Engines: Detailed Measurements and Analysis," Proceedings of the First Annual Heat Engines Contractors Meeting. DOE/METC/84-31 (DE85001953), METC, pp. 225-234, November 1984.

Nelson, L.P. and R.A. Zimperman, "Combustion of Coal/Water Slurry Fuels," Contract No. DEAC21-84MC21100, Proceedings of the Third Annual Heat Engines Contractors Meeting, DOE/METC-86/6041 (DE86001086), pp. 285-294, May 1986.

Nelson, L.P., W.C. Clark, M.P. Heap, and W.R. Seeker, "Combustion Phenomena Associated With Coal Slurries in Medium Speed Diesel Engine," Submitted for the Twentieth International Symposium on Combustion, University of Michigan, Ann Arbor, Michigan, February 1984.

Nelson, L.P., W.R. Seeker, and R.A. Zimperman, "The Atomization, Ignition and Combustion Characteristics of Coal Slurry Fuels in Medium Speed Diesel Engines," Joint Central and Western States Sections, Combustion Institute Paper No. 31A, April 1985.

Nelson, P., B. Zimperman, D. Grant, and R. Seeker, "Detailed Measurements on the Combustion Characteristics of Slurried Fuels in Diesel Engines," Contract No. DE-AC21-84MC21100, Proceedings of the Second Annual Heat Engines Contractors Meeting, DOE/METC85/6023 (DE85008595), pp. 297-313, May 1985. 
Nelson, P. "Combustion of Coal-Water Mixtures in Conventional Diesel Engines," Technical Paper presented at the Third Annual Heat Engines Contractors Meeting, DOE/METC, Report No. DOE/METC/86-6041, May 1986.

Novack, M., G. Roffe, and G. Miller, "Combustion of Coal/Water Mixtures With Thermal Preconditioning," Contract NO. DE-AC21-84MC21390, U.S. DOE, ASME Technical Paper No. 87-GT-268, Presented at the Gas Turbine Conference and Exhibition, Anaheim, California, May 31-June 4, 1987.

Nurick, W.H., "Orifice Cavitation and Its Effect on Spray Mixing," J. Fluids Engineering, , pp. 681-687, December 1976.

Nydick, S.E., "Development of a Coal/Water-Slurry-Fueled Diesel Engine For Industrial Cogeneration," Final and Summary Report Under Contract No. AC02-82CE40539, U.S. DOE/Argonne, IL., Thermo Electron Corp. (Waltham, MA), February 1987.

Nydick, S.E., "Development of a Coal/Water Slurry Fueled Diesel Engine for Industrial Cogeneration - Task 4.0 Single-Cylinder Engine Tests," Thermo Electron Corp. Energy Systems Division Report, DOE/CE/40539-04, April, 1986.

Nydick, S.E. and C.C. Wang, "Development of Coal/Water Slurry-Fueled Diesel Engine for Industrial Cogeneration," Topical Reports prepared by Thermal Electron for DOE Office of Conservation, Contract No. DE-AC02-82CE40539, Task 1, Report No. DOE/CE/4053901 (Fuel Preparation) and Task 2, Report No. DOE/LE/40539-02 (Thermodynamic Analysis), May 1984.

Nyrick, S.E., F. Porchet, and H.A. Steiger, "Continued Development of a Coal/Water Slurry-Fired Slow-Speed Diesel Engine: A Review of Recent Test Results," ASME Technical Paper No. 87-ICE-10, 1987 ETCE, Dallas, TX., Feb. 1987. Journal of Engineering for Gas Turbines and Power, Vol. 109, 1987, pp. 465-476.

"Operating Instructions, AVL 647, Endoscope; Version A/E 5.6," Available from AVL List GmbH, Graz, Austria, April, 1988.

O'Rourke, P.J. and F.V. Bracco, "Modeling of Drop Interactions in Thick Sprays and a Comparison with Experiments," Paper No. C404/80, The Institution of Mechanical Engineers, Publication 1980-9, 1980, pp. 101-116.

O'Rourke, P.J., "Collective Drop Effects on Vaporizing Liquid Sprays," Ph.D Thesis, Department of Mechanical and Aerospace Engineering, Princeton University, 1532-T, 1980.

Oak Ridge National Laboratory, "Transportation Energy Conservation Data Book: Edition 5," 1981. 
Odi-Owei, S. and B.J. Roylance, "The Effect of Solid Contamination on the Wear and Critical Failure Load in a Sliding Lubricated Contact," Wear, Vol. 112, 1986, pp. 239-255.

Pawlikowski, R., "The Coal Dust Engine Upsets Tradition," Power, Vol. 68, 1928, pp. 136-139.

Payne, S.E., "Characterization of Coal-Water Slurry Sprays From an Electronically-Controlled Accumulator Fuel Injection System," Master of Science Thesis, Texas A\&M University, May 1993.

Perrotto, J.A., R.R. Riano, and S.F. Murray, "Effect of Abrasive Contamination on Ball Bearing Performance," Lubrication Engineering, Vol. 35, No. 12, 1979, pp. 698-705.

Petela, R., "Combustion of Mono-Fractional Droplets of Coal-Oil Mixtures," Fuel, Vol. 64, May 1985.

Phatak, R.G. and M.D. Gurney, "Investigation of Diesel Fuel Injection Equipment Response to Coal Slurry Fuels," ASME Technical Paper No. 85-DGP-17, 1985, Heat Engines Contractors Meeting, DOE/METC, 1984.

Prater, J.T. and E.L. Courtright, "Material and Coating Development Alternative Fuel Applications," Prepared for the U.S. DOE Report No. PNL-5257, 1985.

Prater, J.T. and E.L. Courtwright, "Combustion Zone Durability Program," Final Report prepared for DOE/METC, Report No. PNL-5259, January 1985.

Pratt J.T., "The EMD Engine and Blended Fuels - A Progress Report," Electro-Motive Division, General Motors Corporation, 1982.

Prescher, K. and W. Schaffitz, "Verschleiss von Kraftstoff-Einspritzduesen fuer Dieaselmotoren infolge Kraftstoffkavitation," Motortechnische Zeitschrift 40,4, pp. 173-178, 1979.

Prithiviraj, Manikandan and Malcolm J. Andrews, "Simulation of Coal Water Slurry Sprays," ASME ICE-Vol. 19., Coal-Fueled Diesel Engines--1993, Presented at the 16th Annual Energy-Sources Technology Conference and Exhibition, Houston, Texas, January 31February 4, pp. 43-51, 1993.

Rabinowiez, E. and A. Mutis, "Effect of Abrasive Particle Size on Wear," Wear, Vol. 8, pp. 381-390, 1965.

Rairden, J.R., R.L. Mehan, and A.W. Giammarise, "The Effects of Processing Conditions on the Wear Resistance of Plasma Sprayed WC-Co Coatings," Proceedings of the DOE Conference on Coatings for Heat Engines, Meeting, held in Castine, Maine, August 1990.

Ramalingam, S.C. and K. Annamalai, "Non-Steady Group Combustion of a Cloud of Char Particles," ASME Paper 87-WA/FACT-4, 1987. 
Ramalingam, S.C. and K. Annamalai, "Group Ignition and Combustion of a Cloud of Char Particles Under Transient Conditions," ASME Proceedings of the National Heat Transfer Conference, edited by H.R. Jacobs, HTD-Vol. 96, Vol-1, pp. 45-54, 1988.

Rao, A.K., R.P. Wilson, E.N. Balles, R.A. Mayville, M.H. McMilliam, and J.A. Kimberley, "Cooper-Bessemer Coal-Fueled Engine System -- Progress Report," ASME ICE-Vol. 7, Coal-Fueled Diesel Engines, Presented at the Twelfth Annual Energy-Sources Technology Conference and Exhibition, Houston, Texas, January 22-25, 1989, pp. 9-17, also in the Journal of Engineering for Gas Turbines and Power, Vol. 111, pp. 498-506.

Rao, A.K., C.L. Melcher, F.S. Schaub, J.A. Kimberley, R.P. Wilson, E.N. Balles, " Operating Results of the Cooper-Bessemer Coal-Fueled Engine System--Progress Report," Journal of Engineering for Gas Turbines and Power, Vol. 111, 1989, pp. 498-506.

Rao, A.K., C.H. Melcher, R.P. Wilson, E.M. Balles, F.S. Schaub, J.A. Kimberley, "Operating Results of the Cooper-Bessemer JS-1 Engine on Coal-Water Slurry," ASME Paper No. 88-ICE-12, Journal of Engineering for Gas Turbines and Power, Vol. 110, July 1988, pp. 431-436.

Rao, A.K., R.P. Wilson, E.N. Balles, R.A. Mayville, M.H. McMillian, J.A. Kimberley, "CooperBessemer Coal-Fueled Engine System - Progress Report," ASME ICE Division Technical Conference, Coal-Fueled Diesel Engines, ICE-Vol. 7, pp. 9-17, January 1989.

Rao, K., E.N. Balles, and R.P. Wilson Jr., "Features and Performance Data of Cooper-Bessemer Coal-Fueled Six-Cylinder LSB Engine," ASME ICE-Vol 16, Coal-Fueled Diesel Engines, Presented at the Energy-Sources Technology Conference and Exhibition, Houston, Texas, January 26-30, 1992, pp. 11-16, ASME Transactions -- Journal of Engineering for Gas Turbines and Power, Vol. 114, No. 3, pp. 509-514.

Rawlins, D.C., G.J. Germane, P.O. Hedman, and L.D. Smoot, "Laboratory-Scale Combustion of Coal-Water Mixtures, Combustion and Flame 63: 59-72, 1986.

Raymond, R.J., T.-N. Chen, and L. DiNanno, "Wear Reduction System - Liquid Piston Ring," Contract No. DE-AC21-88MC25035, Proceedings of the Annual Coal Fuel Heat Engines and Gas Stream Cleanup Systems Contractors Review Meeting, DOE/METC-88/6094 (DE88001088), pp. 325-333, June 1988.

Reitz, R.D.; "Atomization and Other Breakup Regimes of a Liquid Jet," Ph.D. Thesis, Department of Mechanical and Aerospace Engineering, Princeton University, 1375-T, 1978.

Reitz, R.D. and F.V. Bracco, "Mechanism of Atomization of a Liquid Jet," Physics of Fluids, Vol. 25, 10, pp. 1730-1742, 1982.

Rich, L.L. and M.L. Waker, "Pulverized Coal Burning Diesel Engine," Howard University, Office of the Coal Research, R\&D Report No. 46. USGPO, Washington, DC, 1969. 
Richez, M., K. Winquist and J.O. Storment, "Theoretical and Experimental Study of Ring-Liner Friction," Final Report SwRI-9300, Prepared for Advisory Committee for Research, Southwest Research Institute, 1983.

Robben, F., D.D. Brehob, M. Namazian, R.F. Sawyer, and P. Sherman, "Ignition and Combustion of Coal-Water Slurry in an Experimental Diesel Engine," Contract No. DE-AC00376SF00098, Presented at the Sixth International Symposium on Coal Slurry Combustion and Technology, Orlando, Florida (June 25-27, 1984), LBL-17721 April 1984.

Robben, F., "Coal-Fueled Diesel Engines," SAE International Off-Highway Meeting and Exposition, SAE Technical Paper No. 831747, 1983.

Roberts, P.B., R.T. LeCren, C.S. Wen, and F.J. Smith, "Coal-Water Slurry Costs for Coal-Fueled Industrial Cogeneration Gas Turbine System," Contract No. DE-AC21-86MC23166, Proceedings of the Seventh Annual Coal-Fueled Heat Engines and Gas Stream Cleanup Systems Contractors Review Meeting, DOE/METC-90/6110 (DE90000480), pp. 152-261, March 1990.

Rosegay, K.H., "A Cycle Simulation of Coal Particle Fueled Reciprocating Internal-Combustion Engine," MS Thesis, Texas A\&M University, College Station, 1982.

Rosegay, K.H. and J.A. Caton, "Cycle Simulation of Coal Particle Fueled Reciprocating Internal Combustion Engines," SAE Transactions, Vol. 92, 1984, pp. 895-908.

Rosin, P. and E. Rammler, "The Laws Governing the Fineness of Powdered Coal," Institute of Fuel, 1933, pp. 29-36.

Roth, J.M., "Cycle Simulation of Coal-Fueled Engines Utilizing Low Heat Rejection Concepts," M.S. Thesis, Texas A\&M University, 1988.

Ryan, T.W., III, T.J. Callahan, J.A. Schwalb, H.E., Mecredy, C.M. Urban, Q.A. Baker, M. Ingalls, and E.R. Banick, "Coal Fueled System Research," Final Report, Subcontract to Allison, P.O. No. H524201, U.S. DOE Contract DE-AC21-85MC22123, Submitted June 27, 1989.

Ryan, T.W. III, W.E. Likos, D.S. Moulton, and H.F. Bauer, "Characterization, Processing, and Diesel Engine Evaluation of Coal Liquid Fuels," ASME ICE-Vol. 7, Coal-Fueled Diesel Engines, Presented at the Twelfth Annual Energy-Sources Technology Conference and Exhibition, Houston, Texas, pp. 43-50, January 1989.

Ryan, T.W. III and L.G. Dodge, "Development of Carbon Slurry Fuels for Transportation (Hybrid Fuels - Phase II)," Prepared for National Aeronautics and Space Administration, Lewis Research Center Under Contract DEN3-263 for U.S. Department of Energy Report No. DOE/NASA/0263-1, May 1984. 
Ryan, T.W. III and L.G. Dodge, "Diesel Engine Injection and Combustion of Slurries of Coal, Charcoal, and Coke in Diesel Fuel," SAE Technical Paper No. 840119, International Congress \& Exposition, Detroit, Michigan, February 27-March 2, 1984.

Ryan, T.W. III, T.J. Callahan, L.G. Dodge, and C.A. Moses, "Injection, Atomization, and Combustion of Carbon Slurry Fuels," SAE Technical Paper No. 821199, 1983.

Ryan, T.W. III, W.E. Likos, and C.A. Moses, "The Use of Hybrid Fuels in a Single-Cylinder Diesel Engine," SAE Technical Paper No. 801380, 1980.

Ryan, T.W. III, et al., "Coal-Fueled Diesel Systems Research," Final Report, U.S. DOE Contract DEAC21-85MC22123, February 1989.

Ryan, T.W. III, "Diesel Fuel Ignition Quality as Determined in a Variable Compression Ratio, Direct-Injection Engines, 1987 SAE Transactions, SAE Technical Paper No. 870585, February 1987.

Ryan, T.W. III, "Combustion Characteristics of Coal Fuels in Adiabatic Diesel Engines," Contract No. DE-AC21-84MC21384, Proceedings of the Third Annual Heat Engines Contractors Meeting, DOE/METC-86/6041 (DE86001086), pp. 271-284, May 1986.

Ryan, T.W. III, T.J. Callahan, H.E. Mecredy, Q.A. Baker, and B.T. Jett, "Coal Slurry Combustion-Bomb and Small Engine Test Results," ASME Technical Paper No. 87-ICE31, Energy-Sources Technology Conference and Exhibition, Dallas, Texas, February 15$20,1987$.

Ryan, T.W. III, and J.A. Schwalb, "Wear Mechanism and Wear Prevention in Coal-Fueled Diesel Engines," Contract No. DE-AC21-88MC26044, Proceedings of the Eight Annual CoalFueled Heat Engines and Gas Stream Cleanup Systems Contractors Review Meeting. DOE/METC-90/6110 (DE90000480), pp. 237-246, July 1991.

Ryan, T.W. III, Personal correspondence from M. Gillespie, United Coal Company, Southwest Research Institute, 1986.

Ryan, T.W. III, T.J. Callahan, W.E. Likos, C.A. Moses, and L.G. Dodge, "Alternative (Hybrid) Fuels for Highway Transportation," Final Technical Report, Vol. 1, Contract No. DEAC04-79CS54240, SwRI Project No. 05-5315, U.S. Department of Energy, Division of Transportation Energy Conservation, DOE/CS/54240-T2 (Vol. 1)(DE82007051), 1981.

Ryan, T.W. III, "Combustion Characteristics of Coal Fuels in Adiabatic Diesel Engines," Contract No. DE-AC21-84MC21384, Proceedings of the Second Annual Heat Engines Contractors Meeting, DOE/METC-85/6023 (DE85008595), pp. 314-324, May 1985. 
Ryan, W., K. Annamali and J. Caton, "Group Ignition of a Spherical Cloud of Coal Particles," Eastern Section of Combustion Institute, NBS, Paper No. 87-09, Maryland, pp. 69-1 to 69-4, November 1987.

Ryan, W.R., "Group Pyrolysis, Ignition, and Combustion of a Spherical Cloud of Coal Particles," M.S. Thesis, Texas A\&M University, 1988.

Ryan, W., K. Annamali, and J.A. Caton, "Relation Between Group Combustion and Drop Array Studies," Proceedings of the Central States Section/Combustion Institute Spring Technical Meeting, Paper No. 20 pp. 261-267, May 1989, also in the Combustion and Flame, Vol. 80, pp. 313-321, 1990.

Sadghi, F. and P.C. Sui, "Compressible Elastohydrodynamic Lubrication of Rough Surfaces," ASME Transactions, Vol. 111, January 1989, pp. 56-62.

Sakai, T. and Saito, M. "Single Droplet Combustion of Caol Slurry Fuels," Combustion and Flame, Vol. 51, pp. 141-154, 1983.

Sarofim, A.F., J.M. Beer, J.D. Teare, L.D. Timothy, S.W. Kang, and S. Srinivassachar, "Fundamental Aspects of Coal-Water Droplet Combustion," Grant. No. DE-FG2284PC70268, Proceedings of the Advanced Research and Technology Development (AR\&TD) Direct Utilization Contractors Review Meeting, DOE/METC-85/6027 (DE85013718), METC/PETC, pp. 7-11, August 1985.

Savkar, S.D., "Coal Fueled Diesel Systems Research," Contract No. DE-AC21-85MC22181, Proceedings of the Third Annual Heat Engines Contractors Meeting, DOE/METC-86/6041 (DE86001086), pp. 21-30, May 1986.

Savkar, S.D., et al., "Coal-Fueled Diesel Systems Research," Contract No. DE-AC21$85 \mathrm{MC} 2181$, Proceedings of the Second Annual Heat Engines Contractors Meeting, DOE/METC-85/6023 (DE85008595), pp. 292-296, May 1985.

Saxton, M.J., F.A. Creswick, and J.F. Kircher, "Combustion in a Coal-Fired Internal Combustion Engine: A Simple Theory," ASME Technical Paper No. 78-WA/FU-1, 1978.

Schmidt, J., "An Engine Cycle Simulation With Thermal Nitric Oxide Computations for CoalFueled Diesel Engines," Report No. CF-87-01, Texas A\&M University, June 1987.

Schwalb, J.A., T.W. Ryan III, and J.F. Wakenell, "Wear Mechanism and Wear Prevention in Coal-Fueled Diesel Engines," Contract No. DE-AC21-88MC26044, Advance Research and Technology Development, Direct Utilization, and Instrumentation and Diagnostics Contractors' Review Meeting, CONF-900981--(DE91006344), METC/PETC, September 16-18, pp. 357-366, 1990. 
Schwalb, J.A., T.W. Ryan II, and W.C. Smith, "Lube Oil Contamination Induced Wear in CoalFueled Diesel Engines," ASME ICE-Vol. 12, Coal-Fueled Diesel Engines, Book No. 600507, Presented at the Thirteenth Annual Energy-Sources Technology Conference and Exhibition, New Orleans, Louisiana, pp. 51-58, January 1990.

Schwalb, J.A. and T.W. Ryan III, "Surface Finish and Particle Size Effects on Wear in CoalFueled Diesel Engines," ASME ICE-Vol. 14, Coal-Fueled Diesel Engines, Book No. G00591, Presented at the Fourteenth Annual Energy-Sources Technology Conference and Exhibition, Houston, Texas, pp. 29-37, January 20-23, 1991.

Schwalb, J.A. and T.W. Ryan, III, "Investigation of Break-In Wear, Ring Loading, and Oil Supply Configuration Effects on Wear in Coal-Fueled Diesel Engines," ASME ICE-Vol 16, Coal-Fueled Diesel Engines, Presented at the Energy-Sources Technology Conference and Exhibition, Houston, Texas, pp. 69-77, January 26-30, 1992.

Schwalb, J.A., T.W. Ryan, III, and R.P. Wilson, "Injection System and Combustion Chamber for Coal-Water-Slurry Fueled Medium Speed Diesel Engine," ASME ICE-Vol. 19. Coal Fueled Diesel Engines--1993, Presented at the 16th Annual Energy-Sources Technology Conference and Exhibition, Houston, Texas, pp. 1-7, January 31-February 4, 1993.

Schwalb, J.A., T.W. Ryan III, R.M. Kakwani, and R.E. Winsor, "Study of Coal-Water-Slurry Fuel Combustion in a High-Speed Diesel Engine: Part 2, Bench Test Results," ASME Paper Presented at the Energy-Sources Technology Conference and Exhibition, Houston, Texas, 1993.

Schwalb, J.A., T.W. Ryan III, R.M. Kakwani, and R.E. Wilson, "Coal-Water-Slurry Autoigntiion in a High-Speed Diesel Engine," ASME Paper ICE- , University of West Virginia, September, 1993.

Schwalb, J.A., L.G. Dodge, T.W. Ryan III, T.J. Callahan, and R.J. Mannheimer, "Coal-Water Slurry Fueled Diesel Engine - Injector Atomization and Wear Tests," Final Report for DOE/METC Contract DE-AC2188MC25124, A.D. Little Subcontract 61366.

Sefer, N.R., Personal Correspondence from C. Luebke, UOP Inc. Southwest Research Institute, 1986.

Seibers, D.L. and T. M. Dyer, "The Autoignition and Combustion of Coal-Water Slurry Under Simulated Diesel Engine Conditions," ASME Technical Paper No. 85-DGP-15, EnergySources Technology Conference and Exhibition, February 1987.

Seibers, D.L. and T. M. Dyer, "Coal-Water Slurry Diesel Combustion Bomb Study," Proceedings of the First Annual Heat Engines Contractors Meeting, DOE/METC/84-31 (DE85001953). METC, pp. 235-244, November 1984. 
Sekar, R.R., C.S. Wang, and U.S. Choi, "Viscosity of Coal/Water Slurries at High Shear Rates," work sponsored by U.S. Department of Energy, Report \#ANL/CNSV-66, August 1988

Sekar, R.R., C.D. Wang, and U.S. Choi(Materials and Components Technology Division), "Some Fundamental Factors Affecting the Durability of Coal/Water Slurry Injectors in Diesel Engines," CONF-881256-1 (DE89 004198), U.S. Department of Energy, Office of Industrial Programs, October 1988.

Senior, C.L., C.B. Katz, and S.A. Johnson, "Emission Control Design for the Coal-Fueled Diesel Engine," PSI Technology Company, Technical Report TR-877, 1988.

Senior, C.L., C.B. Katz, and S.A. Johnson, "Coal-Fueled Diesel Technology Development: Emission Control System Development," Proceedings of the Sixth Annual Coal-Fueled Heat Engines and Gas Stream Cleanup Systems Contractors Review Meeting, DOE/METC-89/6101.

Seshadri, A.K., J.A. Caton, and K.D. Kihm, "Coal-Water Slurry Spray Characteristics of a Positive Displacement Fuel Injection System," also in the ASME Transactions -- Journal of Engineering for Gas Turbines and Power, Vol. 114, No. 3, pp. 528-533.

Seshadri, A.K., J.A. Caton, K.D., Kihm, "Coal Water Slurry Atomization Characteristics of a Positive Displacement Fuel Injection System," Presented to the ASME ICE-16 at the 1992 Energy-Sources Technology Conference in Houston, TX, January 1992, also in the ASME Transactions, Journal of Engineering for Gas Turbines and Power, Vol. 112, No. 3, pp. 384-390.

Seshadri, A.K., "Characterization of Coal-Water Slurry Sprays from a Positive Displacement Fuel Injection System," MS Thesis, Department of Mechanical Engineering, Texas A\&M University, 1991.

Shadbolt, C.F., M.P. Hughes, "Advanced Diesel Research Engine Test Facility for D.O.E. Morgantown," Contract No. DE-AC21-85MC22124, Proceedings of the Third Annual Heat Engines Contractors Meeting, DOE/METC-86/6041 (DE86001086), May 1986, pp. 295-307.

Shandare, S.S., R.D. Garg, and R.R. Gaur, "Cycle Simulation of Volatile Coal-Fueled Diesel Engine Using Coal-Dust Induction System," ASME ICE-Vol. 7, Coal-Fueled Diesel Engines, Presented at the Twelfth Annual Energy-Sources Technology Conference and Exhibition, Houston, Texas, pp. 61-74, January 22-25, 1989.

Sitarski, M., Combustion Science and Technology, 54: 177-201, (1987).

Skaggs, S.R and R.A. Gentry, "Numerical Analysis of Coal-Fired Diesel Engines," Contract No. AA-1505000, Proceedings of the Third Annual Heat Engines Contractors Meeting. DOE/METC-86/6041 (DE86001086), pp. 320-334, May 1986. 
Slaughter, D., M. Cohen, E. Samuel, M. Mengel, and E. Gal, "Control of Emissions in the CoalFueled Diesel Locomotive," ASME ICE-Vol. 12, Coal-Fueled Diesel Engines, Presented at the Thirteenth Annual Energy-Sources Technology Conference and Exhibition, New Orleans, Louisiana, pp. 11-16, January 14-18, 1990.

Slaughter, D. and E. KGal, "Coal Fueled Diesel Emissions Development," ASME ICE-Vol 12, 1990.

Slaughter, D., M. Cohen, E. Samuel, M. Mengl, and E. Gal, "Control of Emissions in the Coal Fueled Diesel Locomotive," ASME Publication, Coal Fueled Diesel Engines, ICE Vol. 12, pp. 11-16, 1990.

Slezinger III, J.O., "A Life Cycle Cost Study of Six Advance Coal-Fired Locomotive Concept," GM Electro-Motive and Allison Gas Turbine Division Report to METC under Contract No. DEAC21-85MC22123, Mod. A004.

Smith, I.W., "The Kinetics of Combustion of Pulverized Semianthracite in the Temperature Range 1400-2700K," Journal of Combustion and Flame, Vol. 17 : 303-314, 1971.

Smith, C.F., P.E. Sojka, and A.H. Lefebvre, "Plain-Jet Airblast Atomization of Coal-Water Slurry Fuels," SAE Technical Paper No. 852085, International Fuels and Lubricants Meeting and Exposition, October 1985.

Soehngen, E.E., "Development of Coal-Burning Diesel Engines in Germany," Final Report prepared for the Energy Research and Development Administration/Office of Fossil Energy, Report No. FE/WAPO/3387-1, August 1976.

Som, S.K., and Mukherjee, "Theoretical and Experimental Investigations on the Formation of Air Core in a Swirl Spray Atomizing Nozzle," Applied Scientific Research 36: 1980, Martinus Nijhoff Publishers bv, The Hague, (Printed in the Netherlands), pp. 173-196.

Sreenath, A.V. and N. Raman, "Running-In Wear of a Compression Ignition Engine: Factors Influencing the Conformance Between Cylinder Liner and Piston Rings," Wear, Vol. 38, pp. 271-289, 1976.

Staub, F.W., "Spray Characterization and CW Slurry Atomization," ESB-203 (8833-5385), November 12, 1985:-

Staudt, J.E., D.C. Itse, C. Benson, R.P. Wilson, F.S. Schaub, and A.K. Rao, "Controlling Emissions From Stationary Coal-Fueled Diesel Engines, Presented at the Heat Engines Conference at Morgantown Energy Technology Center, June 1991.

Steiger, H.A., "Sulzer Single Cylinder Test Results with Various Coal-Water Slurries," Seminar Presentation, Coal-Fueled Diesel for Cogeneration, DOE Office of Conservation, Chicago, July 1985. 
Stone, K.R., "Modeling Diesel Performance With Alternate Fuels," Proceedings of the Annual Coal Fuel Heat Engines and Gas Stream Cleanup Systems Contractors Review Meeting, DOE/METC-88/6094 (DE88001088),pp. 140-149, June 1988.

Sudarsahn, T.S. and S.B. Bhaduri, "Wear in Cylinder Liners," Wear, Vol. 91, 1983, pp. 269-279.

Swanson, Michael L., Michael D. Mann, and Michael E. Collings, "Diesel Utilization of LowRank Coals," Contract No. DE-FC21-86MC10637, Advance Research and Technology Development, Direct Utilization, and Instrumentation and Diagnostics Contractors' Review Meeting, CONF-900981--(DE91006344), METC/PETC, pp. 367-376, September 16-18 1990.

Swithenbank, J., J.M. Beer, D.S. Taylor, D. Abbot, and C.G. McCreath, "A Laser Diagnostic Technique for the Measurement of Droplet and Particle Size Distribution," AIAA 14th Aerospace Sciences Meeting, AIAA Paper No. 76-69.

Swithenbank, J., J.M. Beer, and C.G. McCreath, "A Laser Diagnostic Technique for the Measurement of Droplet and Particle Size Distribution," AIAA Progress in Astronautics and Aeronautics, pp. 421-447, 1977.

Syrimis, M. and D. Assanis, "Combustion of Low-Ash Coal-Diesel Slurries in a High Speed, Direct-Injection Diesel Engine," ASME ICE-Vol. 19. Coal-Fueled Diesel Engines--1993, Presented at the 16th Annual Energy-Sources Technology Conference and Exhibition, Houston, Texas, pp. 53-61, January 31-February 4, 1993.

Syrimis, M. "Use of Low Ash Coal-Diesel Slurries in a Small, High Speed, Direct-Injection Diesel Engine," M.S. Thesis, Department of Mechanical Engineering, University of Illinois at Urbana-Champaign, Urbana.

Szekely, G.A., Jr. and G.M. Faeth, "Combustion Properties of Carbon Slurry Drops," AIAA Journal, Vol. 20, No. 3, p. 422.

Tataiah, K. and C.D. Wood, "Performance of Coal Slurry Fuel in a Diesel Engine," SAE Technical Paper No. 800329, Congress and Exposition, February 1980.

Taylor, G.I., "Generation of Ripples by Wind Blowing Over a Viscous Fluid,". Collected Works of G.I Taylor, Cambridge University Press, 1958.

Terracina, D.P., "Synchronized Droplet Size Measurements for Intermittent Sprays of an Electronically-Controlled Fuel Injection System for Both Diesel and Coal-Water Slurry Fuels," Master of Science Thesis, Texas A\&M University, 1992.

Torrance, A.A. and J.M. d'Art, "A Study of Lubricated Abrasive Wear," Wear, Vol. 110, 1986. pp. 49-59. 
Tracy, E.W. Jr., "Feasibility Study of the Use of Powdered Coal as a Fuel for Diesel Engines," SwRI Report No. 8-681-1, Southwest Research Institute, November 1957.

Tsai, S.C., Fundamentals of Coal Beneficiation and Utilization, Elsevier Scientific Publishing Company, 1982, New York.

U.S. Department of Energy, "Conservation and Renewable Energy Fact Book," Report No. DOE/CE-0031, 1981.

U.S. DOE Morgantown Energy Technology Center, "Coal Fueled Heat Engines: Technology Status Report," October 1985.

Unsworth, J.F., F. Cunliffe, S.C. Graham, and P.A. Morgan, "Ash Formation During Pulverized Coal Combustion 1: Aerodynamic Influences," Fuel, Vol. 66, pp. 1672-1679, 1987.

Unsworth, J.F., D.J. Barratt, D. Park and K.J. Titchener, "Ash Formation During Pulverized Coal Combustion; 2. The Significance of Crystalline Anorthite in Boiler Deposits," Fuel, Vol. 67, pp. 632-641, 1988.

Urban, C.M., H.E. Mecredy, T.W. Ryan III, M.N. Ingalls, and B.T. Jett, "Coal-Water Slurry Operation in an EMD Diesel Engine," ASME Technical Paper No. 88-ICE-28, also in the Journal of Engineering for Gas Turbines and Power, Vol. 110, pp. 437-443, July 1988.

Uzkan, T., and C.E. Horton, "Coal-Water Slurry Combustion Studies in an EMD 2-645 Diesel Engine," Final Technical Report Submitted to Allison Gas Turbine Division of GM, U.S. DOE Contract DEAC21-85MC22123, April 1989.

Uzkan, T. and C.E. Horton, "Combustion of Coal-Water Slurry in a Two-Cycle Diesel Engine: Part 2. Effects of Fuel Amounts and Pilot Timing," ASME ICE-Vol. 12, Coal-Fueled Diesel Engines, Presented at the Thirteenth Annual Energy-Sources Technology Conference and Exhibition, New Orleans, Louisiana, pp. 31-39, January 1990, also in the Journal of Engineering for Gas Turbines and Power, Vol. 112, No. 3, pp. 384-390, 1990.

Uzkan, T. and C.E. Horton, "Combustion Of Coal-Water Slurry in a Two-Cycle Diesel Engine: Part 1. Test System Design," ASME ICE-Vol. 12, Coal-Fueled Diesel Engines, Presented at the Thirteenth Annual Energy-Sources Technology Conference and Exhibition, New Orleans, Louisiana, pp. 23-30, January 14-18, 1990.

Uzkan, T. and C.E. Horton, "Effects of Engine Speed, Inlet Air Heating and Slurry Timing on the Combustion of Coal-Water Slurry in a Diesel Engine," ASME ICE-Vol. 14, CoalFueled Diesel Engines, Presented at the Fourteenth Annual Energy-Sources Technology Conference and Exhibition, Houston, Texas, pp. 9-15, January 20-23, 1991.

Verde, K.S., D.M. Popa and L.K. Verde, "Spray Angle and Atomization in Diesel Sprays," SAE Paper No. 841055. 
Volmer, S.A., "Development of an Experimental Test Cell for Alternative Fuel Testing in Diesel Engines," M.S. Theis, Department of Agricultural Engineering, University of Illinois at Urbana-Champaign, 1990.

Wagner, Joel H., and Bruce V. Johnson, "Advance Turbine Design for Coal-Fueled Engines," Contract No. DE-AC21-89MC26052, Advance Research and Technology Development, Direct Utilization, and Instrumentation and Diagnostics Contractors' Review Meeting, CONF-900981--(DE91006344), METC/PETC, pp. 387-396, September 16-18, 1990.

Wahiduzzaman, S., P.N. Blumberg, R. Keribar, and C.I. Rackmil, "A Comprehensive Model for Pilot-Ignited Coal/Water Mixture Combustion in a Direct-Injection Diesel Engine," ASME ICE-Vol. 12, also in the ASME Transactions, Journal of Engineering for Gas Turbines and Power, Vol. 112, No. 3, pp. 384-390, 1990.

Wallace, W.E., M.J. Keane, C.A. Hill, J. Xu, and T.-M. Ong, "Mutagencity of Diesel Exhaust Particles Dispersed in Lecithin Surfactant," J. Toxicology and Environ Health 21:163-171, 1987.

Wallace, W.E., M.J. Keane, S. Xing, T.-M. Ong, "Abs. Mutagenicity of Diesel Exhaust Soot Dispersed in Phospholipid Surfactants," Zentralblatt fur Hygiene und Umweltmedizin $\underline{189}$ 99-100, 1989.

Wallace, W.E. and T.-M. Ong, "Coal-Fueled Diesel Respirable Exhaust Emission," Contact No. DE-AI21-89MC26018, Proceedings of the Seventh Annual Coal-Fueled Heat Engines and Gas Stream Cleanup Systems Contractors Review Meeting, DOE/METC-90/6110 (DE90000480), pp. 227-233, March 1990.

Walsh, P.M., M. Zhang, W.F. Farmayan, and J.M. Beer, "Ignition and Combustion of Coal-Water Slurry in a Confined Turbulent Diffusion Flame," Presented at the Twentieth International Symposium on Combustion, Ann Arbor, MI, Aug. 1984.

Webb, H.A., N.F. Rekos, V.P., Kothari, and R.C. Bedick, "Proceedings of the Seventh Annual Coal-Fueled Heat Engines and Gas Stream Cleanup Systems Contractors Review Meeting," Morgantown, WV, 1990.

Wells, W.F., S.K. Kramer, L. D. Smoot, and A.U. Blackham, "Reactivity and Combustion of Coal Chars," Deparments of Chemical Engineering and Chemistry, Brigham Young University, Provo, Utah.

Werlberger, P. and W.P. Cartelliere, "Fuel Injection and Combustion Phenomena in a High Speed DI Diesel Engine Observed by Means of Endoscopic High Speed Photography," SAE Technical Paper No. 870097, 1987. 
Whyte, R.B., R. Billingham, and F. Chellingworth, "To Investigate the Pumpability of CoalDiesel Fuel Slurries Through Diesel Engine Components," LTR-FL-221, National Research Council Canada, Ottawa, Canada, March 8, 1982.

Wilkes, C., J.W. Rothrock, R.C. Bourke, and K.W. Caraker, "Low Cost Fuels for Coal-Fired Turbines," Proceedings of the Seventh Annual Coal-Fueled Heat Engines and Gas Stream Cleanup Systems Contractors Review Meeting, DOE/METC-90/6110 (DE90000480), March 1990, pp. 241-250.

Williams, M.C., N.T. Holcombe, M. McMillian, "Environmental Aspects of Coal-Fueled Diesel Engines," Journal of Engineering for Gas Turbines and Power, Vol. 111, p. 491, July 1989.

Wilson, R.P., C.L. Senior, S.A. Johnson, and C.B. Katz, "Stationary Coal-Fueled Diesels: Emissions Control," Contract No. DE-AC21-88MC25124, Proceedings of the Seventh Annual Coal-Fueled Heat Engines and Gas Stream Cleanup Systems Contractors Review Meeting. DOE/METC-90/6110 (DE90000480), pp. 197-205, March 1990.

Wilson, R.P., C.E. Benson, T.W. Ryan III, J.A. Schwalb, L.G. Dodge, and T.J. Callahan, "CoalWater Slurry Spray Characterization," Contact No. DE-AC21-88MC2124, Proceedings of the Eight Annual Coal-Fueled Heat Engines and Gas Stream Cleanup Systems Contractors Review Meeting, DOE/METC-90/6110 (DE90000480), pp. 263-272, July 1991.

Wilson, M.A., S. Heng, P.M. Fredricks, P.J. Collin, and A.M. Vassallo, "The Chemical and Physical Structure of Hydrogenation Residues of Maceral Concentrates," Fuel Processing Technology, 13, Elsevier Science Publishers B.V., pp. 243-260, 1986.

Wilson, R.P., K. Benedek, M. Rajchel, L. Baltich, C. Smith, and R. Maxwell, "Coal-Fuels Status Report for Stationary Coal-Fueled Diesels," Contract No. DE-AC21-88MC25124, Proceedings of the Seventh Annual Coal-Fueled Heat Engines and Gas Stream Cleanup Systems Contractors Review Meeting, DOE/METC-90/6110 (DE90000480), pp. 272-280, March 1990.

Wilson, R.P., et al., "Commercialization of Coal-Fired Diesel Engines for Cogeneration and NonUtility Power Markets," Contract No., DE-AC21-88MC25124, Proceedings of the Ninth Annual Coal-Fueled Heat Engines, Advanced Pressurized Fluidized-Bed Combustion (PFBC), and Gas Stream Cleanup Systems Contractors Review Meeting, DOE/METC93/6129 (DE93000232), pp. 19-26, October 1992.

Wilson, R.P., et al., "Coal-Fueled Diesel Systems for Stationary Power Applications," Final Report, DOE Contract No. DE-AC21-85-MC22182, September 1988. 
Wilson, R. P., S. A. Johnson, C. B. Katz, and C. L. Senior, "Coal-Fueled Diesel Technology Development: Emission Control System Development," Contract No. DE-AC2188MC25124, Proceedings of the Annual Coal Fuel Heat Engines and Gas Stream Cleanup Systems Contractors Review Meeting, DOE/METC-88/6094 (DE88001088), pp. 397-401, June 1988.

Wilson, R. P., R.A. Mayville, S.A. Barber, and C.H. Melcher, "Wear Reduction Progress for Stationary Power Coal-Fueled Diesel Engines," Contract No. DE-AC21-88MC-25124, Proceedings of the Annual Coal Fuel Heat Engines and Gas Stream Cleanup Systems Contractors Review Meeting, DOE/METC-88/6094 (DE88001088), pp. 199-210, June 1988.

Wilson, R. P., E. Balles, K. Benedek, R. Mayville, K. Rao, and J. Kimberely, "Coal Fueled Diesel Systems Research Coal Fueled Diesel Combustion: Cooper-Bessemer Test Results," Contract No. DE-AC21-85MC22182, Proceedings of the Annual Coal Fuel Heat Engines and Gas Stream Cleanup Systems Contractors Review Meeting, DOE/METC88/6094 (DE88001088), pp. 371-382, June 1988.

Wilson, R.P., et al., "Coal-Fueled Diesels "Proof-of-Concept" Program - Cooper-Bessemer Stationary Power System," Contract No. 21-88MC25124, Proceedings of the Annual Coal Fuel Heat Engines and Gas Stream Cleanup Systems Contractors Review Meeting. DOE/METC-88/6094 (DE88001088), pp. 20-26, June 1988.

Wilson, R.P., et al., "Stationary Coal-Fueled Diesel System," Contract No. DE-AC2188MC25124, Proceedings of the Seventh Annual Coal-Fueled Heat Engines and Gas Stream Cleanup Systems Contractors Review Meeting, DOE/METC-90/6110 (DE90000480), pp. 3-10, March 1990.

Wilson, R.P., "Coal-Fueled Diesel," Contract No. DE-AC21-85MC22182, Proceedings of the Second Annual Heat Engines Contractors Meeting, DOE/METC-85/6023 (DE85008595), pp. 274-287, May 1985.

Wilson, M.A., S. Heng, P.M. Fredericks, P.J. Collin, and A.M. Vassallo, "The Chemical and Physical Structure of Hydrogenation Residues of Material Concentrates," Fuel Processing Technology, 13 Elsevier Science Publishers B.V., pp. 243-260, 1986.

Wilson, R.P., et al., "Cooper Bessemer Stationary Coal-Fueled Diesel System: Proof of Concept," Contract No. DE-AC21-88MC25124, Proceedings of the Annual Coal Fuel Heat Engines and Gas Stream Cleanup Systems Contractors Review Meeting, DOE/METC-88/6094 (DE88001088), June 1988, pp. 68-78, also in the Sixth Annual Coal-Fueled Heat Engines and Gas Stream Cleanup Systems Contractors' Review Meeting, Morgantown WV, March 1989.

Wilson, R.P., Personal Communication with T.W. Ryan III, June 1989. 
Wilson, R.P., "Coal-Fueled Diesel Systems for Stationary Power Applications: Assessment of Merit," Topical Report Prepared by Arthur D. Little, Inc. under contract to the Department of Energy/Morgantown Energy Technology Center, September 1986.

Wilson, R.P., "Coal-Fueled Diesel Engines for Stationary Power," Technical Paper presented at the Third Annual Heat Engines Contractors Meeting, DOE/METC, Report No. DOE/METC/86-6041, May 1986.

Wilson, R., "Market Assessment and Economic Feasibility of High-Speed Coal-Fueled Diesel Engines," Topical Report submitted to DOE/METC, 1991.

Wilson, R.P., et al., "Coal-Fueled Diesels: Technology Development Single-Cylinder Coal Diesel Engine Results," Contract No. DC-AC21-88MC25124, Proceedings of the Annual Coal Fuel Heat Engines and Gas Stream Cleanup Systems Contractors Review Meeting, DOE/METC-88/6094 (DE88001088), pp. 188-196, June 1988.

Woschni, G., "A Universally Applicable Equation for the Instantaneous Heat Transfer Coefficient in the Internal Combustion Engine," SAE Technical Paper No. 670931, 1967.

Wu, K.J., R.D. Reitz, and F.V. Bracco, "Measurements of Drop Size at the Spray Edge Near the Nozzle in Atomizing Liquid Jets," Physics of Fluids, Vol. 29, No. 4, 1986, pp. 941-951.

Yahagi, Y., "Corrosive Wear of Diesel Engine Cylinder Bore," Tribology International, Vol. 20, No. 6, pp. 365-373, 1987.

Yao, S.-C. and L. Liu, "Behavior of Suspended Coal-Water Slurry Droplets in a Combustion Environment," Combustion and Flame 51: 335-345, 1983.

Yu, T.U. and J.M. Beer, "Particle Sizing and Spray Analysis with a Laser Diffraction Analyzers," Fourth Conference on Rapid Solidification Processing, Santa Barbara, CA., 1986.

Yu, T.U., M.-C. Lai, J.M. Beer, and W.K. Cheng, "Injection and Atomization of Coal-Water Slurry in High Pressure Diesel Engine Environment," ASME ICE-Vol. 7, Coal-Fueled Diesel Engines, pp. 51-60, also in Journal of the Institute of Energy, Vol. 64, pp. 12-20, March 1991.

Yu, T.U., S.C. Rah, S.W. Kañg, and J.M. Beer, "Measurement of Viscosity of Coal-Water Fuels at High Shear Rate," Eighth International Symposium on .Coal Slurry Fuels, 1986.

Yu, T.U., et al., Eighth International Coal Slurry Fuels Preparation and Utilization Symposium, FL, 1986.

Yu, T.U., S.W. Kang, J.M. Beer, A.F. Sarofim, and J.M. Teare, "Atomization Quality and High Shear Rate Viscosity of Coal Water Fuels," Twelfth International Conference on Slurry Technology, New Orleans, Louisiana, 1987. 
Zel'dovich, J. "The Oxidation of Nitrogen in Combustions and Explosions," Acta Physico Chemeca, USSR, Vol. 21, pp. 577-628, 1946. 